
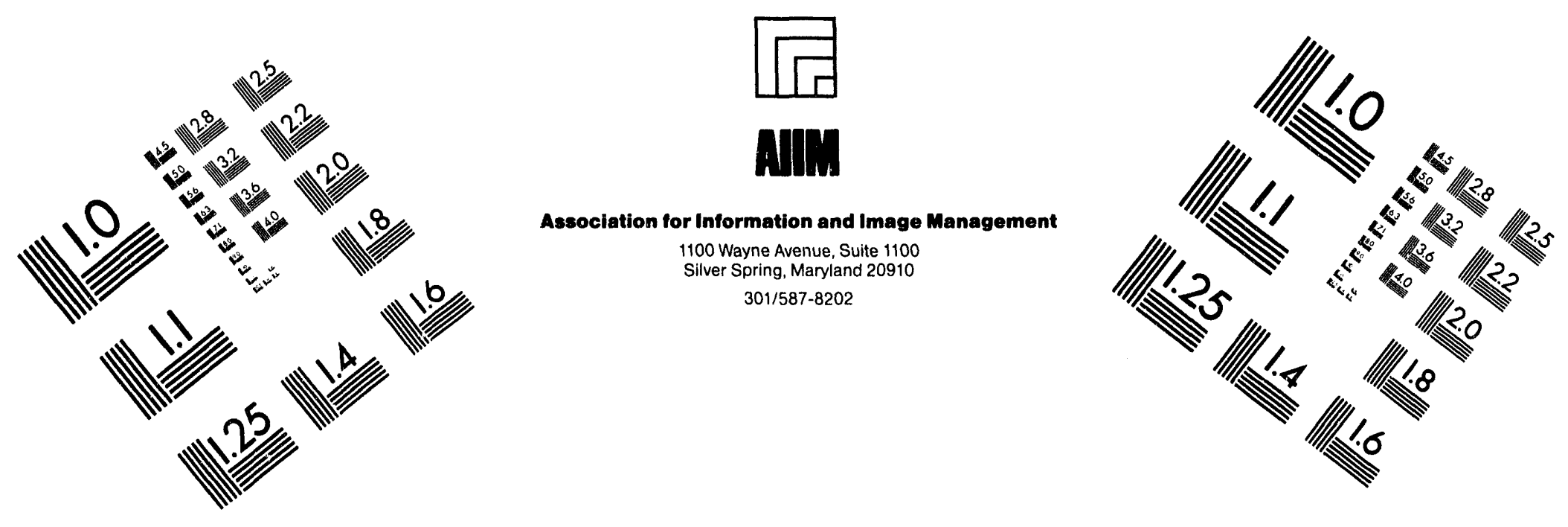

\title{
Centimeter
}

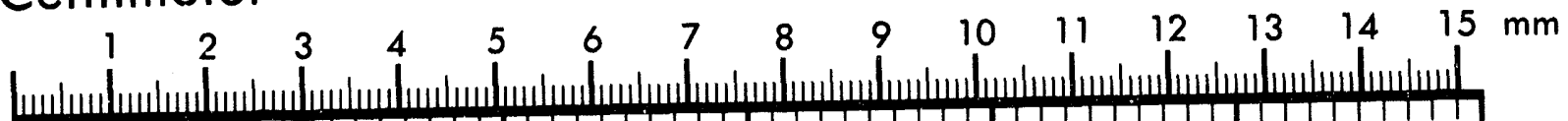

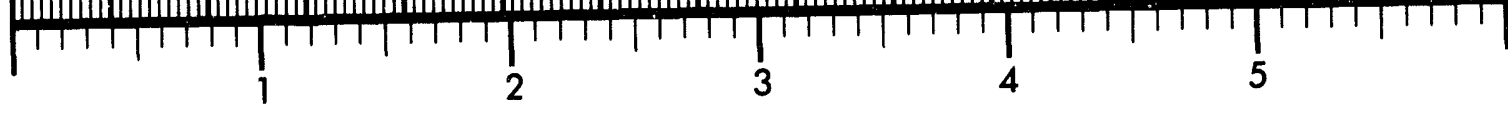
Inches
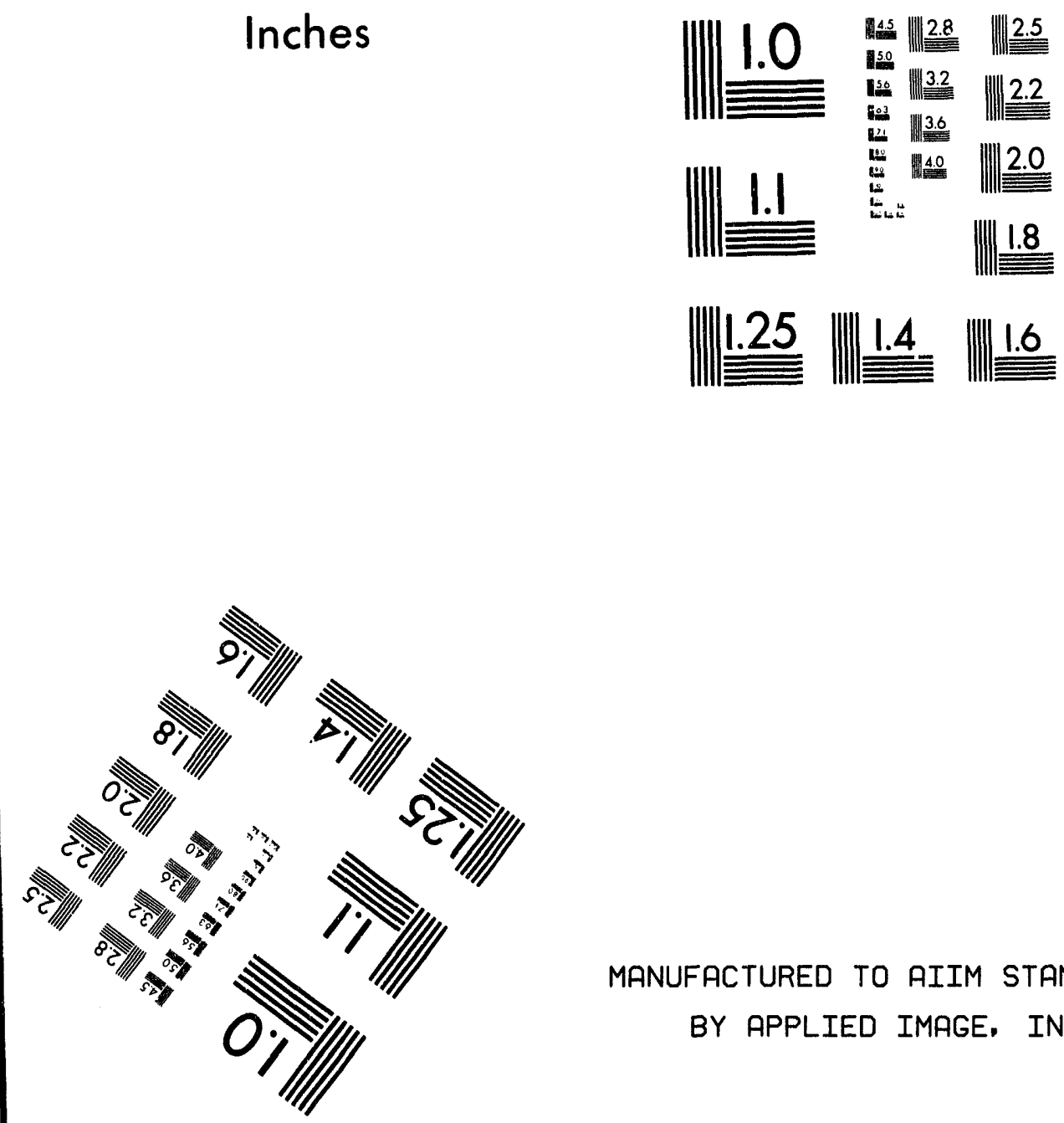

MANUFACTURED TO AIIM STANDARDS BY APPLIED IMAGE, INC.

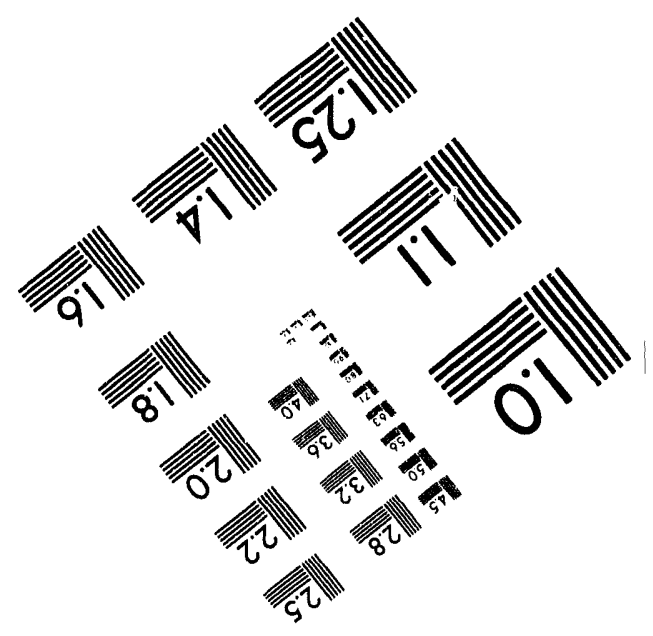



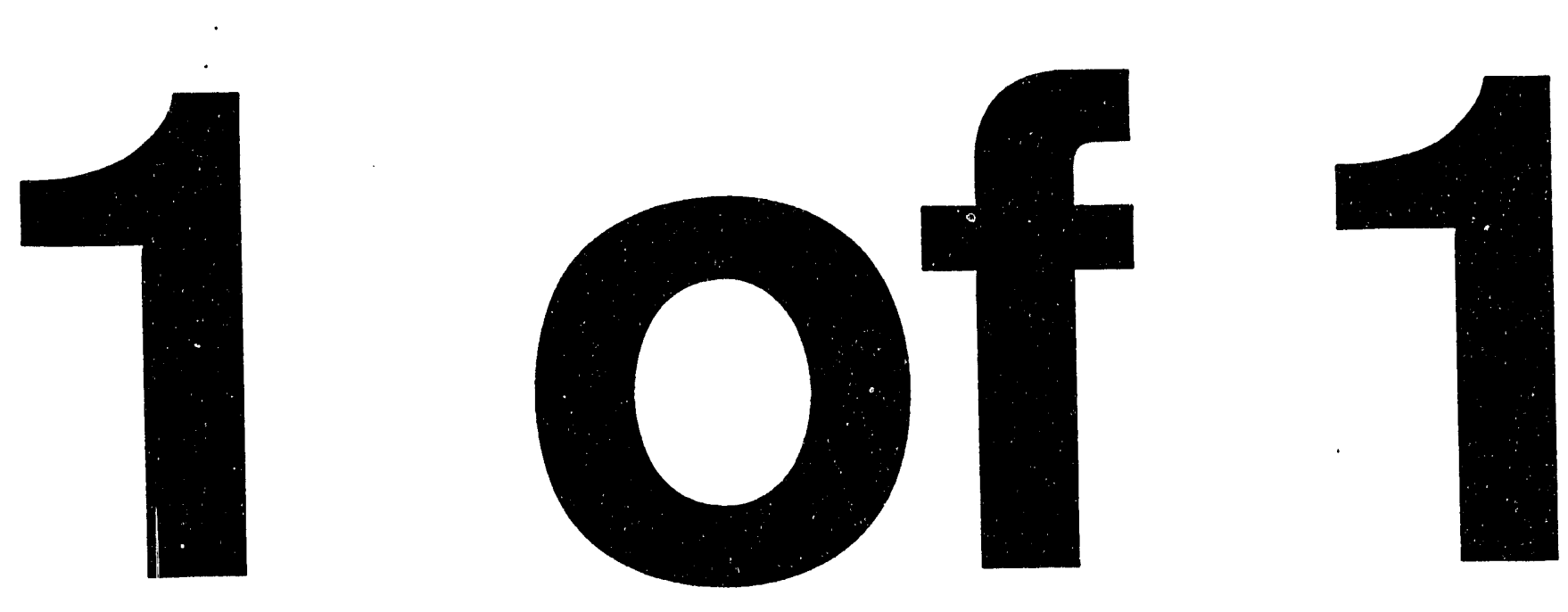
NUREG/CR-6095

SAND93-1803

\section{Aging, Loss-of-Coolant Accident (LOCA), and High Potential Testing of Damaged Cables}

Manuscript Completed: January 1994

Date Published: April 1994

Prepared by

R. A. Vigil/SEA

M. J. Jacobus/SNL

Science \& Engineering Associates, Inc.

6100 Uptown Blvd. NE

Albuquerque, NM 87110

Under Contract to

Sandia National Laboratories

Albuquerque, NM 87185

Prepared for

Division of Reactor Controls and Humgn Factors

Ofince of Nuclear Reactor Regulation

U.S. Nuclear Regulatory Commission

Washington, DC 20555-0001

NRC FIN L1903 


\begin{abstract}
Experiments were conducted to assess the effects of high potential testing of cables and to assess the survivability of aged and damaged cables under Loss-of-Coolant Accident (LOCA) conditions. High potential testing at $240 \mathrm{Vdc} / \mathrm{mil}$ on undamaged cables suggested that no damage was incurred on the selected virgin cables. During aging and LOCA testing, Okonite ethylene propylene rubber (EPR) cables with a bonded jacket experienced unexpected failures. The failures appear to be primarily related to the level of thermal aging and the presence of a bonded jacket that ages more rapidly than the insulation. For Brand Rex crosslinked polyolefin (XIPO) cables, the results suggest that 7 mils of insulation remaining should give the cables a high probability of surviving accident exposure following aging. The voltage necessary to detect when 7 mils of insulation remain on unaged Brand Rex cables is approximately $35 \mathrm{kVdc}$. This voltage level would almost certainly be unacceptable to a utility for use as a damage assessment tool. However, additional tests indicated that a $35 \mathrm{kVdc}$ voltage application would not damage virgin Brand Rex cables when tested in water. Although two damaged Rockbestos silicone rubber cables also failed during the accident test, no correlation between failures and level of damage was apparent.
\end{abstract}




\section{Table of Contents}

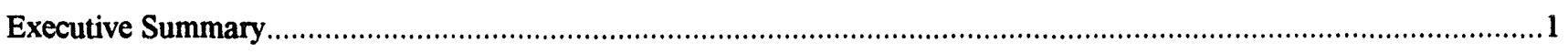

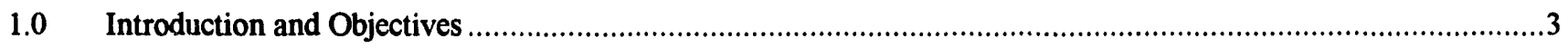

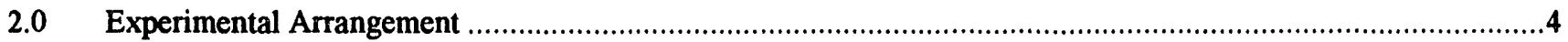

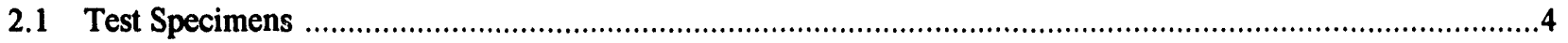

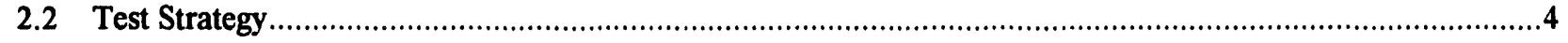

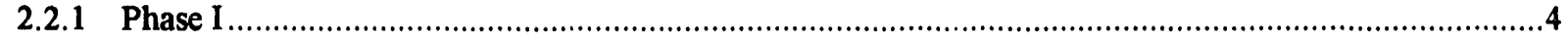

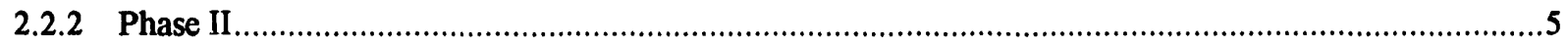

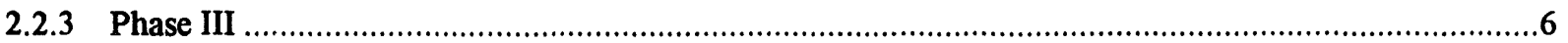

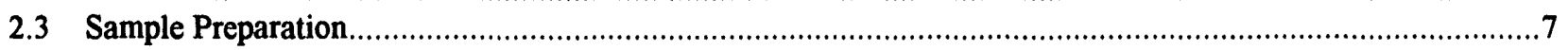

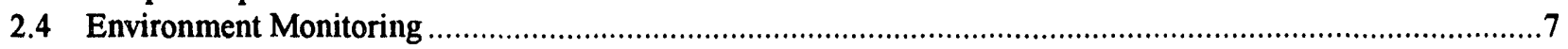

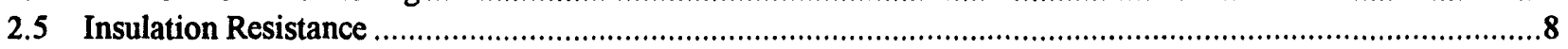

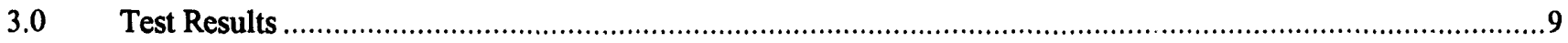

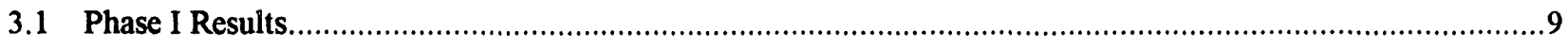

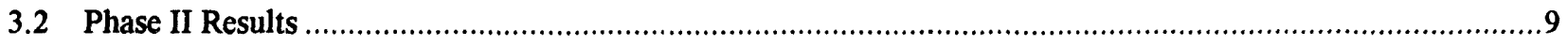

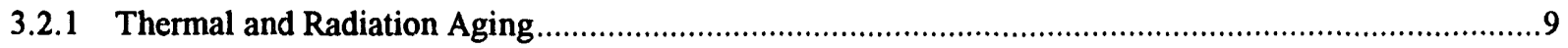

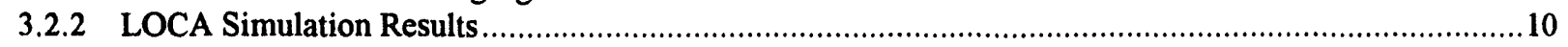

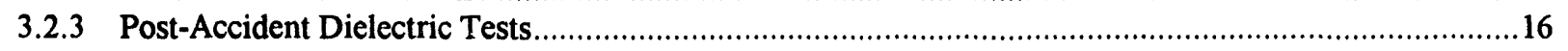

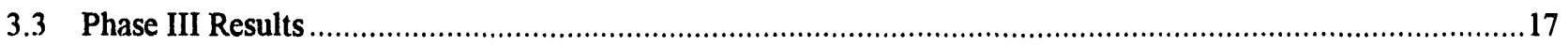

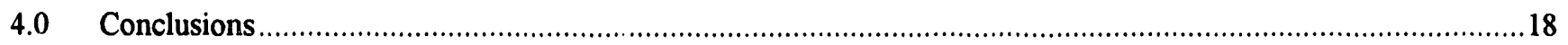

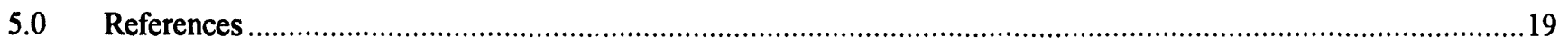

Appendix A Insulation Resistance of Each Conductor During Accident Testing ........................................................ A-1

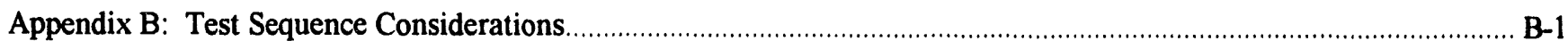




\section{List of Figures}

1. Lengthwise Cross-Sections of Samples With 30, 15, and 7 Mils of Insulation Remaining ................................8

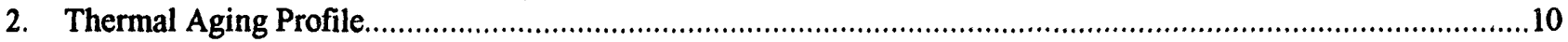

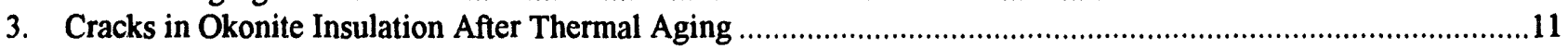

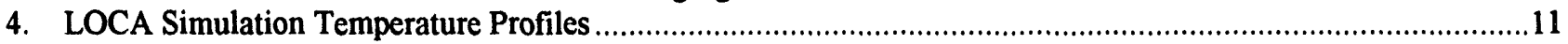

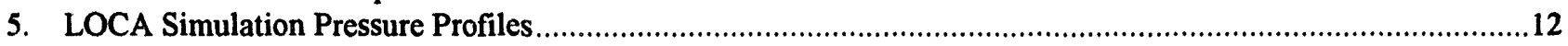

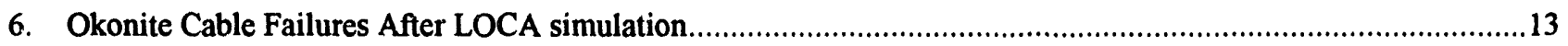

7. Equivalent Time-Temperature Corresponding to the Thermal Aging in this Program and Previous Sandia Testing....

8. Dielectric Strength Based on Nominal Remaining Insulation Thickness .....................................................16

9. Breakdown Voltages for Damaged Brand Rex Cables Tested in Water .........................................................17

B-1. Failure of Okonite Cable Sample from Reference B-1 Test Program ........................................................... B-3

\section{List of Tables}

1. Number of Samples for Each Test Condition

2. Approximate Equivalent Aging Temperatures for 40 and 60 Years .......................................................6

3. Cable Numbering Scheme and Damage Estimates for Cables Tested in this Program ........................................7

4. Breakdown Voltages and 95\% Confidence Intervals from Phase I.................................................................

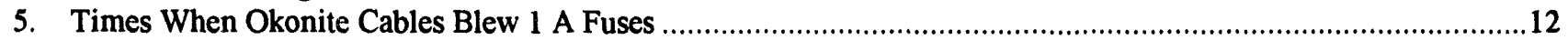

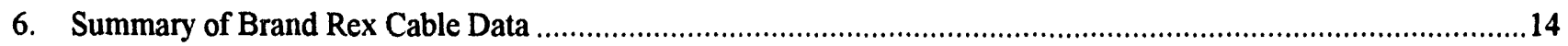

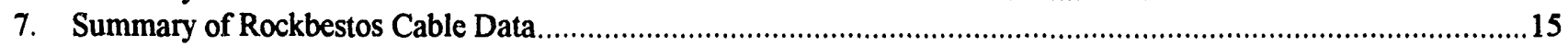

8. Breakdown Voltages and 95\% Confidence Intervals from Phase III ............................................................17

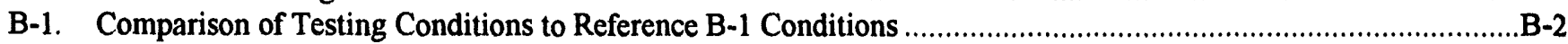




\section{Nomenclature}

ACRS Advisory Committee on Reactor Safeguards

AWG American Wire Gauge

CSPE chlorosulfonated polyethylene (also known as Hypalon®)

EPDM ethylene propylene diene polymethylene

EPR ethylene propylene rubber

EPRI Electric Power Research Institute

EQ Equipment Qualification

failure During LOCA exposure, failure is used to indicate the opening of a 1 Amp fuse. Actual failure in real circuits would depend on the application.

ID inner diameter

IR Insulation Resistance

LICA Low Intensity Cobalt Array, facility for performing irradiation exposures at Sandia National Laboratories.

LOCA loss-of-coolant accident; a design basis event for nuclear power plants.

mil one-thousandth of an inch

NRC Nuclear Regulatory Commission

SR silicone rubber

TVA Tennessee Valley Authority

XLPE crosslinked polyethylene

XLPO crosslinked polyolefin 


\section{Acknowledgments}

Our appreciation is extended to all who contributed to this research effort. Ed Baynes and Mike Ramirez assisted with test preparations and test monitoring. Gary Fuehrer created the data logging programs and the data reduction programs. Curt Nelson assisted with data reduction and technical advice. Deanna Sevier performed the $\mathrm{x}$-rays. Special thanks go to Hukam Garg for his support and guidance throughout this program. Special thanks to a number of industry and Nuclear Regulatory Commission personnel who provided draft review comments. 


\section{Executive Summary}

Experiments were performed to assess concerns about high potential testing of cables in conduits flooded with water and to determine the amount of cable insulation necessary to survive aging and a Loss-of-Coolant Accident (LOCA). The test program was designed in three phases. Phase I was the high potential testing of virgin cables to determine if $240 \mathrm{Vdc} / \mathrm{mil}$ testing damages cables; Phase II determined the voltage level necessary to detect when damaged cables will not survive aging and accident testing; and Phase III was the high potential testing of virgin cables to determine if testing at the voltages defined in Phase II damages virgin cables. Three cable types were chosen for this test program:

Okonite Okolon \#12 AWG single conductor cable insulated with 30 mils $(0.030 \mathrm{in})$ of ethylene propylene diene polymethylene (EPDM) insulation with a 15-mil bonded chlorosulfonated polyethylene (CSPE) jacket (also called a composite insulation);

Rockbestos silicone rubber (SR) \#16 AWG single conductor cable insulated with 30 mils of silicone rubber and jacketed with a fiberglass braid; and

Brand Rex \#12 AWG, stranded single conductor cable with 30 mils of crosslinked polyethylene (XLPE) insulation.

The conclusions of this experimental effort with regard to the specific objectives of the program are addressed below:

OBJECTIVE: Assess whether high potential testing at $240 \mathrm{Vdc} / \mathrm{mil}$ causes damage to selected cables. CONCLUSION: Based on ultimate voltage breakdown strength, 24 cycles of high potential testing of cables at $240 \mathrm{Vdc}$ imil did not cause damage to the three cable types tested.

OBJECTIVE: Assess the minimum insulation thickness necessary for accident functionality after accelerated aging to nominal lifetimes of 40 or 60 years through aging and accident testing of damaged cables.

CONCLUSION: Brand Rex XIPE cables milled to as little as 7 mils of insulation remaining are likely to survive in an accident after thermal and radiation aging to the conditions defined in this test program. However, if higher applied voltages $(>110 \mathrm{Vdc})$ or ac voltages had been used during the LOCA simulation, post-LOCA dielectric strength data suggests earlier failures may have occurred. With more than 12 mils of insulation, however, there is no indication of potential failure even at higher voltages.

Rockbestos SR cables milled to as little as 4 mils of insulation remaining have a reasonable probability of surviving in an accident after thermal and radiation aging to the conditions defined in this test program. It appears that aging may have been a significant factor (together with the reduced wall thickness) in causing two failures that were observed for the Rockbestos SR cables. Thus, reduced aging (thermal and/or radiation) might decrease the failure rate of these (damaged) cables.

Survival data for Okonite Okolon cables were not available because of failures during thermal aging. All of the (intentionally) damaged Okonite EPDM/CSPE cables with less than 15 mils of insulation remaining failed before the completion of aging (circumferential cracks open to the conductor). The one undamaged cable failed during the LOCA exposure shortly after the test chamber environment became saturated steam. The one cable that had approximately 15 mils of insulation remaining caused a 1 A fuse to open 182 hours into the LOCA simulation, although there were indications of erratic insulation resistance behavior much earlier. The major causes of the Okonite cable failures are the extent of the thermal aging and the presence of a bonded CSPE jacket that ages more rapidly than the underlying insulation. It should be noted that the tested cable was rated for 40-year operation at $90^{\circ} \mathrm{C}\left(194^{\circ} \mathrm{F}\right)$, while our testing simulated only about $72^{\circ} \mathrm{C}$ $\left(162^{\circ} \mathrm{F}\right)$ for the jacket and $76^{\circ} \mathrm{C}\left(169^{\circ} \mathrm{F}\right)$ for the insulation, using the activation energies given in Table 2 and the Arrhenius equation.

OBJECTIVE: Assess the voltage level necessary for a high potential test to detect when the insulation thickness has been reduced to the minimum level determined by the previous objective.

CONCLUSION: To detect when Brand Rex insulation has been milled to 7 mils remaining, a test voltage of $35 \mathrm{kVdc}$ will suffice $(1170 \mathrm{Vdc} / \mathrm{mil}$ based on the nominal insulation thickness of 30 mils). Note that this voltage level is considerably above the $240 \mathrm{Vdc} / \mathrm{mil}$ test in IEEE 383-1974 [1]. A test criterion for Rockbestos cables was not established since the damage level necessary to survive an accident simulation was not definitive based on the results of these tests.

OBJECTIVE: Assess whether high potential testing at voltage levels found in the previous objective causes damage to selected virgin cables.

CONCLUSION: Based on ultimate voltage breakdown strength, six cycles of high potential testing of virgin Brand Rex cables at $35 \mathrm{kVdc}$ did not cause damage to the cables. However, testing at $35 \mathrm{kVdc}$ would probably be unacceptable to utilities for use in in situ testing based on field experience with high potential testing. 
OBJECTIVE: Determine the relationship between cable length and dc breakdown voltage.

CONCLUSION: In a limited set of tests with applied dc voltages, no unexpected length effects were noted. Such effects had been suggested in previous ac testing at Sandia when cables were tested in an ionized gas environment [2].

Additional results, beyond the objectives, were provided by this test program. The failures of the Okonite cables in this program and in a previous test program suggest that the bonded CSPE jacket is detrimental to overall cable integrity. These results indicate that even the undamaged cable cannot meet its rating with the bonded CSPE jacket when thermal aging is performed according to the Arrhenius theory as used in this testing. Another interesting result indicates that even though the Okonite cables sustained cracks during thermal aging (prior to the LOCA simulation), all of the cables survived for a period of time in the LOCA simulation. The first Okonite failure (opening of $1 \mathrm{~A}$ fuse) occurred at 11 hours (just after the chamber environment became saturated steam) and the final Okonite failure occurred 182 hours into the LOCA profile (although there were indications of erratic behavior and perhaps even failure well before the fuse opened). It must be noted that no chemical spray was used during the LOCA simulation. Because of cracks through to conductors that existed prior to the LOCA tests, the use of chemical spray would almost certainly have caused electrical failures to appear shortly after the chemical spray was started because of the enhanced ground plane created by the chemical spray. 


\subsection{Introduction and Objectives:}

Amid allegations that cables had been improperly handled and potentially damaged during installation at the Watts Bar and Sequoyah nuclear power plants, the Tennessee Valley Authority (TVA) proposed an in situ high voltage dielectric test program to assess whether installed cables had been damaged. Under agreement with the Nuclear Regulatory Commission (NRC), TVA disconnected suspect cables from service, filled the cable conduit with water, and performed a $240 \mathrm{Vdc} / \mathrm{mil}$ dielectric withstand test on the cables [3]. Cables passing this test were assumed to be functional, while cables that failed this test were replaced. The NRC had objected to the testing of cables in air, but agreed to testing with the conduits flooded with water prior to the high voltage application. Plant operations personnel had objected to the use of water in the conduits, but eventually agreed to perform the tests. Some results from the TVA testing were described in Information Notice 87-52 [3]. Concerns from the Advisory Committee on Reactor Safeguards (ACRS), TVA, and internally at the NRC were raised that these high potential tests may be damaging cables and/or that the technical basis for setting the test voltage was inadequate. To resolve these concerns, a test program was set up to assess potential damage resulting from high potential testing and to examine the performance of damaged cable in accident environments.
The specific program objectives were as follows:

a. Assess whether high potential testing at $240 \mathrm{Vdc} / \mathrm{mil}$ causes damage to selected cables. High potential testing of cables will be performed with the cables immersed in water.

b. Assess the minimum insulation thickness necessary for accident functionality after accelerated aging to nominal lifetimes of $40 / 60$ years through aging and accident testing of damaged cables.

c. Assess the voltage level necessary for a high potential test to detect when the insulation thickness has been reduced to the minimum level as defined in objective $b$.

d. Assess whether high potential testing (at voltage levels found in objective c.) causes damage to selected virgin cables.

e. Determine the relationship between cable length and dc breakdown voltage. 


\subsection{Experimental Arrangement}

\subsection{Test Specimens}

Cable types were selected on the basis of material, usage in nuclear power plants, and availability. Also taken into consideration were results from previous Sandia test programs, specifically the Aging Degradation of Cables Program $[4,5,6]$. Each cable type chosen was approved for use in this test program by the NRC. Three cable types were chosen for this test program:

1. Okonite Okolon \#12 AWG single conductor cable insulated with 30 mils $(0.030$ in) of ethylene propylene diene polymethylene (EPDM) insulation with a 15 -mil bonded 1 chlorosulfonated polyethylene (CSPE) jacket (also called a composite insulation);

2. Rockbestos silicone rubber (SR) \#16 AWG single conductor cable insulated with 30 mils of silicone rubber and jacketed with a fiberglass braid;

3. Brand Rex \#12 AWG, stranded single conductor cable with 30 mils of crosslinked polyethylene (XLPE) insulation.

Both the Okonite and Brand Rex cables are nuclear qualified, while the Rockbestos cables are not nuclear qualified. The Rockbestos cables were the only silicone rubber product that we were able to procure for testing. Rockbestos does have a nuclear qualified silicone rubber product, but we were previously unable to procure it because of manufacturing and/or quality assurance problems. We did not reattempt to procure the nuclear qualified silicon rubber cable for this program because of time constraints. We obviously do not know how their nuclear qualified product would have performed in the testing described in this report.

\subsection{Test Strategy}

The test program consisted of three phases. Phase I was the high potential testing of virgin cables to determine if $240 \mathrm{Vdc} / \mathrm{mil}$ testing damages cables; Phase II was the testing of intentionally damaged cables to determine the voltage level necessary to detect when damaged cables will not survive aging and accident testing; and Phase III was the high potential testing of virgin cables to

\footnotetext{
${ }^{1} \mathrm{~A}$ bonded jacket is defined as a cable jacket which cannot easily be separated from the insulation. Possibly during natural aging or accelerated aging, a jacket initially unbonded may effectively become bonded.
}

determine if testing at the voltages defined in Phase II damages cables.

\subsubsection{Phase I}

The objective of Phase I was to assess whether $240 \mathrm{Vdc} / \mathrm{mil}$ high potential testing of cables immersed in water causes damage to selected cables. The $240 \mathrm{Vdc} / \mathrm{mil}$ criterion is identical to that used in the TVA testing. Ultimate cable breakdown voltage was the criterion that was used to evaluate damage. A set of 60 cables (20 of each of the three types of cable), each 3-ft long, was subjected to $24 \mathrm{cycles}$ of $240 \mathrm{Vdc} / \mathrm{mil} \mathrm{high}$ potential testing. Each cycle consisted of five minutes on and five minutes off, giving a total of 120 minutes energized and 120 minutes deenergized. The intent of this procedure was to simulate $240 \mathrm{Vdc} / \mathrm{mil}$ testing performed periodically during a cable's lifetime (although the cable was neither thermally nor radiation aged). This set and a similar set of 60 virgin cables were then subjected to dc breakdown testing (Because of the high dc breakdown voltage of the Okonite cables, ac testing had to be used for breakdown testing of these cables.). The breakdown voltages of the two sets of cable were compared to establish whether the $240 \mathrm{Vdc} / \mathrm{mil}$ affected the ultimate breakdown of the cables.

The high potential testing was performed using a Hipotronics $880 \mathrm{PL}$ portable dc tester with a range of $0-80 \mathrm{kVdc}$ and a Hipotronics 750-2 ac tester with a range of $0-50 \mathrm{kVac}$. The current trip sensitivity setting for the ac and dc testers was approximately $20 \mathrm{~mA}$ and $5 \mathrm{~mA}$, respectively. High potential testing was performed using ramp rates of approximately $1000 \mathrm{Vdc} / \mathrm{sec}$ or $940 \mathrm{Vac} / \mathrm{sec}$. The breakdown voltage was taken from the peak meter reading prior to tripping the test set.

Results from previous tests at Sandia indicated that dc testing results in more scattered data than ac high potential testing when testing damaged cable in the presence of an ionized gas [2]. To address this possibility when testing in water, two additional sets of 15 Brand Rex cables (one set cycled at $80 \mathrm{Vac} / \mathrm{mil}$ as described above, and the other set virgin) were tested to breakdown in water with an ac potential applied. Table 1 shows the overall testing conditions for Phase I. 
Table 1 Number of Samples for Each Test Condition

\begin{tabular}{cccc}
$\begin{array}{c}\text { Cable } \\
\text { Type }\end{array}$ & $\begin{array}{c}\text { Voltage } \\
\text { Aging Condition }\end{array}$ & $\begin{array}{c}\text { Number of } \\
\text { Samples } \\
\text { Unaged }\end{array}$ & $\begin{array}{c}\text { Aged 240 } \\
\text { Minutes }\end{array}$ \\
\hline $\begin{array}{c}\text { Brand Rex } \\
\text { XLPE }\end{array}$ & $\begin{array}{c}240 \mathrm{Vdc} / \text { mil in Water } \\
80 \mathrm{Vac} / \mathrm{mil} \text { in Water }\end{array}$ & 20 & 20 \\
& & 15 & 15 \\
$\begin{array}{c}\text { Rockbestos } \\
\text { Silicone }\end{array}$ & $240 \mathrm{Vdc} /$ mil in Water & 20 & 20 \\
$\begin{array}{c}\text { Okonite } \\
\text { Okolon }\end{array}$ & $240 \mathrm{Vdc} /$ mil in Water & 20 & 20
\end{tabular}

In addition to these tests, the relationship between cable length and dielectric withstand voltage was investigated. A decrease in dielectric withstand voltage is expected as cable length increases because of the random nature and magnitude of cable imperfections. This concept is the premise of the "weak-link" theory.

Previous tests at Sandia indicated that the decrease in withstand voltage might be greater than expected when testing cables in the presence of an ionized gas with ac voltages[2]. To briefly examine whether such an effect might occur with de testing in water, three longer lengths of Brand Rex cable were tested (in addition to the 3-ft long samples). Two samples were 25 -ft long and one was $50-\mathrm{ft}$ long. The data from the longer cable lengths were then compared statistically with the data from the shorter cable lengths.

\subsubsection{Phase II}

Phase II consisted of aging and accident testing of 31 intentionally damaged cables (10 each of Brand Rex and Okonite, and 11 of Rockbestos) to assess the minimum insulation thickness necessary to give reasonable confidence that the aged cables would survive during accident conditions. The radiation aging was performed in Sandia's Low Intensity Cobalt Array (LICA) facility in a stainless steel test chamber surrounded by Cobalt pencils arranged in a configuration to meet desired test conditions. Thermal aging followed the radiation exposure and was performed in the same test chamber (out of the LICA pool), with electric circulation heaters used to maintain the temperature within the chamber. Air was introduced into the chamber during both radiation and thermal aging exposures to maintain ambient oxygen concentrations. The nominal plant radiation aging simulated was $20 \mathrm{Mrad}$.

The thermal aging conditions were chosen to give a 60 -year equivalent life at $65^{\circ} \mathrm{C}$ for a material with an activation energy of $1.00 \mathrm{eV}$. With a selected aging time of 2 weeks ( $336 \mathrm{hr}$ ), Anhenius calculations gave an aging temperature of $158^{\circ} \mathrm{C}\left(316^{\circ} \mathrm{F}\right)$. Because all samples were aged simultaneously, each material had a different equivalent aging temperature for a 40- or 60 -year life. Table 2 gives the approximaie equivalent aging temperatures for 40- and 60-year lifetimes for each of the materials tested. The activation energies in the table were either approximated from manufacturers' data on the same or similar materials, or approximated from available literature. They should not be considered definitive since actual material activation energies were not determined.

The activation energy for CSPE was estimated based on the data in References 8 and 9. Three different Hypalon 18 materials were tested in References 8 and 9: the insulation of a Kerite cable, the jacket of the same Kerite cable, and the inner jacket of an Anaconda cable. In previous contacts, Kerite indicated that their insulation material is a considerably modified form of CSPE. In fact, Kerite stated that their insulation material is not Hypalon $(\AA$, the trade name for DuPont's CSPE. However, the testing in References 8 and 9 indicated the Kerite material is very similar to other Hypalons ${ }^{\circledR}$ and the term Hypalon $\circledast$ is used in References 8 and 9. Because base Hypalon $\left({ }^{\circ}\right.$ is known to degrade in thermal aging much faster than materials such as EPR and XLPO, it is not at all surprising that Kerite would significantly modify it for use as their cable insulation. However, the jacket would not be expected to have as much modification on either the Kerite or the Anaconda cables. Thus, we feel the jacket materials should be most representative of the Okonite jacket. The activation energies in References $\mathbf{8}$ and $\mathbf{9}$ for thermal aging only are $24 \pm 1 \mathrm{kcal} / \mathrm{mole}(1.04 \pm 0.04 \mathrm{eV})$ for the Kerite jacket, $25 \mathrm{kcal} / \mathrm{mole}(1.08 \mathrm{eV})$ for the Anaconda inner jacket, and $21 \pm 2 \mathrm{kcal} / \mathrm{mole}(0.91 \pm 0.09 \mathrm{eV})$ for the Kerite insulation. Giving more weight to the jackets than the Kerite insulation, 1.04-1.08 eV seems to be a reasonable choice for the Okonite jacket. The difference between the $1.04 \mathrm{eV}$ and $1.08 \mathrm{eV}$ is quite small and the lower value was selected for this test program.

The accident radiation exposure consisted of $110 \mathrm{Mrad}$ and was performed concurrently with the aging radiation exposure. The desired dose rate during radiation exposure was approximately $300 \mathrm{krads} / \mathrm{hr}$ for 433 hours to achieve the total radiation exposure of $130 \mathrm{Mrad}$. Actual dose rates in the chamber were determined by using 50 thermoluminescent dosimeters placed around the mandrel on which the cables were mounted in the test chamber. The cobalt pencil configuration produced a mean dose rate of $297.2 \mathrm{krad} / \mathrm{hr}$ with a $1-\sigma$ sample standard deviation of $23.9 \mathrm{krads} / \mathrm{hr}$. The desired temperature during thermal aging was maintained by two circulation heaters and the test chamber was insulated to 
Table 2 Approximate Equivalent Aging Temperatures for 40 and 60 Years

\begin{tabular}{|c|c|c|c|c|c|}
\hline Cable Type & $\begin{array}{c}\text { Aging } \\
\text { Temperature } \\
\left({ }^{\circ} \mathbf{F} /{ }^{\circ} \mathbf{C}\right) \\
\end{array}$ & $\begin{array}{l}\text { Aging Time } \\
\text { Hours }\end{array}$ & $\begin{array}{c}\text { Activation } \\
\text { Energy } \\
\text { (eV) }\end{array}$ & $\begin{array}{c}\text { 40-yr } \\
\text { Ambient } \\
\text { Temperature } \\
\left({ }^{\circ} \mathbf{F} /{ }^{\circ} \mathrm{C}\right) \\
\end{array}$ & $\begin{array}{c}\text { 60-yr } \\
\text { Ambient } \\
\text { Temperature } \\
\left({ }^{\circ} /^{\circ} \mathrm{C}\right) \\
\end{array}$ \\
\hline $\begin{array}{l}\text { Okonite } \\
\text { CSPE }\end{array}$ & $316 / 158$ & 336 & 1.04 & $162 / 72$ & $154 / 68$ \\
\hline $\begin{array}{c}\text { Okonitie } \\
\text { EPR }\end{array}$ & $316 / 158$ & 336 & 1.10 & $169 / 76$ & $162 / 72$ \\
\hline $\begin{array}{l}\text { Brand Rex } \\
\text { XLPE }\end{array}$ & $316 / 158$ & 336 & $\begin{array}{c}1.37^{\#} \\
0.91^{\# \#}\end{array}$ & $\begin{array}{l}192 / 89 \\
145 / 63\end{array}$ & $\begin{array}{l}187 / 86 \\
136 / 58\end{array}$ \\
\hline $\begin{array}{c}\text { Rockbestos } \\
\text { SR }\end{array}$ & $316 / 158$ & 336 & $\begin{array}{l}2.55^{*} \\
0.91^{* *}\end{array}$ & $\begin{array}{c}244 / 118 \\
145 / 63\end{array}$ & $\begin{array}{c}241 / 116 \\
136 / 58\end{array}$ \\
\hline
\end{tabular}

to minimize heat loss. During the thermal aging exposure, the temperature inside the chamber was monitored by 20 type K thermocouples.

After completion of the aging and accident radiation and the accelerated thermal exposure, the cables were exposed to a LOCA simulation similar to the test profile specified in Figure Al of IEEE STD 323-1974 Standard for Qualifying Class IE Equipment for Nuclear Power Generating Stations [10]. No chemical spray was used during the accident exposure. The LOCA exposure followed the IEEE STD 323-1974 temperature and pressure profiles for the first four days. After the first four days, the temperature and pressure were not decreased according to IEEE STD 323-1974. Rather, they remained at the same level for an additional six days, giving a total test duration of ten days. This abbreviated test is substituted for a longer test at reduced exposure levels with the understanding that the two tests are not necessarily technically equivalent. The EQ-Risk Scoping Study [11] indicated that equipment operability is most important during the initial few days of an accident. The study concluded that "PRAs [probabilistic risk assessments] calculate that equipment function only has high risk significance if the equipment operation occurs during the first few days after accident initiation. Hence, PRAs only model plant accident response for the first 24 to 48 hours." Thus, use of results from a test having an accelerated post-accident phase appears to have relatively little risk significance.

The cables were energized at $110 \mathrm{Vdc}, 0$ Amps during the LOCA test. Each cable was individually connected to a 1 A fuse. The fuse was sized to protect the power supply when gross failure of a cable occurred. A data logger and computer system automatically monitored the insulation resistance of each cable at intervals ranging from 10 seconds to 10 minutes during the LOCA simulation.

Following completion of the LOCA simulation, those cables that survived were subjected to the following dielectric tests until failure of the cable was observed:

- $\quad 240 \mathrm{Vdc} / \mathrm{mil}$ for five minutes based on the lowest remaining amount of insulation as measured by pre-test $\mathrm{x}$-rays or by diameter measurements;

- $\quad 240 \mathrm{Vdc} / \mathrm{mil}$ for five minutes based on the nominal cable insulation thickness; and

- ultimate breakdown voltage.

The LOCA test failures were assessed to determine a criterion for approximate remaining cable insulation thickness necessary for cable functionality during accident conditions. To determine the voltage necessary to detect when less than the minimum thickness of insulation remains, cables were milled to varying thicknesses and tested to breakdown. The resulting voltage levels were then used for the Phase III testing.

\subsubsection{Phase III}

The objective of Phase III was to assess whether high potential testing at the voltage levels defined in Phase II causes damage to selected virgin cables. As in Phase $I$, ultimate cable breakdown voltage in water was the criterion used to evaluate whether damage had been done. A set of virgin cables was subjected to high potential testing at the voltage determined in Phase II for six cycles 
of five minutes on and five minutes off, for a total of 60 minutes. Breakdown voltages of these cables were compared to the breakdown voltages of the unaged cables from Phase I to establish whether the voltage cycling affected the ultimate breakdown of the cables.

\subsection{Sample Preparation}

No special sample preparation was needed for Phases I and III. Samples were cut in 3-ft lengths with one end having a Raychem heat shrinkable endcap. Samples were cycled under defined conditions and tested to breakdown in a 2.1-in inner diameter (ID) conduit that was filled with water.

Sample preparation for the Phase II aging and accident exposures required approximately $60 \mathrm{ft}$ of cable per sample. Ten samples of the Okonite and Brand Rex cables and eleven samples of the Rockbestos cable were tested. All of the cables, except a virgin specimen of each type, were damaged at five locations. A miniature lathe with a high speed grinding attachment was used to produce a nominal one-inch length of damaged insulation as shown in Figure 1. The cables were mounted in a V-block clamping device in the lathe cross-feed, which is adjustable in 0.001 -in (1-mil) increments. Hence, the depth of cable damage can be controlled to a few thousandths of an inch. The length of the damage area was controlled by the longitudinal feed on the lathe. Light clamping pressure was used during milling to hold the specimens in place. This pressure is well below the level required to damage the cables. Damage extent on the Rockbestos cables was difficult to reproduce because of the eccentricity between the insulator and conductor. In addition, as the damage to the Rockbestos insulation increased, the insulation easily tore. Thus, heavily damaged insulation ( $<5$ mils remaining out of a nominal 30-mil wall) was not easily induced by our damage technique. The extent of damage at each location was confirmed by measuring the cable diameter before and after the milling operation and/or by selected $x$-rays of the sample and/or by post-test thickness measurements using an optical comparator. The cable numbering scheme, together with various thickness measurements range is given in Table 3 along with the nominal damage range based on diameter measurements.

The cables were then wrapped around a 12-inch diameter mandrel mounted in a test chamber. The section of cable with the five damaged sites was approximately $1.5 \mathrm{~m} \mathrm{(5 \textrm {ft } )}$ long within the chamber; the lead wires inside the chamber were about another $1.5 \mathrm{~m}$ long (varies slightly depending on the position of the cable in the test chamber); and the remaining cable length (approximately $50 \mathrm{ft}$ ) was used for external connections. The damaged locations on the cables were located near the metal vertical supports on the test mandrel.

Table 3 Cable Numbering Scheme and Damage Estimates for Cables Tested in this Test Program

\begin{tabular}{|c|c|c|}
\hline Cable Type & $\begin{array}{l}\text { Cable } \\
\text { Number }\end{array}$ & $\begin{array}{l}\text { Mils of } \\
\text { Insulation } \\
\text { Removed } \\
\text { (Range)* }\end{array}$ \\
\hline $\begin{array}{l}\text { Brand Rex } \\
\text { XLPE }\end{array}$ & $\begin{array}{c}1 \\
2 \\
3 \\
4 \\
5 \\
6 \\
7 \\
8 \\
9 \\
10 \\
\end{array}$ & $\begin{array}{c}20.5-22 \\
19.5-25 \\
24-27 \\
24.5-27.5 \\
25-26 \\
24 \\
22-23 \\
20 \\
0 \\
15 \\
\end{array}$ \\
\hline $\begin{array}{l}\text { Rockbestos } \\
\text { Silicone } \\
\text { Rubber }\end{array}$ & $\begin{array}{l}11 \\
12 \\
13 \\
14 \\
15 \\
16 \\
17 \\
18 \\
19 \\
20 \\
\end{array}$ & $\begin{array}{c}14.5-18.5 \\
20-26.5 \\
17.5-24 \\
22.5-23.5 \\
20.5-21 \\
17-19.5 \\
17-17.5 \\
10-11 \\
14.5-15.5 \\
0\end{array}$ \\
\hline $\begin{array}{l}\text { Okonite } \\
\text { Okolon }\end{array}$ & $\begin{array}{l}21 \\
22 \\
23 \\
24 \\
25 \\
26 \\
27 \\
28 \\
29 \\
30 \\
\end{array}$ & $\begin{array}{c}24-26 \\
23.5-28.5 \\
19.5-24.5 \\
22.5-24.5 \\
16-27 \\
20-24 \\
17.5-24 \\
22-27 \\
15-15.5 \\
0 \\
\end{array}$ \\
\hline $\begin{array}{l}\text { Rockbestos } \\
\text { Silicone } \\
\text { Rubber }\end{array}$ & 31 & $17-21$ \\
\hline
\end{tabular}

\subsection{Environment Monitoring}

Twenty type-K thermocouples were placed near the cables to record temperatures. The thermocouples were monitored via an HP3497A data logger. The pressure inside the test chamber was also monitored during the accident steam exposure using a Heise pressure gauge. 
Experimental Arrangement

\subsection{Insulation Resistance}

Insulation resistance measurements were made prior to and after radiation aging and after thermal aging using a Keithley 619 electrometer connected to a computer-based data acquisition system. A thorough explanation of the Keithley electrometer IR setup, procedures, and limitations can be found in Appendix A of Reference 4.

During the accident steam exposure, a data logger and computer system automatically monitored the insulation resistance of each cable at discrete times, ranging from 10 seconds to 10 minutes between measurements. These IRs are referred to as continuous IRs, although in reality they are not continuous. The continuous IRs are quite accurate for resistances as low as $100 \Omega$. However, accuracy for high resistance measurements $\left(>10^{7} \Omega\right)$ is limited by the design of the system [4]. (IRs above $10^{7} \Omega$ for a 3-m length of non-coaxial cable would be expected to have little adverse effect on nuclear power plant circuitry.) Using the Keithley electrometer setup, IR measurements were made at several times during the accident steam exposure. These IRs were performed at voltages of 100 and $250 \mathrm{Vdc}$ for 1 minute, and can accurately measure $\mathbb{R}$ values up to approximately $10^{12} \Omega$.
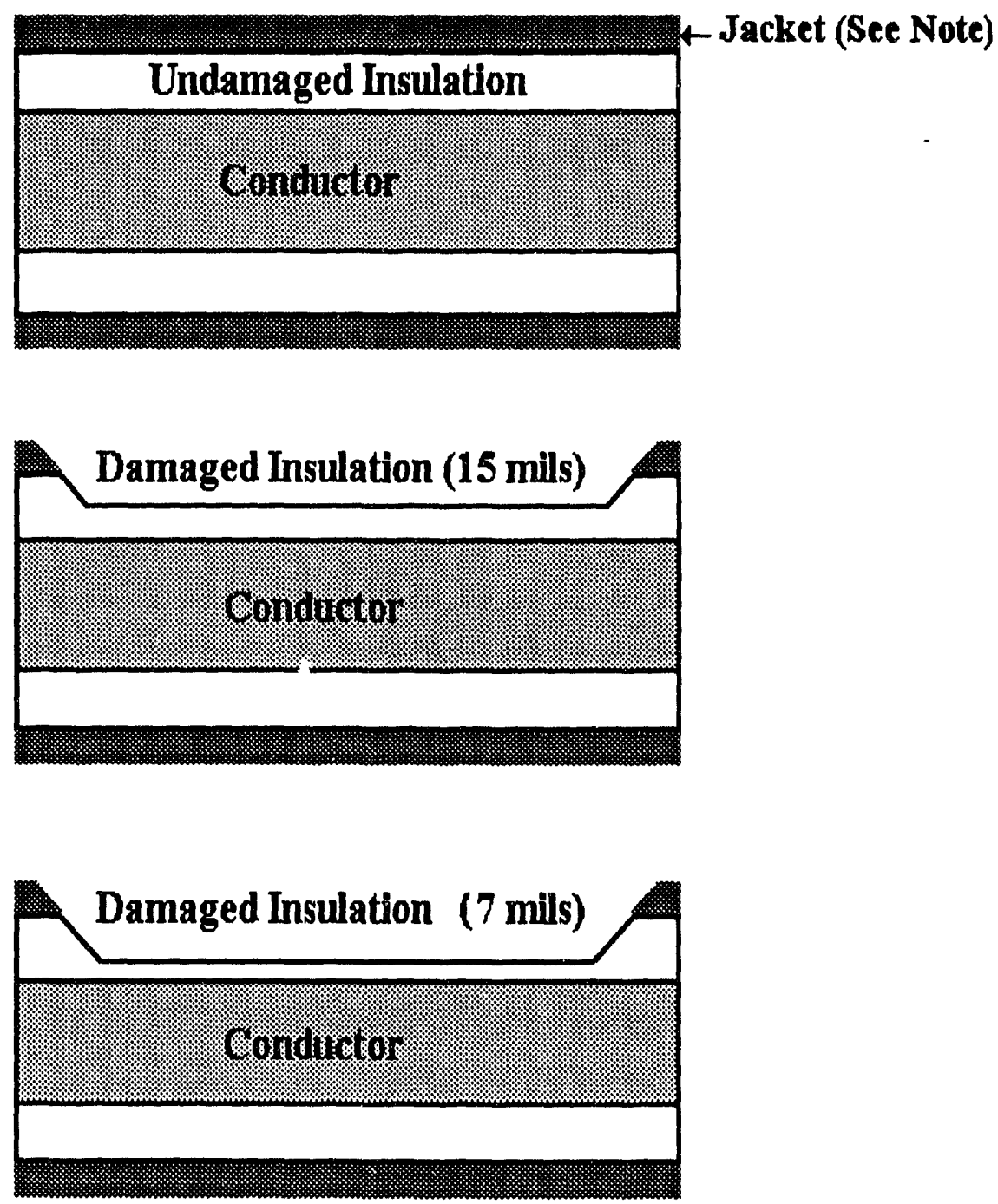

Figure 1 Lengthwise Cross-Sections of Samples With 30, 15, 7 mils of Insulation Remaining (NOTE: Only Okonite Samples Have the Additional 15-mil Bonded CSPE Jacket.) 


\subsection{Test Results}

\subsection{Phase I Results}

The results of the Phase I testing indicate the differences in breakdown voltage between cycled and uncycled cables for each undamaged cable type. Following the 24 cycles of voltage aging at $240 \mathrm{Vdc} / \mathrm{mil}$, all cables were tested to breakdown using the dc test set except for the Okonite cables. Because the Okonite cables had breakdown voltages over $80 \mathrm{kVdc}$ (based on the first 12 samples tested), they were tested to breakdown using the ac test set. The additional set of 15 Brand Rex cables was also tested with ac applied voltages.

Table 4 gives the mean and $95 \%$ confidence intervals for the differences between breakdown voltages of uncycled (virgin) and cycled cables. The statistical data in Table 4 are based on the assumption that the breakdown voltages are normally distributed. Note that, except for the Rockbestos cables, all of the confidence intervals include 0 , indicating that the difference between mean breakdown voltages of cycled and uncycled cables cannot be considered statistically significant at the $95 \%$ confidence level. It may also be concluded that, with 95\% confidence, the differences between the mean breakdown voltages of uncycled and cycled cables do not exceed $9.2 \mathrm{kVdc}$ or $4.1 \mathrm{kVac}$ for the Brand Rex cables, $2.0 \mathrm{kVac}$ for the Okonite cables and $3.1 \mathrm{kVdc}$ for the Rockbestos cables. Note that two of the differences in means were positive and two were negative. Based on the above data, high potential testing at $240 \mathrm{Vdc} / \mathrm{mil}$ does not significantly change the ultimate breakdown voltage of the tested cables.

In the tests to compare the scatter of ac versus dc testing, the standard deviations of the dc breakdown voltages compared to the means were $10.6 \%$ for cycled cables and $13.8 \%$ for uncycled cables. The standard deviations of ac breakdown voltages compared to the means were $10.7 \%$ for cycled cables and $12.6 \%$ for uncycled cables. Thus, ac and dc tests did not produce significantly different amounts of scatter in these tests. Note that the dc-to-ac breakdown voltage ratio is about 2.0 for the Brand Rex cables, somewhat below the conventional 3-to-1 ratio that is typically used to compare $\mathrm{dc}$ and ac testing. The same ratio for the Okonite cable is no less than 2.55 (>80 kVdc/31.4 kVac).

The results from the tests to assess whether breakdown voltage decreases with length indicated that the $3-\mathrm{ft}$ cable results (40 samples, for a total length of $120-\mathrm{ft}$ ) did not differ appreciably from the longer length cable results ( 3 samples, for a total length of $100 \mathrm{ft}$ ). For this comparison, the "weak-link" theory indicates that the lowest breakdown of exin group of cables should be roughly the same. The lowest breakdown voltage of the 3-ft samples was $44 \mathrm{kVdc}$, while the lowest breakdown voltage of the three longer samples was $45 \mathrm{kVdc}$. Of course the average breakdown of the 3-ft samples was higher $(62.0 \mathrm{kVdc}$, including both the cycled and the uncycled samples) than the average breakdown of the longer lengths $(55.6 \mathrm{kVdc})$, again in accordance with the "weak-link" theory. Thus, these limited dc tests in watcr do not suggest any unexpected cable length effect (although the expected effect is present).

\subsection{Phase II Results}

\subsubsection{Thermal and Radiation Aging}

For the Phase II testing, the total radiation dose ranged* from 95-145 Mrad (because of gradients in the test chamber). All of the cables had at least $120 \mathrm{Mrad}$ total dose to some part of the cable. The chamber was not rotated during the radiation aging. No test anomalies were reported during the irradiation period. Temperature gradients during thermal aging were limited to about $\pm 7^{\circ} \mathrm{F}\left( \pm 4^{\circ} \mathrm{C}\right)$. Figure 2 shows the temperature during

Table 4 Breakdown Voltages and 95\% Confidence Intervals from Phase I

\begin{tabular}{ccccc}
$\begin{array}{c}\text { Cable Type/ } \\
\text { Test Type }\end{array}$ & $\begin{array}{c}\text { Uncycled } \\
\text { Breakdown } \\
\text { (Mean kV) }\end{array}$ & $\begin{array}{c}\text { Cycled } \\
\text { Breakdown } \\
\text { (Mean kV) }\end{array}$ & $\begin{array}{c}\text { Difference in Means \& } \\
\text { 95\% } \\
\text { Confidence Interval } \\
\mathbf{( k V )}\end{array}$ & $\begin{array}{c}\text { Number of } \\
\text { Samples } \\
\text { Tested } \\
\text { Uncycled/Cycled }\end{array}$ \\
\hline Brand Rex/ac & 29.2 & 27.5 & $-1.7 \pm 2.4$ & $15 / 15$ \\
Brand Rex/dc & 59.7 & 64.2 & $4.5 \pm 4.7$ & $20 / 20$ \\
Okonite/ac & 31.4 & 31.8 & $0.4 \pm 1.6$ & $20 / 20$ \\
Rockbestos/dc & 38.6 & 36.8 & $-1.8 \pm 1.4$ & $20 / 20$
\end{tabular}


thermal aging. Note the drop in temperature at approximately 6 days. This anomaly in temperature was caused by a failed electric circulation heater. The defective electric circulation heater was removed while the remaining electric circulation heater maintained the chamber temperature above $100^{\circ} \mathrm{C}$ until a new electric circulation heater was added to restore the chamber to the desired temperature. The drop in temperature existed for approximately 24 hours. The thermal aging was extended by 24 hours to compensate for this anomaly. The effect of this anomaly is an insignificant increase in the total thermal aging.

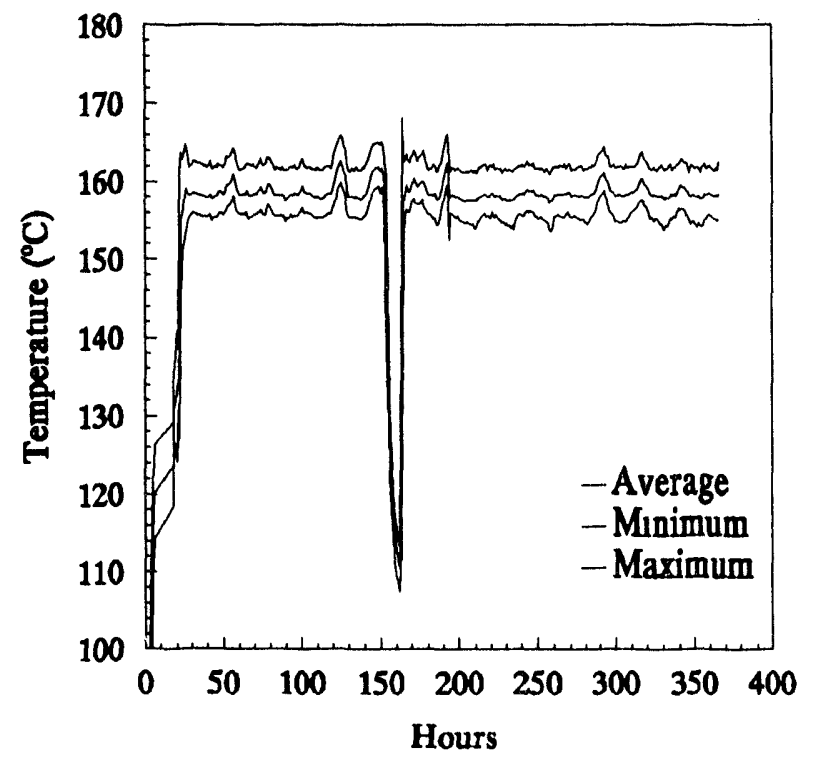

Figure 2 Thermal Aging Profile

After completion of the thermal aging, a visual inspection revealed that all of the (intentionally) damaged Okonite cables had developed cracks in their insulation and/or jackets. The virgin sample did not appear to have any signs of cracks. Most of the cracks were adjacent to the damage locations, but outside the damaged area. Figure 3 is a photograph of these cracks in several of the Okonite cables. The cracks were circumferential and most were through to the conductor, although some cracks were apparent only in the CSPE jacket (especially on the cable with the least amount of damage). No cracks through to the conductor were noted on the cable with the least amount of damage. The exact cause of the cracks is unknown, but a major factor appears to be thermal aging of the bonded jacket material, followed by jacket cracking that propagated to the insulation. The bending of the cables around the test mandrel also appears to be a significant factor. The cracks were clearly not caused by sample preparation or handling during testing. Samples were carefully prepared using minimal clamping pressure and inspected after milling. There was no sample handling after aging. Because of these failures and other subsequent accident test failures, the NRC issued Information Notice 92-81 [12]. The other two cable types (Brand Rex and Rockbestos) did not have cracks in the insulation.

\subsubsection{LOCA Simulation Results}

Following aging, the cables were subjected to the LOCA simulation. The temperature and pressure profiles during the LOCA simulation are shown in Figures 4 and 5 , respectively. Plots for the first 24 hours of the accident simulation are shown along with overall test profiles. The IR of each cable during the accident simulation is shown in Appendix A. The power supply energizing the test cables failed unexpectedly at approximately 30 hours into the LOCA simulation. A new power supply was installed at approximately 46 hours into the LOCA simulation - this accounts for the brief transient noted in many of the insulation resistance graphs. The only effect of the failed power supply was a loss of continuous IR data during the outage.

Because of the cracks in the Okonite cables, we expected that all the damaged Okonite cables, except for the undamaged cable and the cable with the least amount of damage, would fail early in the LOCA test. In fact, the , undamaged cable was one of the first cables to blow a 1 A fuse after the chamber environment became saturated steam at approximately 11 hours from the start of the LOCA exposure. (The undamaged cable blew its fuse at about 14 hours into the test as shown in Table 5.) The last surviving Okonite cable sample blew its $1 \mathrm{~A}$ fuse at approximately 182 hours into the LOCA simulation. Other cables that were known to have cracks through to the conductor did not blow $1 \mathrm{~A}$ fuses until as late as 137 hours into the LOCA test. Had chemical spray been present during the test, these cables would have almost certainly all blown fuses earlier because of the enhanced ground plane. These failures would probably have occurred soon after the chemical spray was started.

An analysis of the IR data of the Okonite cables (including the data in Reference 5) suggests that by the beginning of the second transient, the undamaged Okonite cable had cracked. Undamaged cable in Reference 5 had virtually identical IR behavior during both initial high temperature peaks while the undamaged cable in this program (Figure A-59) had IRs more than an order of magnitude lower during the second high temperature peak. Based on the long time that it took for the fuse to open (about 40 hours) after the first indication of IR degradation on Okonite conductor \#43 in Reference 5, it is further evident that the longitudinal cracking of the other Okonite cables almost certainly occurred prior to opening of the circuit fuses. When a cable splits longitudinally (as all the Okonite cables did), the geometry changes and the IR degrades until complete 
Results

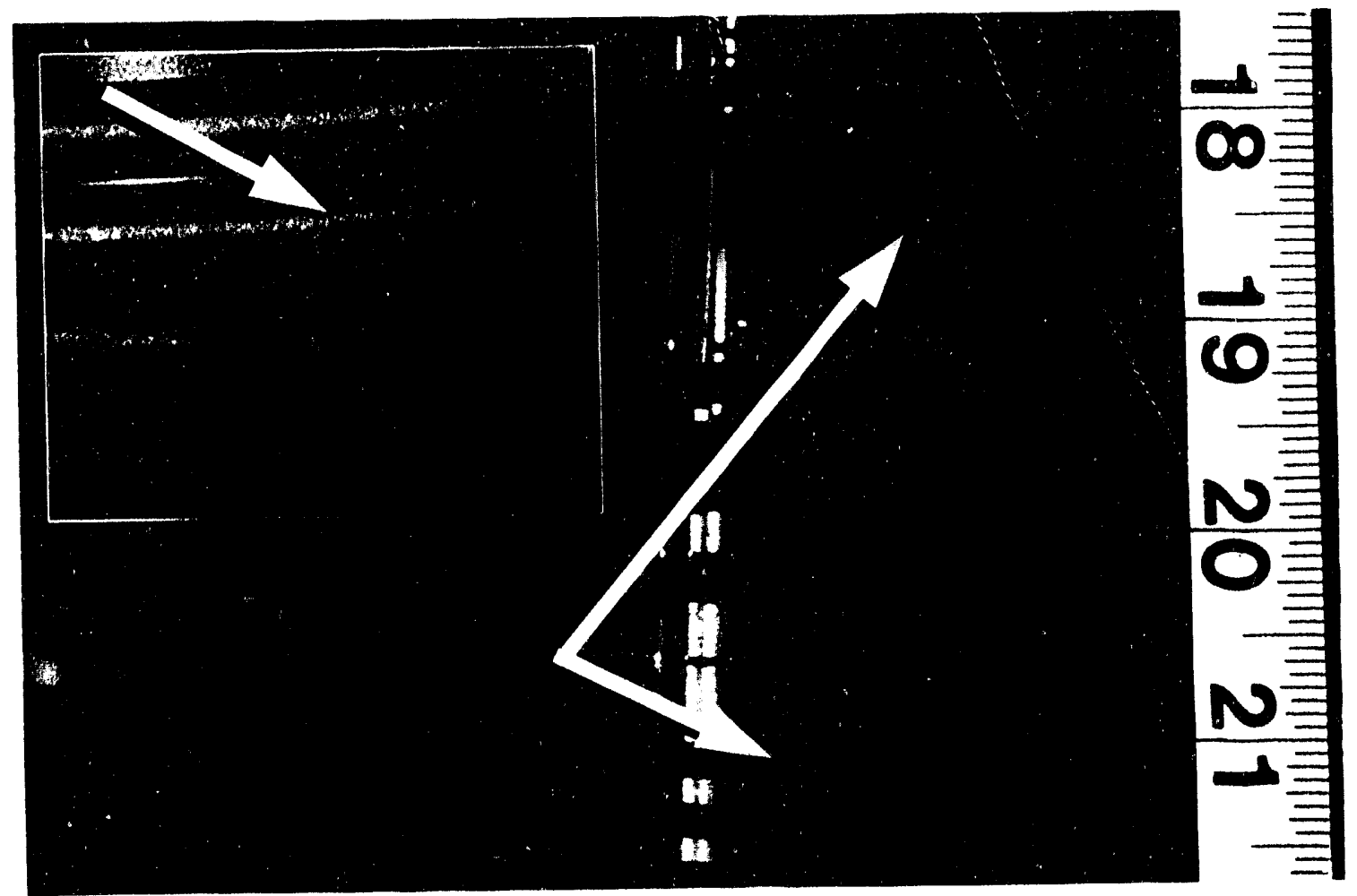

Figure 3 Cracks in Okonite Insulation After Thermal Aging
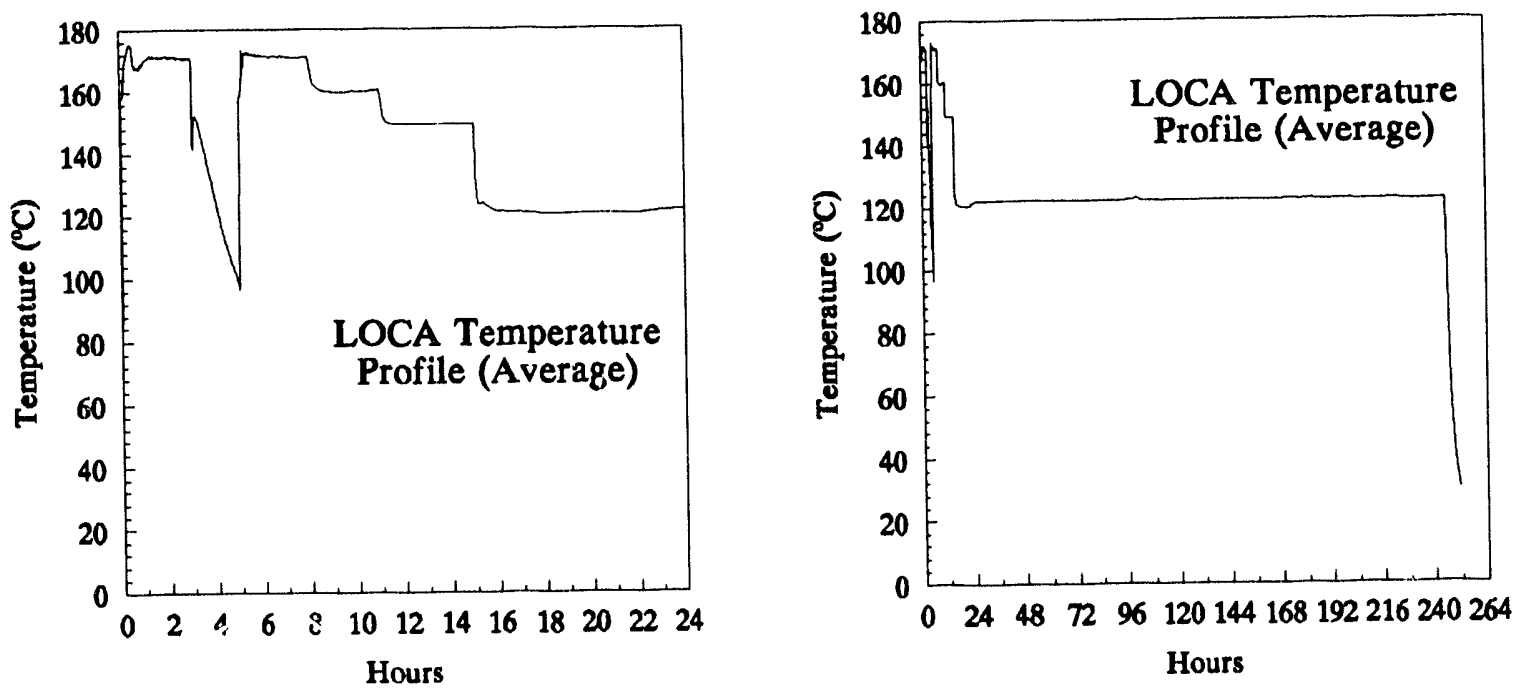

Figure 4 LOCA Simulation Temperature Profiles

failure occurs. Because no chemical spray was used in these tests and because actual geometry would be unknown in a real application, the exact timing of the IR behavior should not be considered generally applicable.
Rather, any cable that demonstrated erratic IR behavior during the LOCA simulation should be considered vulnerable to failure even prior to blowing the $1 \mathrm{~A}$ fuse. ${ }^{2}$

2 In a steam environment, a cable with a crack through to the conductor behaves much like a terminal block (in the sense that power and ground are only separated by the environment), with IR very dependent on geometry and environment. Some theoretical considerations regarding terminal block IR are given in Reference [13]. 

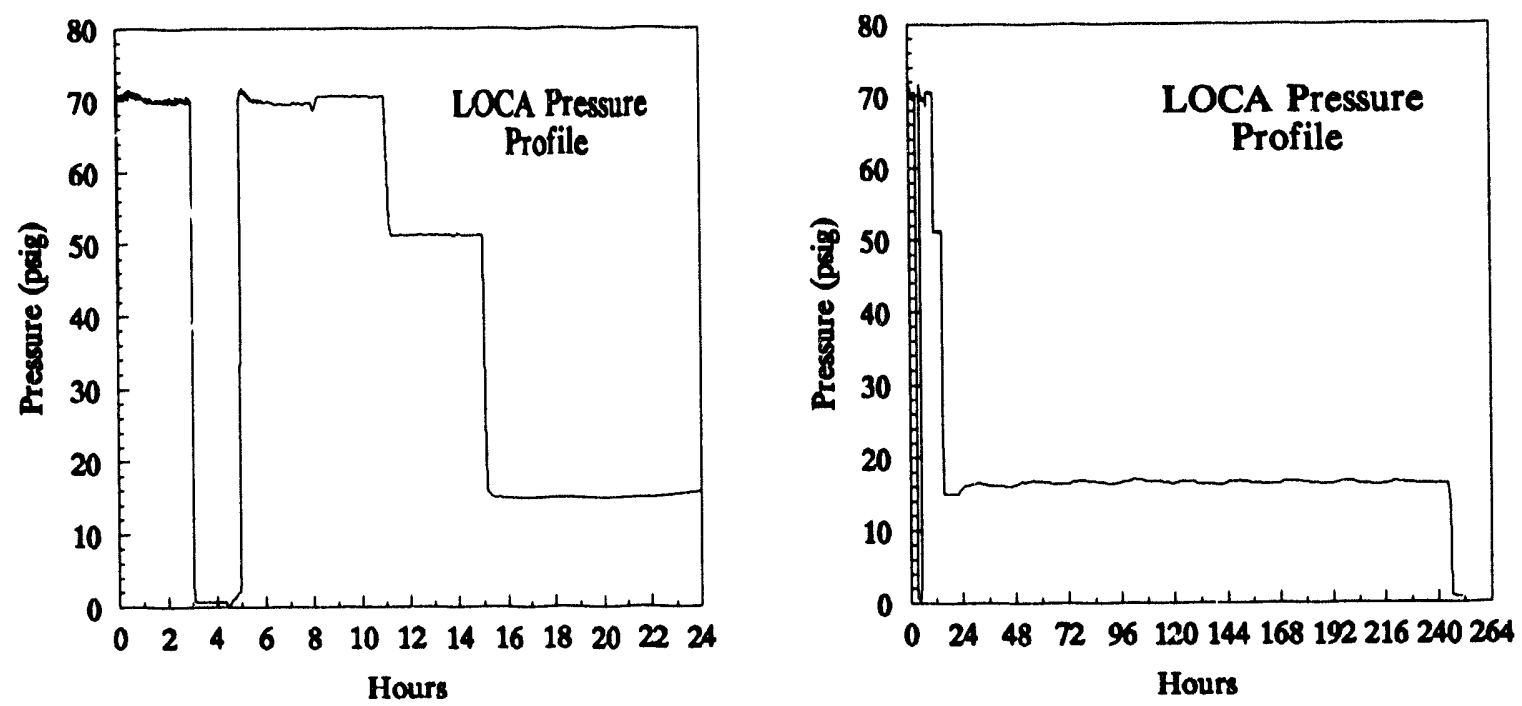

Figure 5 LOCA Simulation Pressure Profiles

It was evident during the post-LOCA inspection that the Okonite cables had clearly deteriorated grossly during the LOCA exposure. All the Okonite cables had longitudinal cracks over much of their length, exposing the center conductor as shown in Figure 6. In addition, identical undamaged single conductor Okonite Okolon cables that were used as cable ties in the test chamber exhibited the same type of extensive longitudinal cracking. Because of the nature of these failures and comparison with previous testing (discussed later), we believe that the failure rate of the Okonite Okolon cables under our test conditions is essentially $100 \%$. Because of their unexpected failures, no data for the minimum insulation thickness necessary to survive aging and accident tests can be determined for the Okonite cables. The observed failures were very similar in appearance to a failure of an Okonite cable and several failures of another cable that had bonded CSPE jackets in previous testing at Sandia [5].

Based on a comparison of the experimental conditions in this test programs and Reference 5, the only significant difference that could affect the undamaged cables as well as the damaged cables appears to be the increased thermal aging used in this program (see Appendix B for a discussion of test sequence, which was also different between the two test programs). Thus we strongly believe that the level of thermal aging used in this test program was the single most important environmental factor that caused the Okonite cables to fail. Note that the data in Figure 10 of Reference 8 for Hypalon-C suggests that this material would have an elongation of only about $20 \%$ absolute after 4 days of aging at $158^{\circ} \mathrm{C}$. After two weeks at $158^{\circ} \mathrm{C}$, the Hypalon is expected to have no residual elongation (even without any radiation application).

In the previous testing [5], one of four Okonite cables failed during a LOCA simulation after aging for 9 months at about $98^{\circ} \mathrm{C}\left(208^{\circ} \mathrm{F}\right)$, while none of three cables failed during a LOCA simulation after aging for 6 months at $98^{\circ} \mathrm{C}\left(208^{\circ} \mathrm{F}\right)$. In both cases, radiation aging was performed concurrently with the thermal aging. The equivalent 40-year aging temperatures corresponding to the 9- and 6-month aging exposures are $57^{\circ} \mathrm{C}\left(135^{\circ} \mathrm{F}\right)$ and $54^{\circ} \mathrm{C}\left(129^{\circ} \mathrm{F}\right)$, respectively, assuming an activation energy of $1.04 \mathrm{eV}$ (which corresponds to an approximate activation energy for the Okonite CSPE jacket). Thus, in an approximate sense, we can say that after the equivalent

Table 5 Times When Okonite Cables Blew 1A Fuses*

\begin{tabular}{cccc}
\hline $\begin{array}{c}\text { Cable } \\
\text { Number }\end{array}$ & $\begin{array}{c}\text { Time of } \\
\text { Blown Fuse } \\
\text { (hours) }\end{array}$ & $\begin{array}{c}\text { Cable } \\
\text { Number }\end{array}$ & $\begin{array}{c}\text { Time of } \\
\text { Blown Fuse } \\
\text { (hours) }\end{array}$ \\
\hline 21 & 102 & 26 & 90 \\
22 & 137 & 27 & 122 \\
23 & 50 & 28 & 97 \\
24 & 11 & 29 & 182 \\
25 & 81 & 30 & 14
\end{tabular}




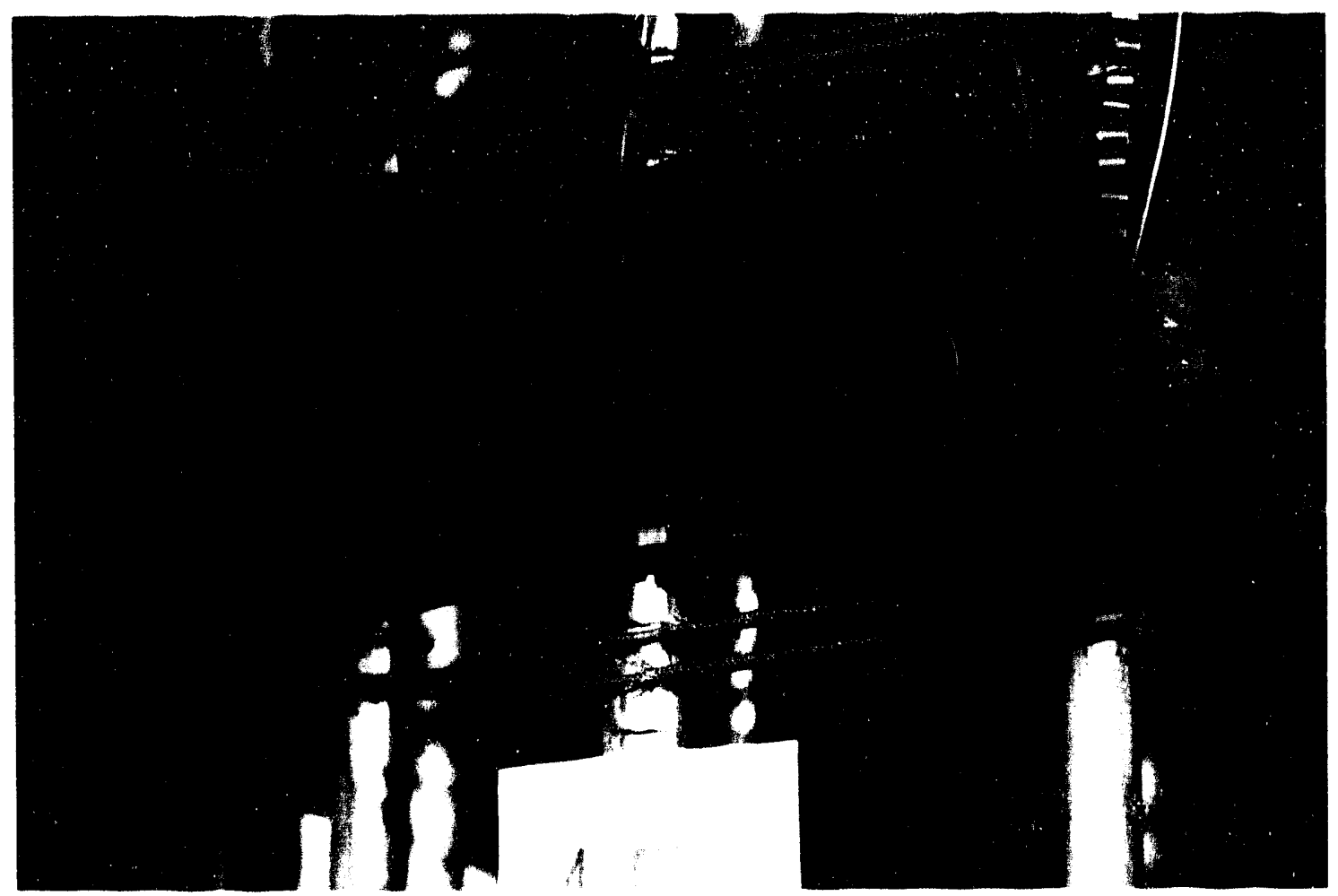

Figure 6 Okonite Cable Failures After LOCA Sinulation

of 40 years at $54^{\circ} \mathrm{C}\left(129^{\circ} \mathrm{F}\right), 0$ of 3 cables failed; after the equivalent of 40 years at $57^{\circ} \mathrm{C}\left(135^{\circ} \mathrm{F}\right), 1$ of 4 cables failed; and after the equivalent of 40 years at $76^{\circ} \mathrm{C}$ $\left(169^{\circ} \mathrm{F}\right)$, all of the tested cables failed. Based on this data, it is reasonable to conclude that after aging at $54^{\circ} \mathrm{C}$ $\left(129^{\circ} \mathrm{F}\right)$ for 40 years (and assuming an activation energy of $1.04 \mathrm{eV}$ ), the cables are likely to survive accident testing. Beyond $55^{\circ} \mathrm{C}\left(131^{\circ} \mathrm{F}\right)$ normal temperature for 40 years, the probability of failure during an accident increases and by $72^{\circ} \mathrm{C}\left(162^{\circ} \mathrm{F}\right)$ for 40 years, failure appears almost certain (for the radiation exposure dose and accident profilc used in our testing). Appendix B includes some discussion of the effect of the radiation exposure and the approximate equivalent thermal aging if radiation had not been included.

To apply the data to lifetimes of other than 40 years, the Arrhenius theory can be used to equate the test conditions to a temperature for any given lifetime (or conversely, a lifetime at any given temperature). This is shown in Figure 7, where the thermal aging data from the previous testing and the current testing is compared, using an activation energy of $1.04 \mathrm{eV}$. The top curve is based on the current testing and is obviously the most severe of the thermal aging conditions. The middle curve corresponds to 9 month of aging at $98^{\circ} \mathrm{C}\left(208^{\circ} \mathrm{F}\right)$ and the lower curve corresponds to 6 months of aging at $98^{\circ} \mathrm{C}\left(208^{\circ} \mathrm{F}\right)$. Assuming the Arrhenius theory to be valid, any time- temperature point on a given curve represents the same thermal aging as any other point on the same curve. Thus, for example, at $50^{\circ} \mathrm{C}$ for 60 years, no failures would be expected; at $54^{\circ} \mathrm{C}$ for 60 years, some failures would be expected; and at $68^{\circ} \mathrm{C}$ for 60 years, almost certain failure would be expected (with the radiation and accident profile used in this testing).

In addition to the Okonite cables, five Brand Rex and two Rockbestos cables that had been (intentionally) damaged prior to aging also blew their $1 \mathrm{~A}$ fuses during the LOCA simulation. The failures of the Brand Rex and Rockbestos cables during accident testing were all at damaged locations. The damage locations were cut from the cable, cross-sectioned as close to the breakdown location as possible, and the insulation thickness was measured using an optical comparator. Tables 6 and 7 give a summary of the performance of the Brand Rex and Rockbestos cables in the LOCA tests. The nominal remaining insulation is based upon diameter measurements during milling. The optical measurement was performed after LOCA testing. From Table 6, it appears that 7-mils is about the minimum insulation thickness necessary for Brand Rex cable functionality during accident conditions after aging to the conditions used in this test program. Cable 4 exhibited signs of failure in 4 out of 5 damage locations; thus, the data for cable 4 in Table 6 is reported as a range of remaining insulation thickness. Cables 2 and 6 both 
Results

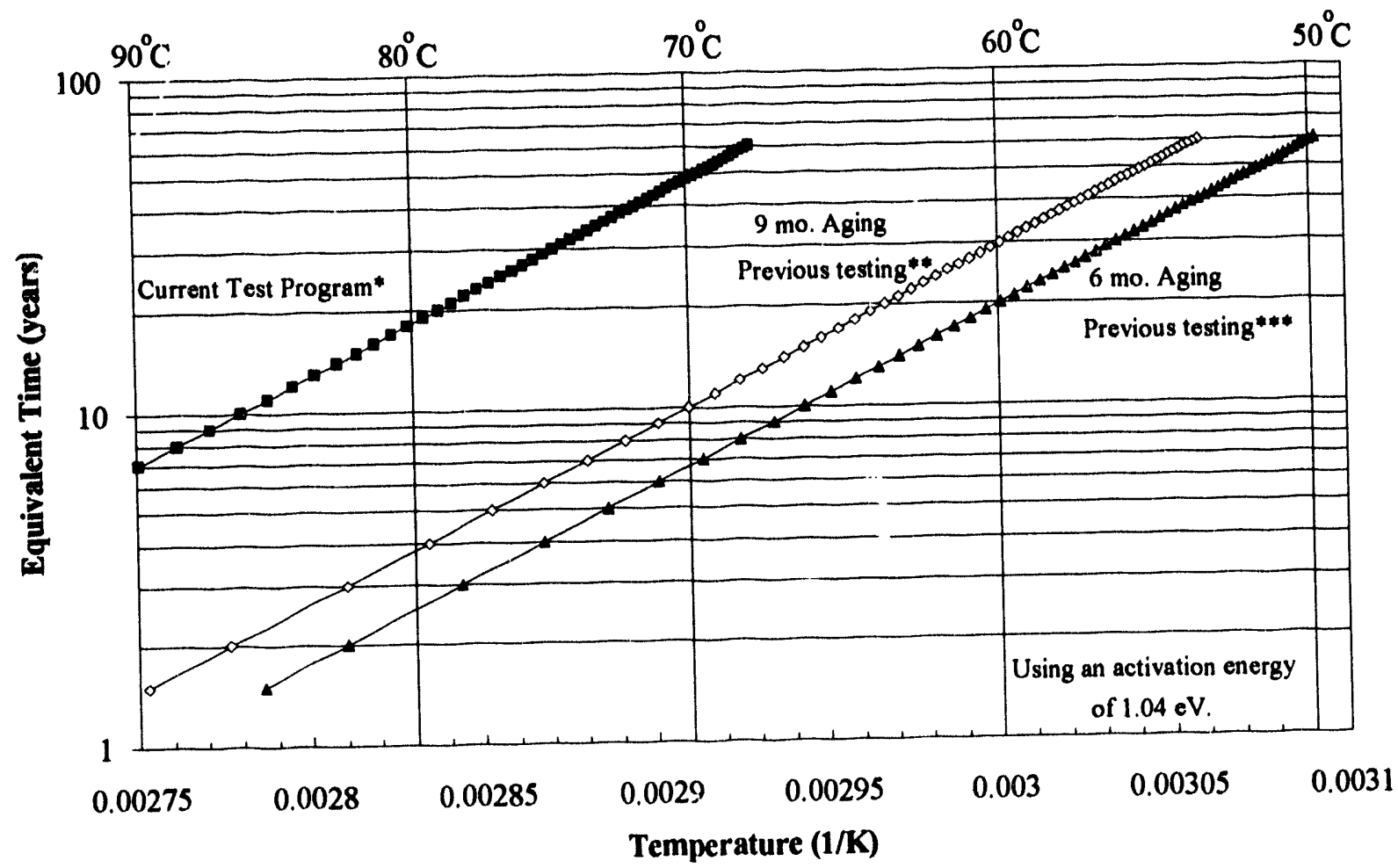

- All Okonite cables failed

** 1 of 4 Okonite cables failed.

*** 0 of 3 Okonite cables failed.

Figure 7 Equivalent Time-Temperature Corresponding to the Thermal Aging in this program and Previous Sandia Testing

Table 6 Summary of Brand Rex Cable Data

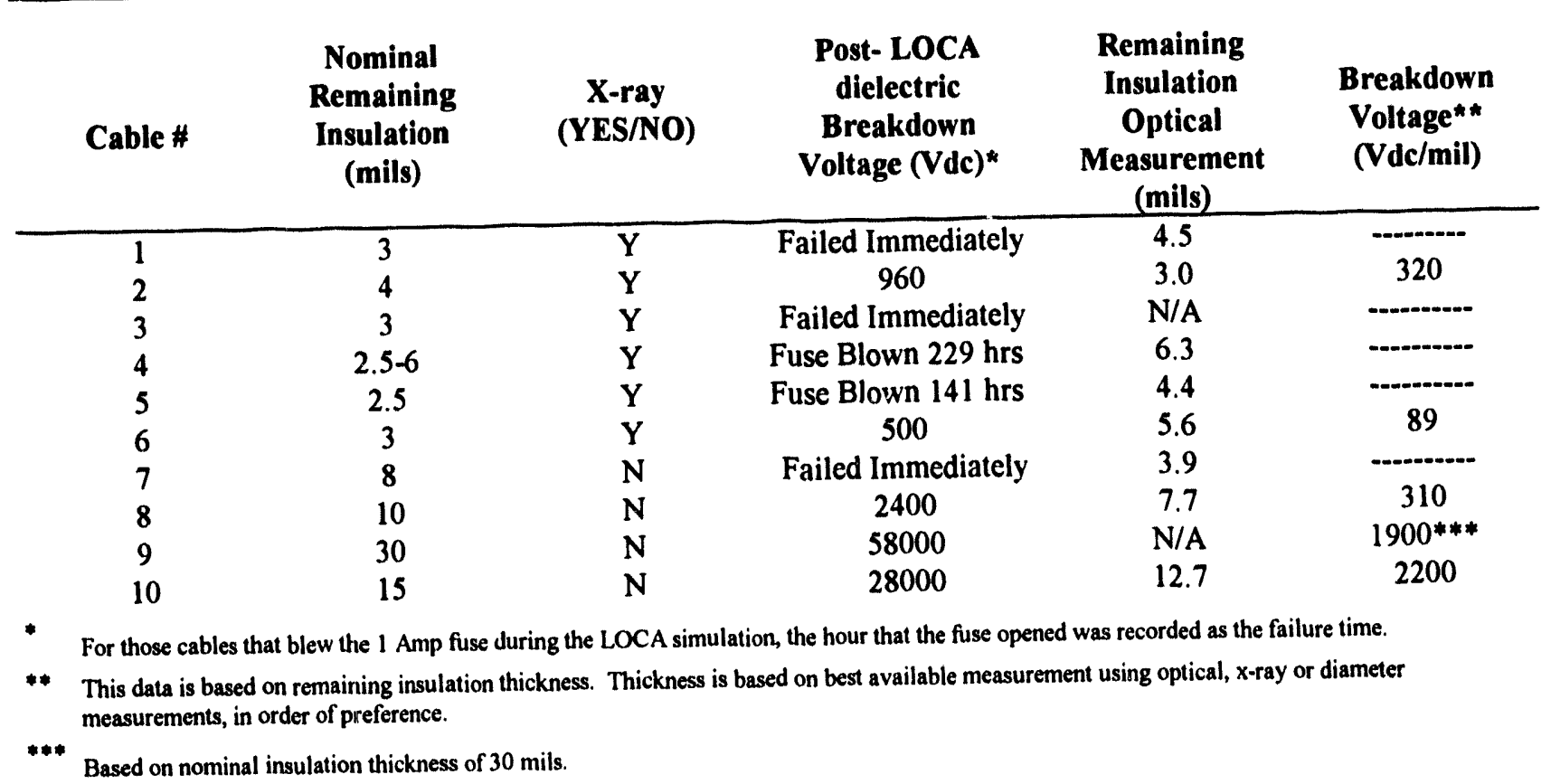


Results

Table 7 Summary of Rockbestos Cable Data

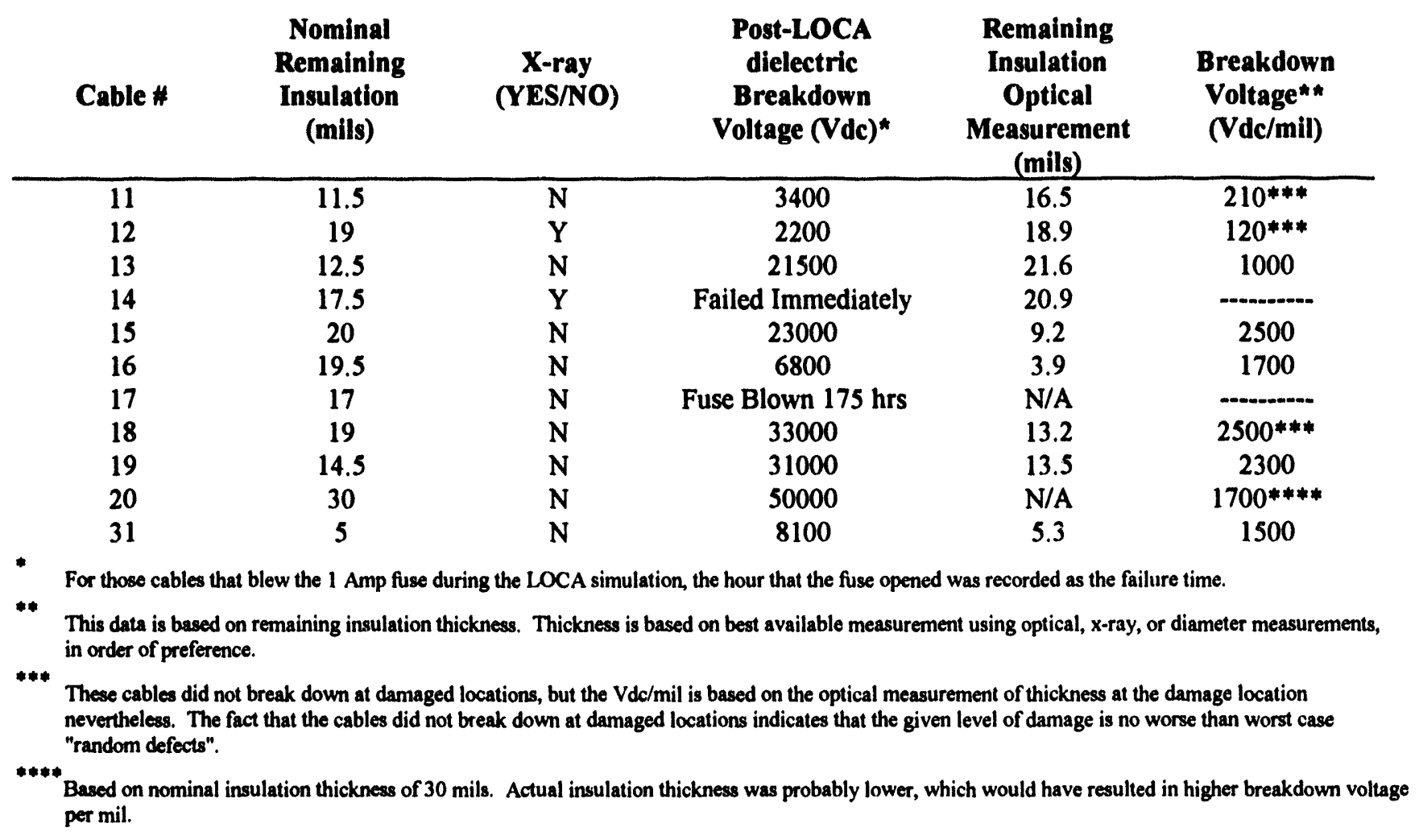

passed the LOCA test with less than 6 mils of insulation remaining. However, these cables failed very early in dielectric testing (discussed later), indicating that they may have failed during the LOCA if ac voltages had been applied and/or if the applied voltage had been higher (but still within the rating of the cable).

Table 7 indicates that the two Rockbestos cables that failed during LOCA exposure had approximately 17-21 mils of insulation remaining. These two Rockbestos cables began to show degradation during the accident test at about 26 hours (cable that blew $1 \mathrm{~A}$ fuse) and 212 hours (cable that did not blow a 1 A fuse). Only one of these cables underwent pre-test $x$-rays to confirm remaining insulation estimates, with the $x$-ray indicating a minimum remaining thickness of 17.5 mils. The actual failure point of this same cable was measured as $\mathbf{2 0 . 9}$ mils with the optical comparator after the test (note that the actual failure point would not necessarily be the point of minimum insulation thickness). After the accident, the remaining thickness on the other sample could not be determined because of severe degradation at the failure point. Unfortunately, this cable was not $x$-rayed before aging and the only measurement of insulation thickness is based on the diameter measurements during milling. Because of the strong eccentricity of the Rockbestos SR cables, this latter measurements can be significantly in error (perhaps by as much as 10-mils or more; for example, see the error in the measurement of cable 15 ).

In contrast to the two cable failures, several Rockbestos cables survived the accident test with insulation thicknesses ranging down to 3.9 mils. Because the only failures occurred with about 15-20 mils of insulation remaining and because all five cables with less than 15 mils of insulation remaining survived the accident test, the reduced insulation thickness was probably not the most critical factor in the failures. However, it must be noted that the cable that blew a $1 \mathrm{~A}$ fuse during the LOCA exposure and the cable that failed immediately during the post-LOCA dielectric test both had failures occur at damaged locations, indicating that the reduced insulation was at least an important factor in the failures. The results suggest that if this silicone rubber is used at somewhat lower thermal and/or radiation aging conditions, it might be expected to survive accident testing for cables with 4 mils or more of remaining insulation. It is even possible that cables with less remaining insulation would survive since all of the tested cables with less than 15 mils of insulation survived the accident testing. During sample preparation, we found that when the insulation was milled below a certain point (approximately 25 mils of insulation removed), the insulation tore and exposed the conductor; 
Results

thus, we were unable to easily mill samples to remaining insulation thicknesses less than 5 mils.

Several of the Rockbestos conductors tested had some unusual IR behavior during the accident exposure (Figures A-22, A-26, A-30, A-38, and A-62). The IR measurements were nevertheless almost always above $10^{6} \Omega$ for all of these cables. Based on the consistency of the redundant IR measurements in this program as well as with the data in Reference 6 (the values in this program have to be divided by about 50 to give the $\Omega-100 \mathrm{~m}$ units in Reference 6) and the lack of similar unusual reading for any other cables tested, we must conclude that the observed IR behavior is real. Because similar behavior was not, noted in Reference 5, we are led to the conclusion that the unusual IR readings have something to do with the fact that the cables were damaged, although we do not have any reasonable explanation for the mechanism behind the unusual readings.

\subsubsection{Post-Accident Dielectric Tests}

Following completion of the accident test, surviving cables were subjected to the following dielectric tests until failure of the cable was observed. Cables remained on the mandrel for the dielectric test except for the Okonite cables, which were removed because of their total failures.

a. $\quad 240 \mathrm{Vdc} / \mathrm{mil}$ for five minutes based on the lowest nominal remaining amount of insulation. See Figure 8 curve A.

b. $\quad 240 \mathrm{Vdc} / \mathrm{mil}$ for five minutes based on the nominal cable insulation thickness $(7200 \mathrm{Vdc}$ for all cables tested). See Figure 8 line B.

c. Ultimate breakdown voltage.

The results of these post-LOCA breakdown tests are given in Tables 6 and 7 . Figure 8 presents the dielectric strength data in $\mathrm{Vdc} / \mathrm{mil}$ of remaining insulation versus remaining insulation thickness for the Brand Rex and Rockbestos cables. Notu that the two Brand Rex cables that passed the accident test with less than 7 mils of insulation remaining (samples 2 and 6 ) both had breakdown voltages less than the $600 \mathrm{Vac}$ rating of the cable (considering $600 \mathrm{Vac}$ to be equivalent to $1800 \mathrm{Vdc}$ ). In addition, the breakdown voltage in $\mathrm{Vdc} / \mathrm{mil}$ for these two cables was much lower than the expected breakdown voltage of this material after LOCA (i.e. about $14000 \mathrm{kVac}$ for an undamaged cable [6] or the equivalent of about $1800 \mathrm{Vdc} / \mathrm{mil}$ ). If the cables had been energized with ac potential and/or if the applied voltage had been higher (but still within the rating of the cable), it is possible that these cables would have also failed during the accident exposure. However, unlike the cables that immediately failed the post-LOCA dielectric tests, neither of these two cables had any indication of problems during the LOCA simulation. There appears to be a clear difference in breakdown voltage in $\mathrm{Vdc} / \mathrm{mil}$ between the Brand Rex cables with less than 8 mils of insulation remaining and those with greater than 12 mils remaining. With less than 8 mils remaining, the breakdown voltage did not exceed $320 \mathrm{Vdc} / \mathrm{mil}$, while above 12 mils the breakdown voltage was not less than $1900 \mathrm{Vdc} / \mathrm{mil}$.

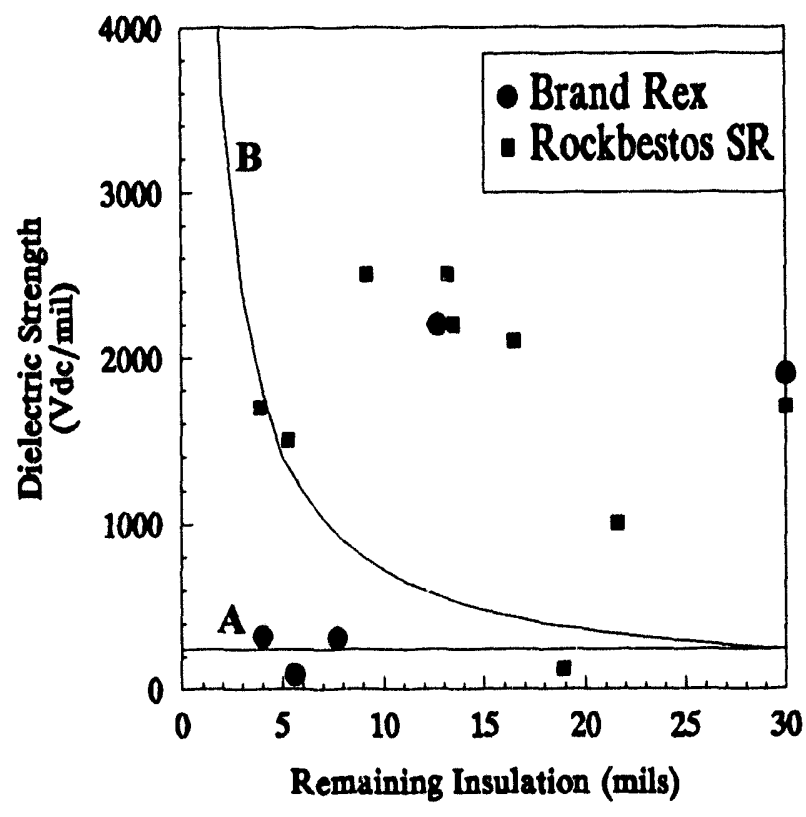

Figure 8 Dielectric Strength Based on Nominal Remaining Insulation Thickness

After the accident exposure, the silicone rubber cables were very fragile. The silicone rubber cables all had breakdown voltages of at least $1000 \mathrm{Vdc} / \mathrm{mil}$ except cable 12 , which had a breakdown voltage of $120 \mathrm{Vdc} / \mathrm{mil}$. Note that cable 12 had no indication of degradation during the LOCA exposure. Cables 11, 12, and 18 did not break down at damage locations. Cable 11 broke down at a location away from any damage, while cables 12 and 18 broke down in locations adjacent to a damage area. When cable 12 was inspected after the breakdown, a crack was found adjacent to a damaged area. It is possible that this cable was accidentally bumped and damaged during the removal of the Okonite cables from the test mandrel (the Okonite cables were removed from the mandrel prior to the breakdown testing of the remaining cables), causing the premature breakdown. However, the fact that the breakdown voltage was over $2000 \mathrm{Vdc}$ tends to indicate that damage was not done during removal, since any damage done during removal would be expected to cause through-wall cracks [5]. Rather, the crack was probably induced when the cable broke down. Similar behavior was observed with a Kerite cable in previous Sandia tests when 
the cable was subjected to post-LOCA bends and high potential testing [6].

\subsection{Phase III Results}

The results from the Phase III testing show the differences in breakdown voltages between Brand Rex cables cycled at $35 \mathrm{kVdc}$ and the uncycled Brand Rex cables from Phase I. The $35 \mathrm{kVdc}$ cycling voltage criterion was determined by examining the results of numerous breakdown tests of damaged (milled) Brand Rex cables as shown in Figure 9 and from previous Sandia tests [2]. The $35 \mathrm{kVdc}$ test voltage will detect when Brand Rex cables have insulation damage greater than 23 mils provided that the cables are tested in water. Twenty-five cables were cycled as in Phase I for a total of 60 minutes at $35 \mathrm{kVdc}(30$ minutes with voltage applied and 30 minutes without voltage applied). The cables were then tested to breakdown in a 2.1-inch ID conduit filled with water. Table 8 gives the mean and $95 \%$ confidence intervals for the breakdown voltages for these cycled cables and the virgin cables from Phase I. Note that the difference in means is positive, indicating that cycling did not appear to adversely affect the breakdown strength of the cables. However, it should be noted that the Brand Rex cables tested in Phase III were from a different reel of cable than those tested in Phase I. Thus, one possible explanation for the unexpected increase in breakdown voltage after cycling is reel-to-reel variations.

Table 8 Breakdown Voltages and 95\% Confidence Intervals from Phase III

\begin{tabular}{lcccc}
$\begin{array}{c}\text { Cable Type/ } \\
\text { Test Type }\end{array}$ & $\begin{array}{c}\text { Uncycled } \\
\text { Breakdown } \\
\text { (Mean kV) }\end{array}$ & $\begin{array}{c}\text { Cycled } \\
\text { Breakdown } \\
\text { (Mean kV) }\end{array}$ & $\begin{array}{c}\text { Difference in } \\
\text { Means \& 95\% } \\
\text { Confidence } \\
\text { Interval (kV) }\end{array}$ & $\begin{array}{c}\text { Number of } \\
\text { Samples Tested } \\
\text { Uncycled/Cycled }\end{array}$ \\
\hline Brand Rex/DC & 59.7 & 69.4 & $9.7 \pm 4.0$ & $20 / 25$
\end{tabular}

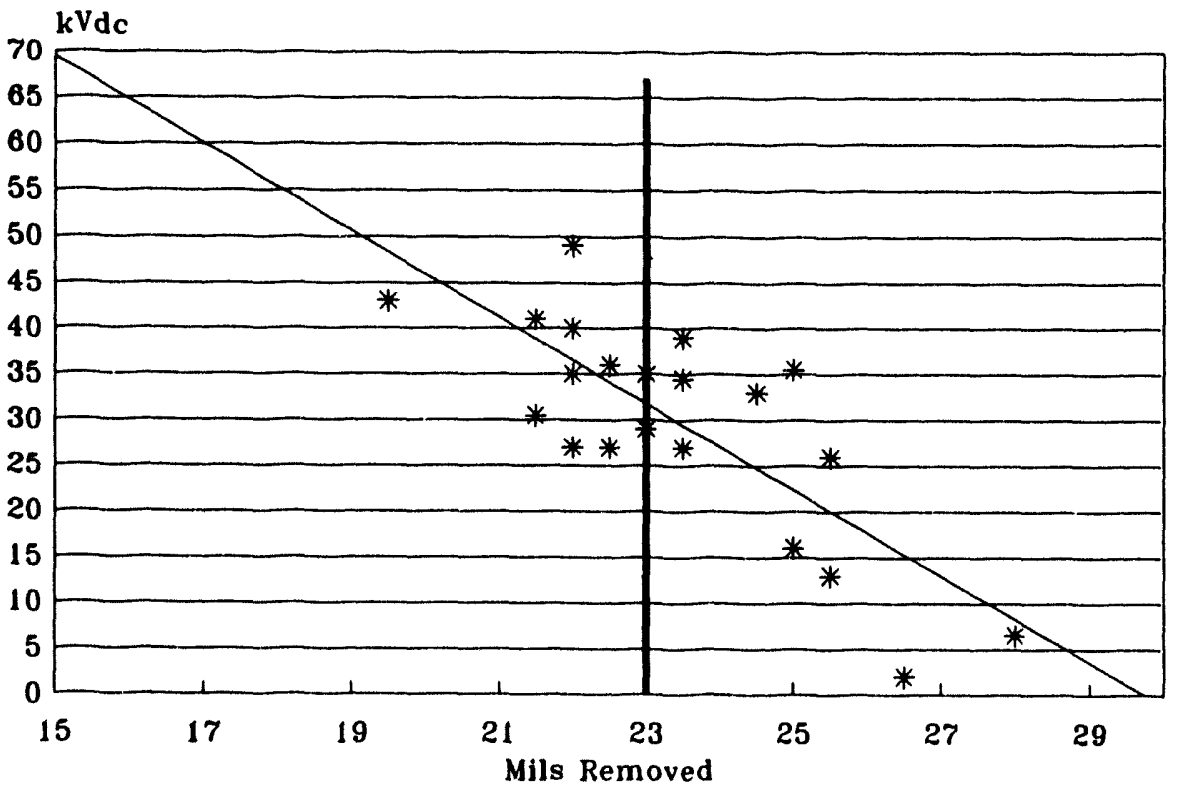

Figure 9 Breakdown Voltages for Damaged Brand Rex Cables Tested in Water 


\subsection{Conclusions}

The following conclusions may be drawn from this program:

a. Brand Rex XLPE cables milled to 7 mils of insulation remaining (compared with a nominal 30 mils of insulation for an undamaged cable) are likely to survive in an accident after thermal and radiation aging to the conditions defined in this test program. A high potential test at $35 \mathrm{kVdc}$ was required to detect this level of damage.

b. Rockbestos SR cables milled to have as little as 4 mils of insulation remaining (compared with a nominal 30 mils of insulation for an undamaged cable) have a reasonable probability of surviving in an accident after thermal and radiation aging to the conditions defined in this test program.

c. All of the (intentionally) damaged Okonite EPDM/CSPE cables with less than 15 mils of insulation remaining failed before the completion of aging. The one undamaged cable failed during the LOCA simulation shortly after the test chamber environment became saturated steam. The one cable that had approximately 15 mils of insulation remaining blew a 1 A fuse 182 hours into the LOCA simulation. This cable had cracks in the jacket, but not in the insulation, after aging. d. The major causes of the Okonite cable failures seem to be the extent of the thermal aging and the presence of a bonded CSPE jacket that ages more rapidly than the underlying insulation. The tested cable was rated for 40 -year operation at $90^{\circ} \mathrm{C}$ $\left(194^{\circ} \mathrm{F}\right)$, while our testing simulated only about $72^{\circ} \mathrm{C}\left(162^{\circ} \mathrm{F}\right)$ for the jacket and $76^{\circ} \mathrm{C}\left(169^{\circ} \mathrm{F}\right)$ for the insulation, using the activation energies given in Table 2.

e. In a limited set of testing with applied dc voltages, no unexpected length effects were noted. Such effects had been suggested in previous ac testing at Sandia when the cables were tested in an ionized gas environment.

f. Twenty-four cycles of high potential testing of cables at $240 \mathrm{Vdc} / \mathrm{mil}$ did not cause a reduction in breakdown voltage for the three cable types tested.

g. Six cycles of high potential testing using a test voltage of $35 \mathrm{kVdc}$ for Brand Rex cables did not appear to cause damage to the virgin cables. However, the effect of testing actual plant installed cable at this voltage level is unknown. This conclusion is certainly not a recommendation to perform any specific breakdown testing on installed cables. 


\subsection{References}

1. IEEE Standard for Type Test of Class IE Electric Cables, Field Splices, and Connections for Nuclear Power Generating Stations, ANSI/IEEE Standard 383-1974 (ANSI N41.1C-1975), New York, NY.

2. Vigil, R. A. and M. J. Jacobus, "Detecting Damaged Cables Using a Preionized Gas Technique," SAND92-2917C, Proceedings: 1993 EPRI Workshop on Power Plant Cable Condition Monitoring, EPRI TR-102399 Electric Power Research Institute, San Francisco, CA, February 1993.

3. United States Nuclear Regulatory Commission. Office of Nuclear Reactor Regulation, NRC Information Notice 87-52: Insulation Breakdown of Silicone Rubber Insulated Single Conductor Cables During High Potential Testing Washington, DC, October 1987.

4. Jacobus, M. J., Aging, Condition Monitoring, and Loss-of-Coolant Accident (LOCA) Tests of Class IE Electrical Cables,: Crosslinked Polyolefin Cables, NUREG/CR-5772, Vol. 1, SAND91-1766/1, Sandia National Laboratories, August 1992.

5. Jacobus, M. J., Aging, Condition Monitoring, and Loss-of-Coolant Accident (LOCA) Tests of Class IE Electrical Cables,: Ethylene Propylene Rubber Cables, NUREG/CR-5772, Vol. 2, SAND91-1766/2, Sandia National Laboratories, November 1992.

6. Jacobus, M. J., Aging, Condition Monitoring, and Loss-of-Coolant Accident (LOCA) Tests of Class IE Electrical Cables,: Miscellaneous Cable Types, NUREG/CR-5772, Vol. 3, SAND91-1766/3, Sandia National Laboratories, November 1992.
7. Gillen, K. T. and R. L. Clough, Aging Predictions in Nuclear Power Plants--Crosslinked Polyolefin and EPR Cable Insulation Materials, SAND91-0822, Sandia National Laboratories, June 1991.

8. Gillen, K. T. and R. L. Clough, Predictive Aging Results for Cable Materials in Nuclear Power Plants, SAND90-2009, Sandia National Laboratories, November 1990.

9. Gillen, K. T. and R. L. Clough, TimeTemperature-Dose Rate Superposition: $A$ Methodology for Predicting Cable Degradation Under Ambient Nuclear Power Plant Aging Conditions, SAND88-0754, Sandia National Laboratories, August 1988.

10. IEEE Standard for Qualifying Class 1E Equipment for Nuclear Power Generating Stations, IEEE Standard 323-1974, New York, NY.

11. Bustard, L. D., J. Clark, G. T. Medford, and A. M. Kolaczkowski, Equipment Qualification (EQ)-Risk Scoping Study, NUREG/CR-5313, SAND88-3330, Sandia National Laboratories, January 1989.

12. United States Nuclear Regulatory Commission. Office of Nuclear Reactor Regulation, NRC Information Notice 92-81: Potential Deficiency of Electrical Cables with Bonded Hypalon Jackets, Washington, DC, December 1992.

13. Craft, C. M., An Assessment of Terminal Blocks in the Nuclear Power Industry, NUREG/CR-3691, SAND84-0422, Sandia National Laboratories, September 1984. 


\section{Appendix A Insulation Resistance of Each Conductor During Accident Testing}

In this appendix, the insulation resistance measurements are shown for each conductor tested during the accident testing. For each of the conductors, two figures are shown. The first figure shows the data for the first 24 hours of the LOCA exposure and the second figure shows the data for the entire LOCA exposure. The Keithley discrete measurements shown on the plots are identified as 100 or $250 \mathrm{Vdc}$. These measurement were made at these voltages for a 1 minute duration. Table A-1 shows the Keithley IR measurements taken between the aging and accident sequences. 
Table A-1 Keithley Discrete IR Measurements Taken Prior to LOCA Testing

Cable Number

$\begin{array}{cc}\text { Cable Number } & \begin{array}{c}\text { Baseline IR } \\ \left(\times 10^{11} \Omega\right)\end{array}\end{array}$

Brand Rex

1

2

3

4

5

6

7

8

9

10

Rockbestos SR

11

12

13

14

15

16

17

18

19

20

Okonite Okolon

21

22

23

24

25

26

27

28

29

30

Rockbestos SR

31

\subsection{4}

3.70

3.55

3.50

3.86

4.28

4.82

3.64

3.84

3.55

0.42

0.20

0.40

0.16

0.34

0.27

0.28

0.35

0.38

0.24

2.92

2.25

2.10

2.58

3.02

2.57

2.33

2.65

2.85

2.94

0.37
Post Radiation Aging

Pre-Thermal Aging $\left(\mathrm{x10}^{11} \Omega\right)$

1.85

2.16

1.82

1.73

1.67

2.06

2.21

1.79

1.71

1.88

0.40

0.17

0.13

0.16

0.02

0.11

0.35

0.37

0.39

0.27

1.24

1.04

0.99

1.03

1.32

1.12

1.16

1.11

1.03

1.15

0.28
Post Thermal Aging Pre-LOCA $\left(\mathbf{1 1 0}^{11} \Omega\right)$

14.22

17.88

16.41

18.81

17.81

17.20

16.71

14.51

20.29

17.87

3.22

1.67

2.23

1.63

1.49

2.05

2.37

2.53

3.05

2.08

7.58

5.65

5.85

6.28

6.96

7.14

7.72

6.93

6.91

8.00

3.71 


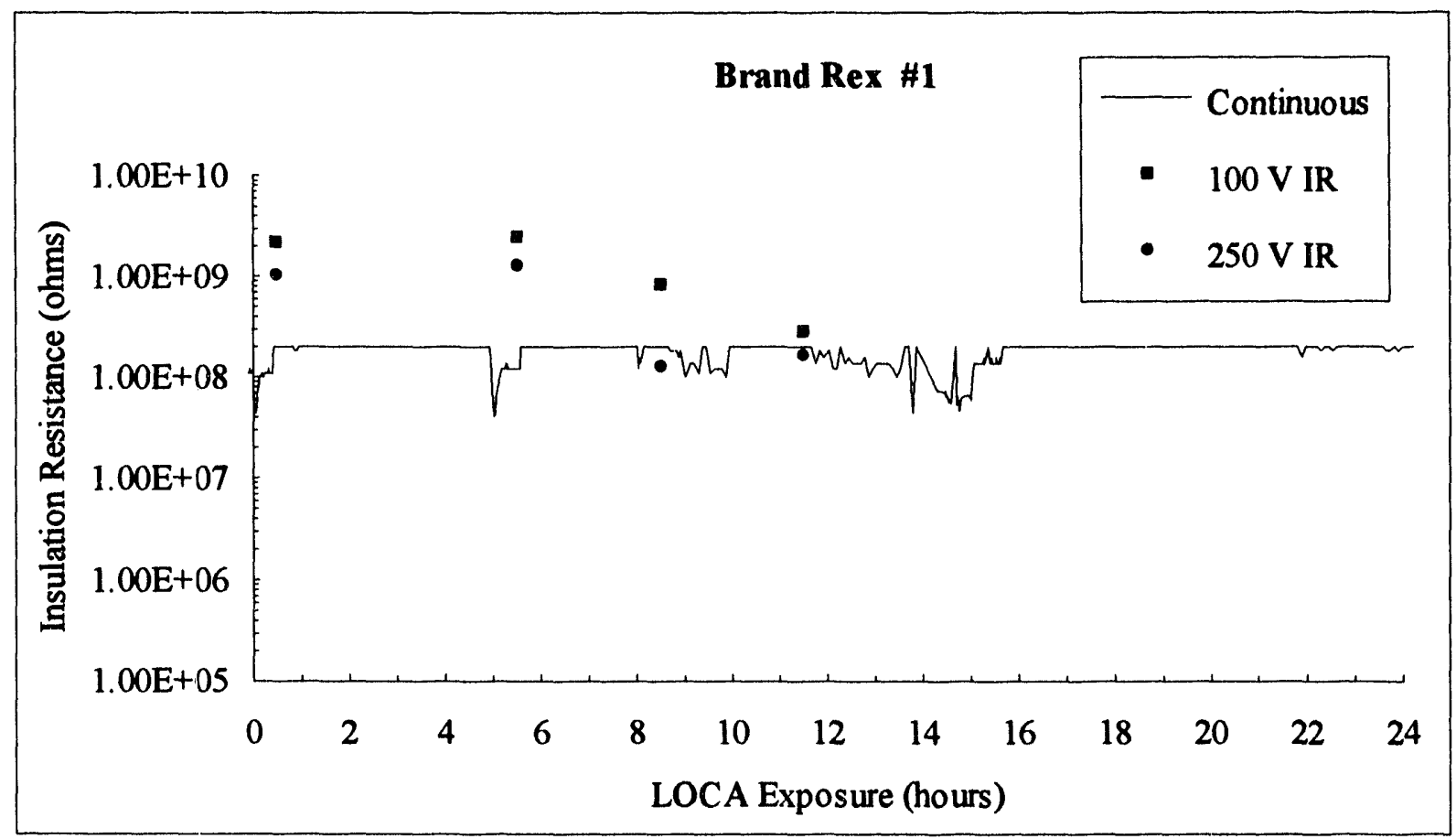

Figure A-1 Insulation Resistance for Brand Rex Sample \#1 during the first 24 hours.

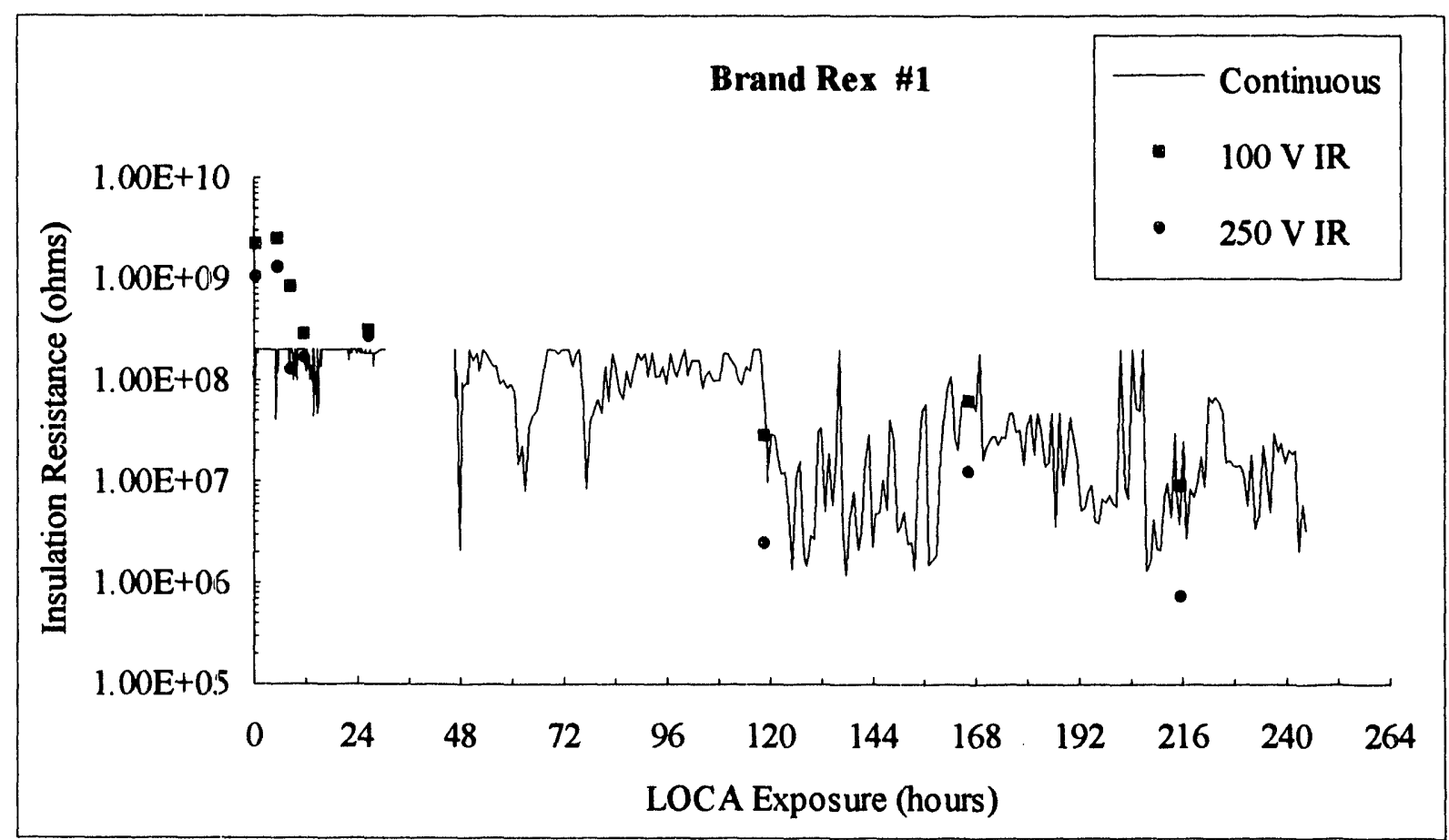

Figure A-2 Insulation Resistance for Brand Rex Sample \#1. 


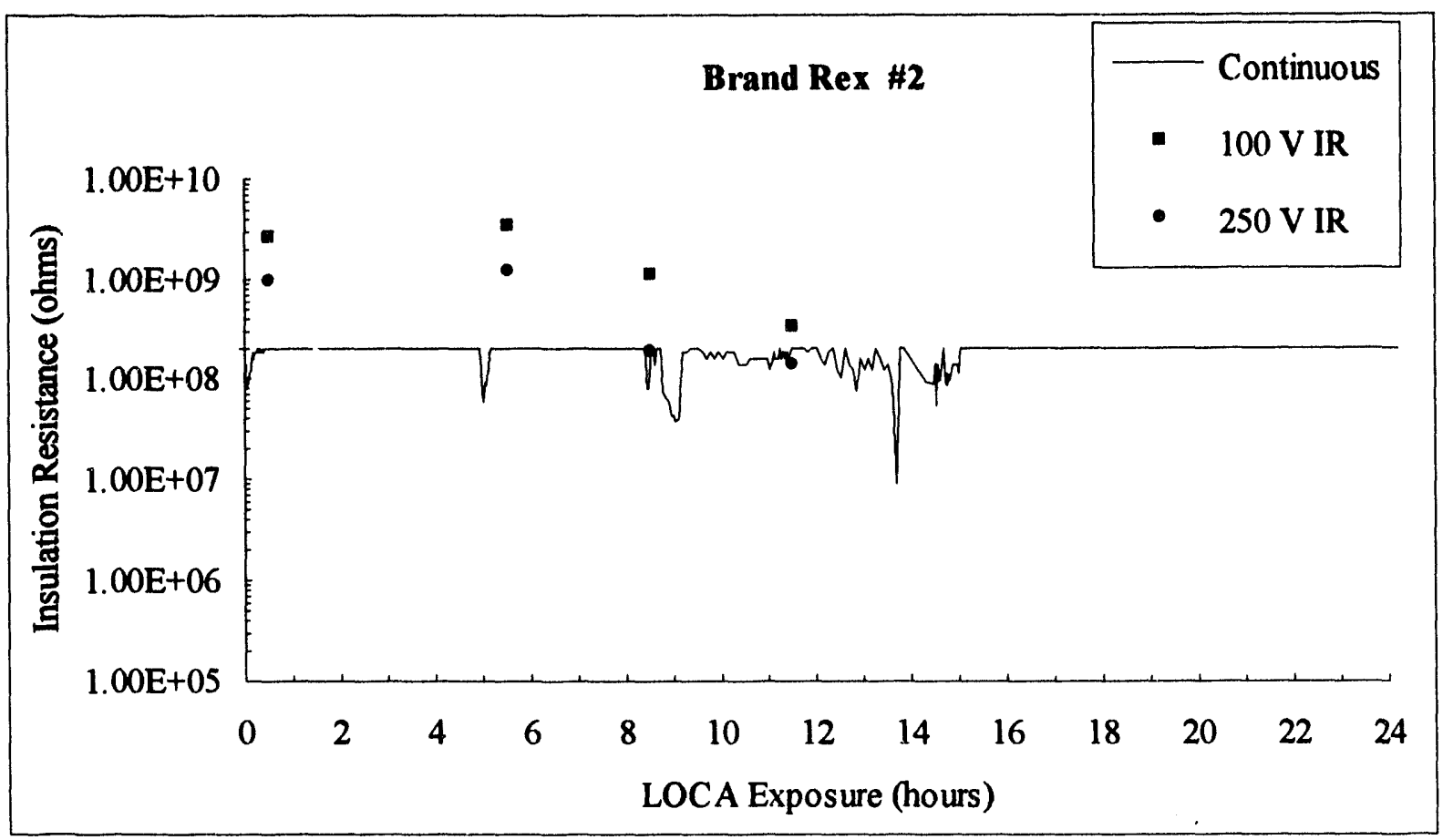

Figure A-3 Insulation Resistance for Brand Rex Sample \#2 during the first 24 hours.

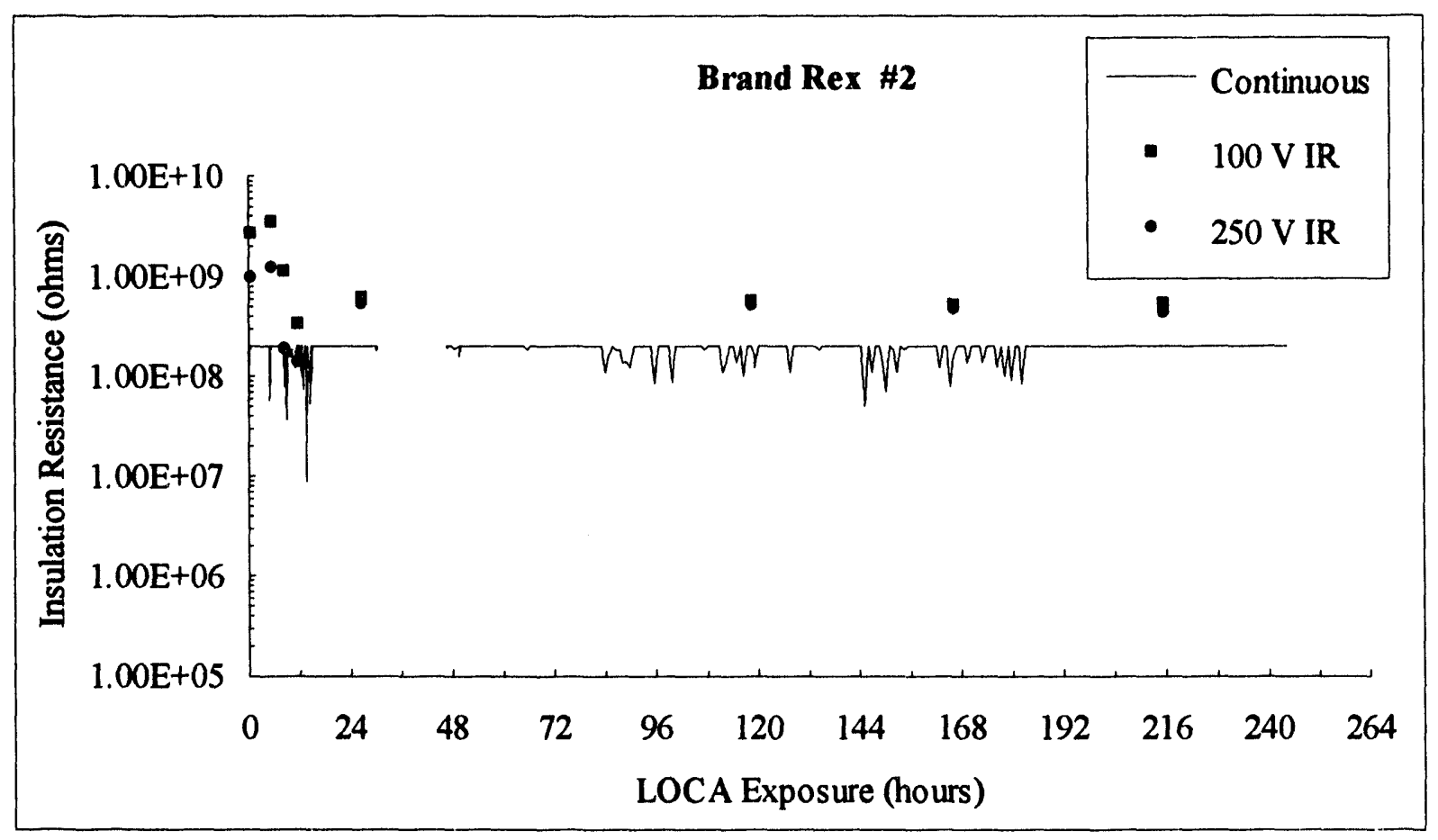

Figure A-4 Insulation Resistance for Brand Rex Sample \#2 . 


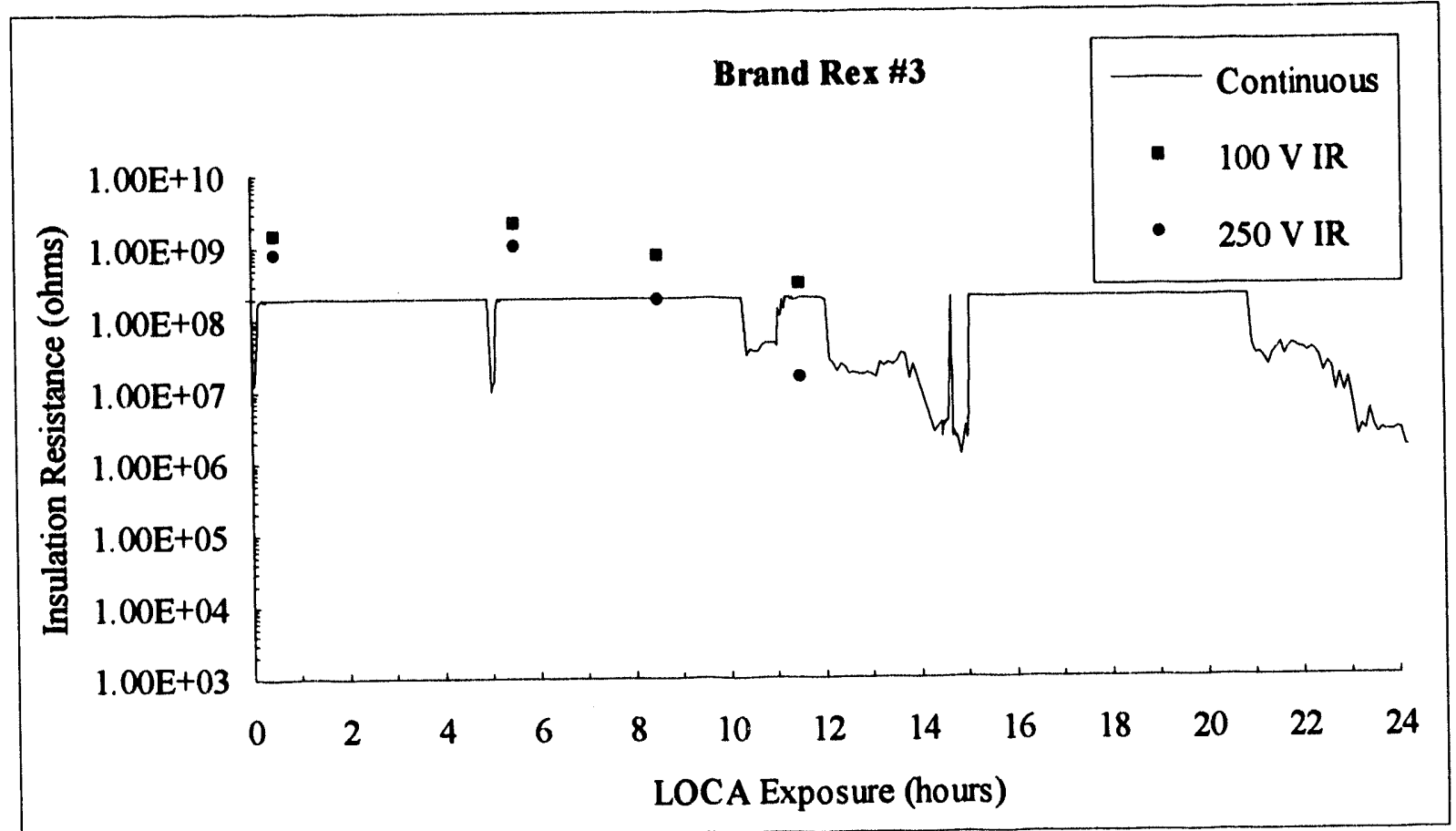

Figure A-5 Insulation Resistance for Brand Rex Sample \#3 during the first 24 hours.

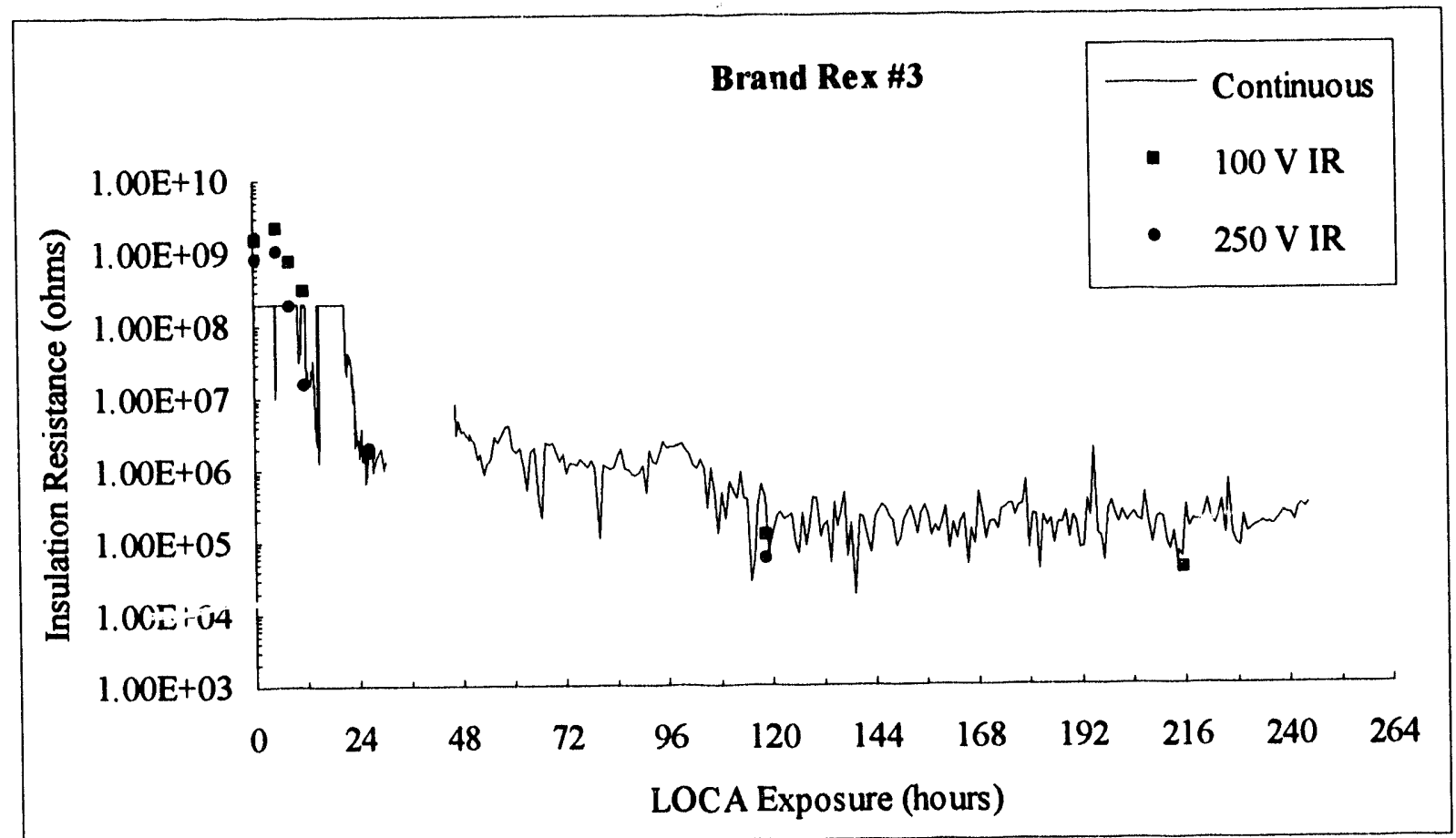

Figure A-6 Insulation Resistance for Brand Rex Sample \#3 . 


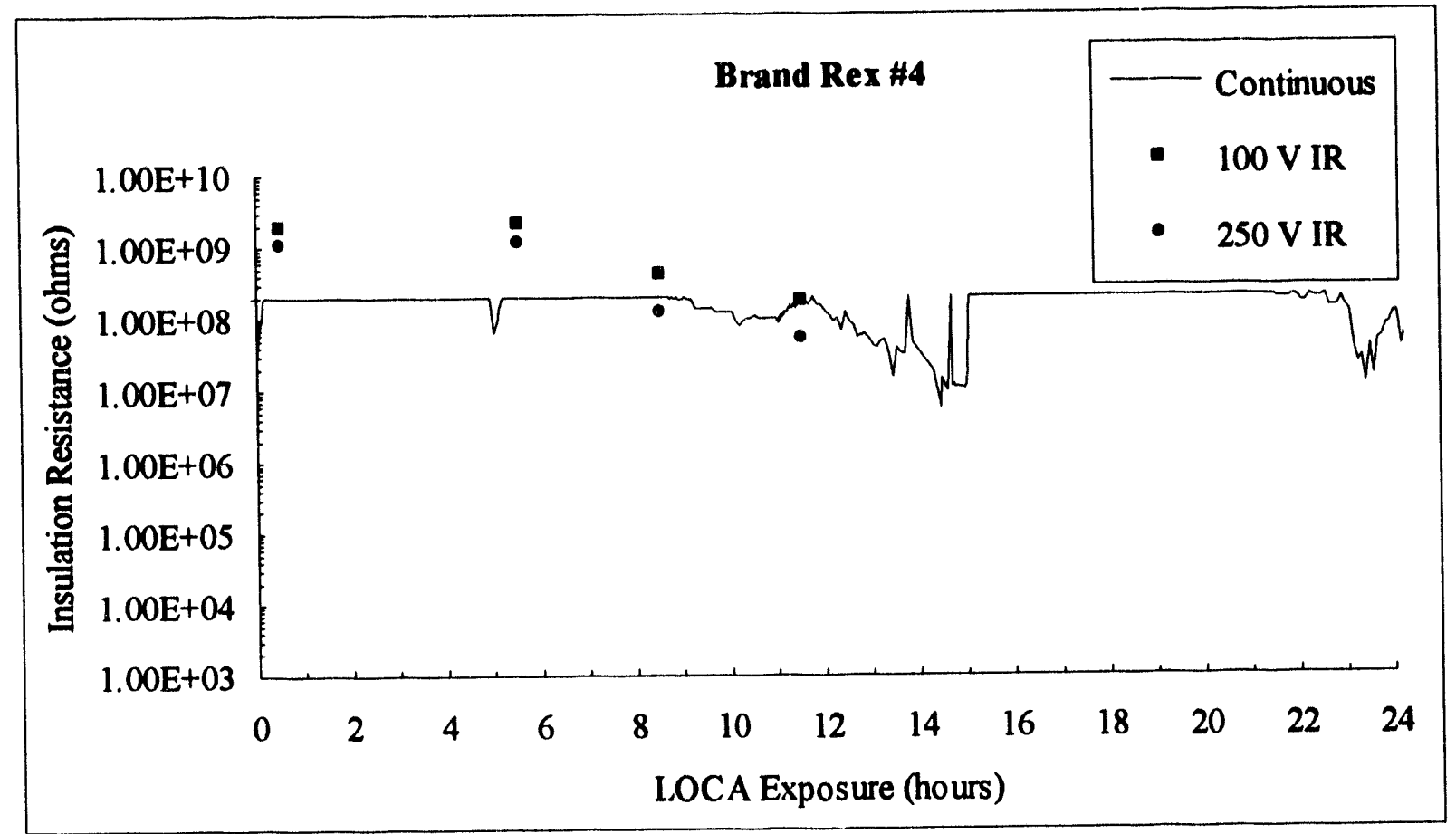

Figure A-7 Insulation Resistance for Brand Rex Sample \#4 during the first 24 hours.

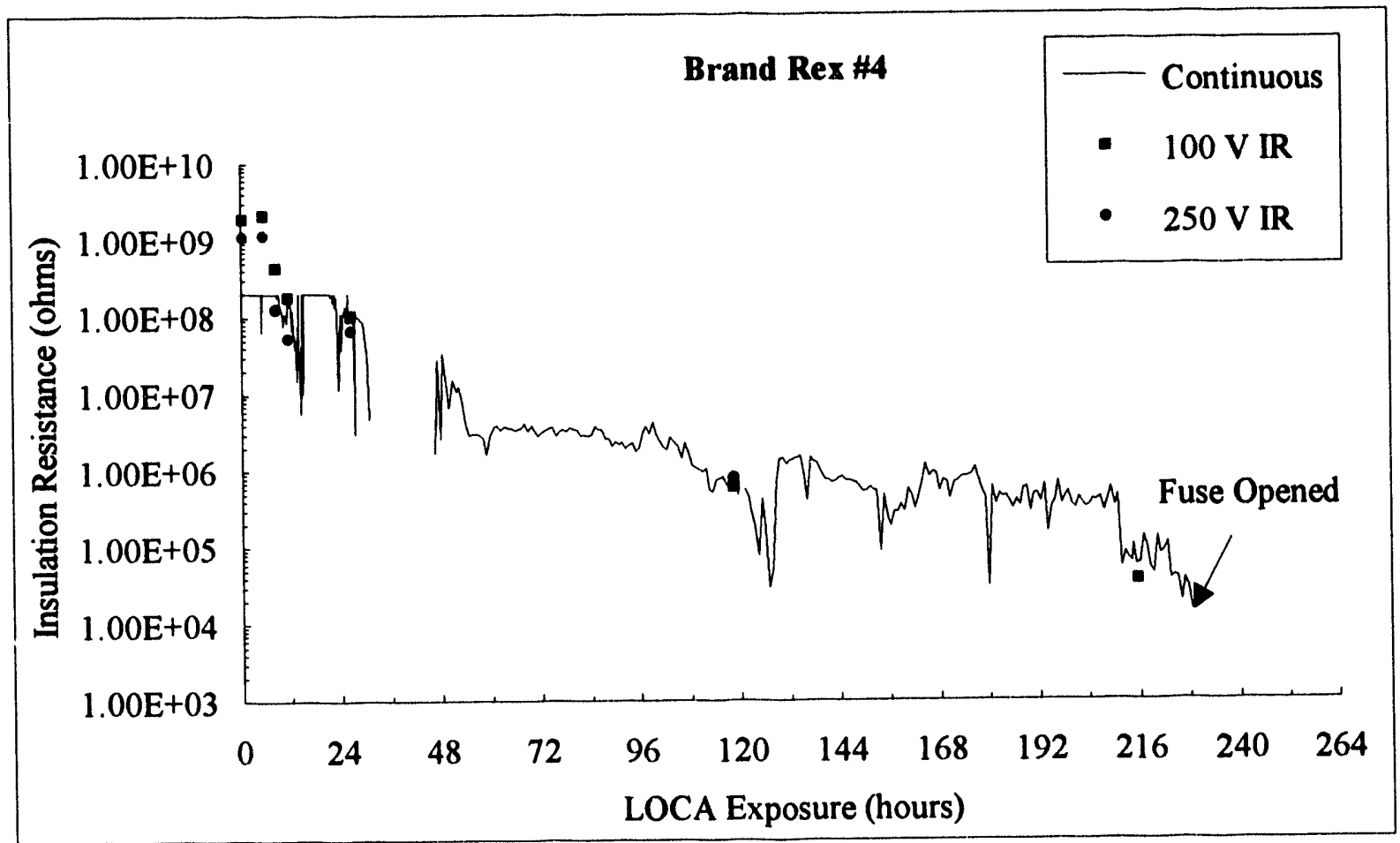

Figure A-8 Insulation Resistance for Brand Rex Sample \# 4. 


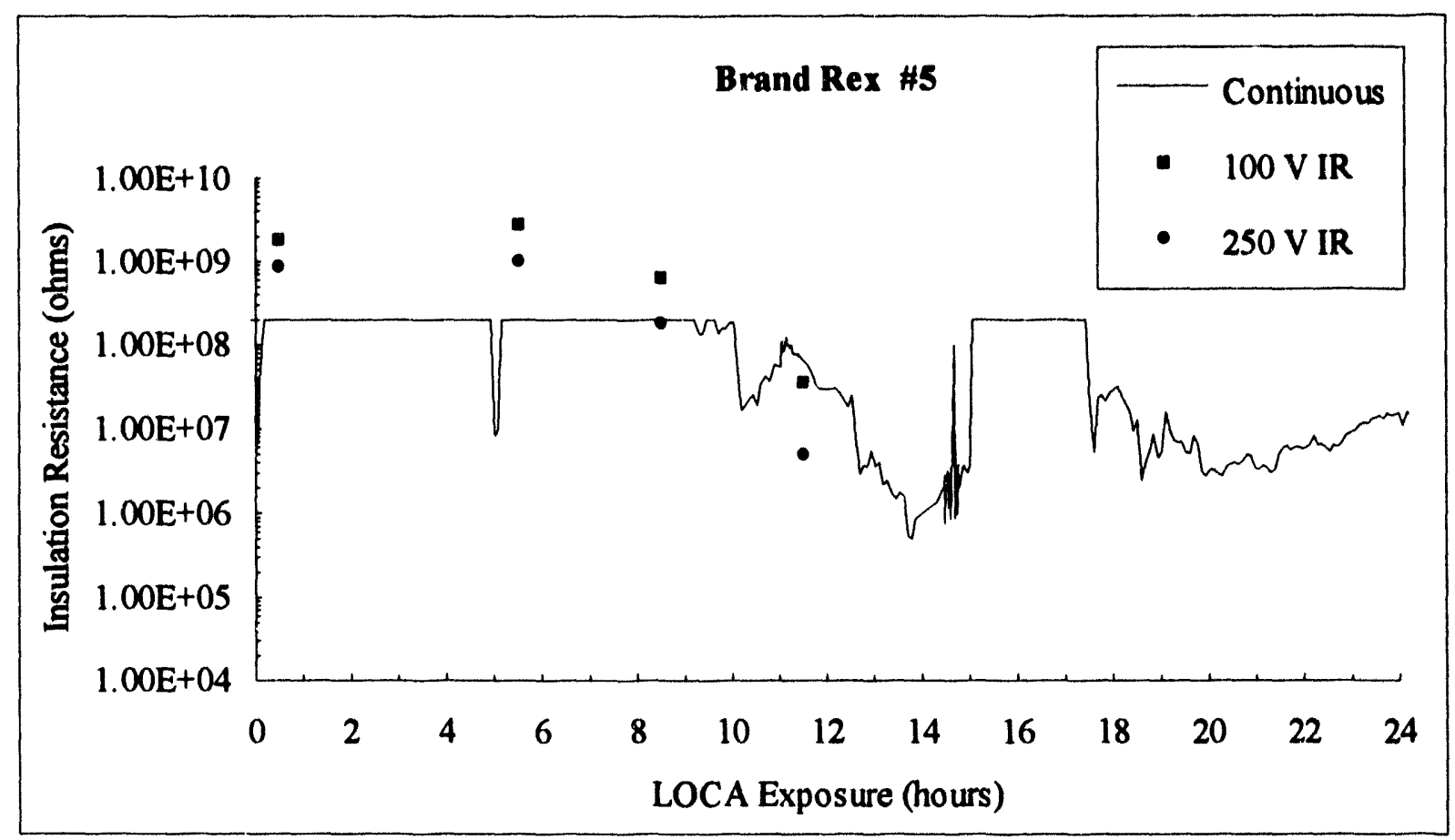

Figure A-9 Insulation Resistance for Brand Rex Sample \#5 during the first 24 hours.

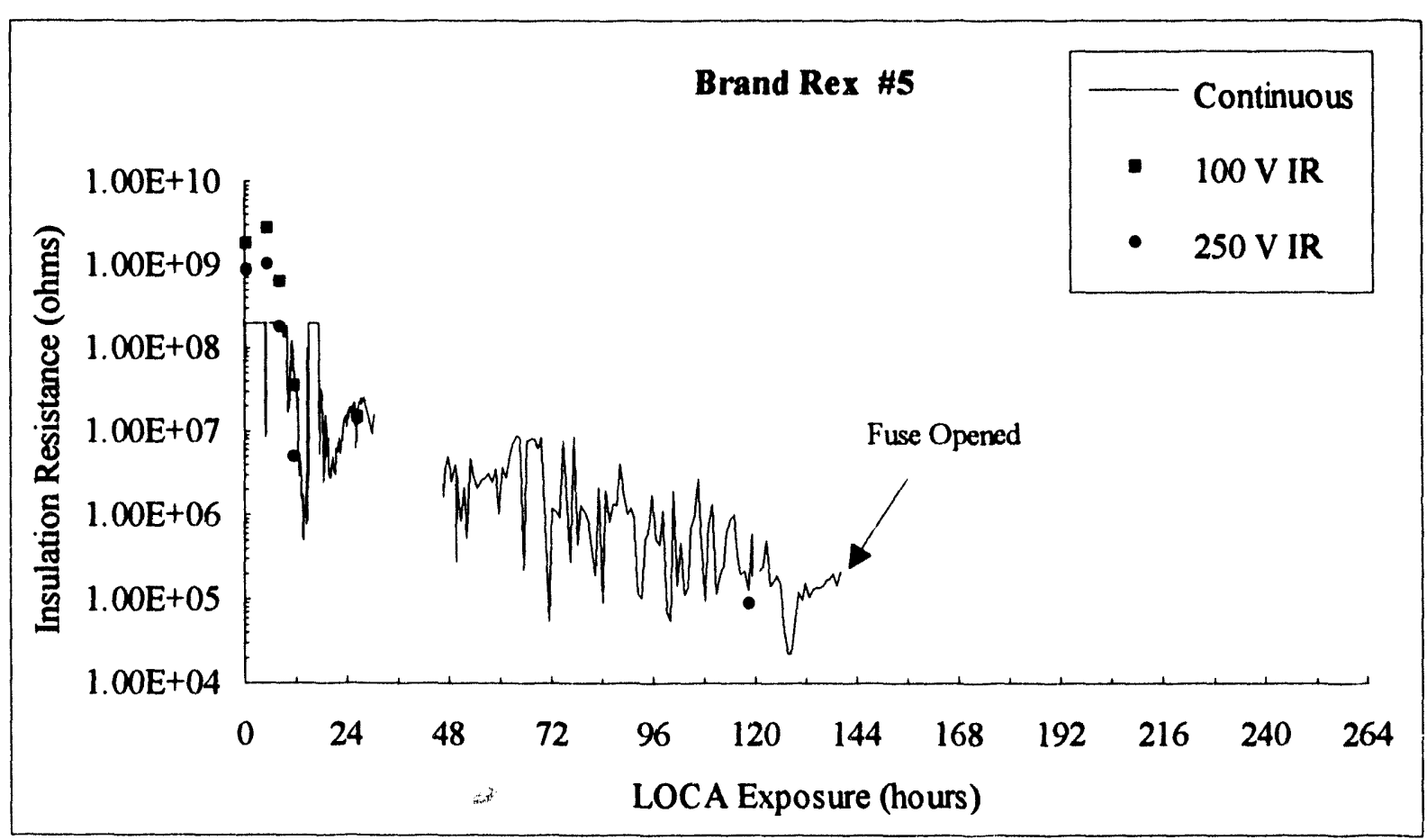

Figure A-10 Insulation Resistance for Brand Rex Sample \#5 . 


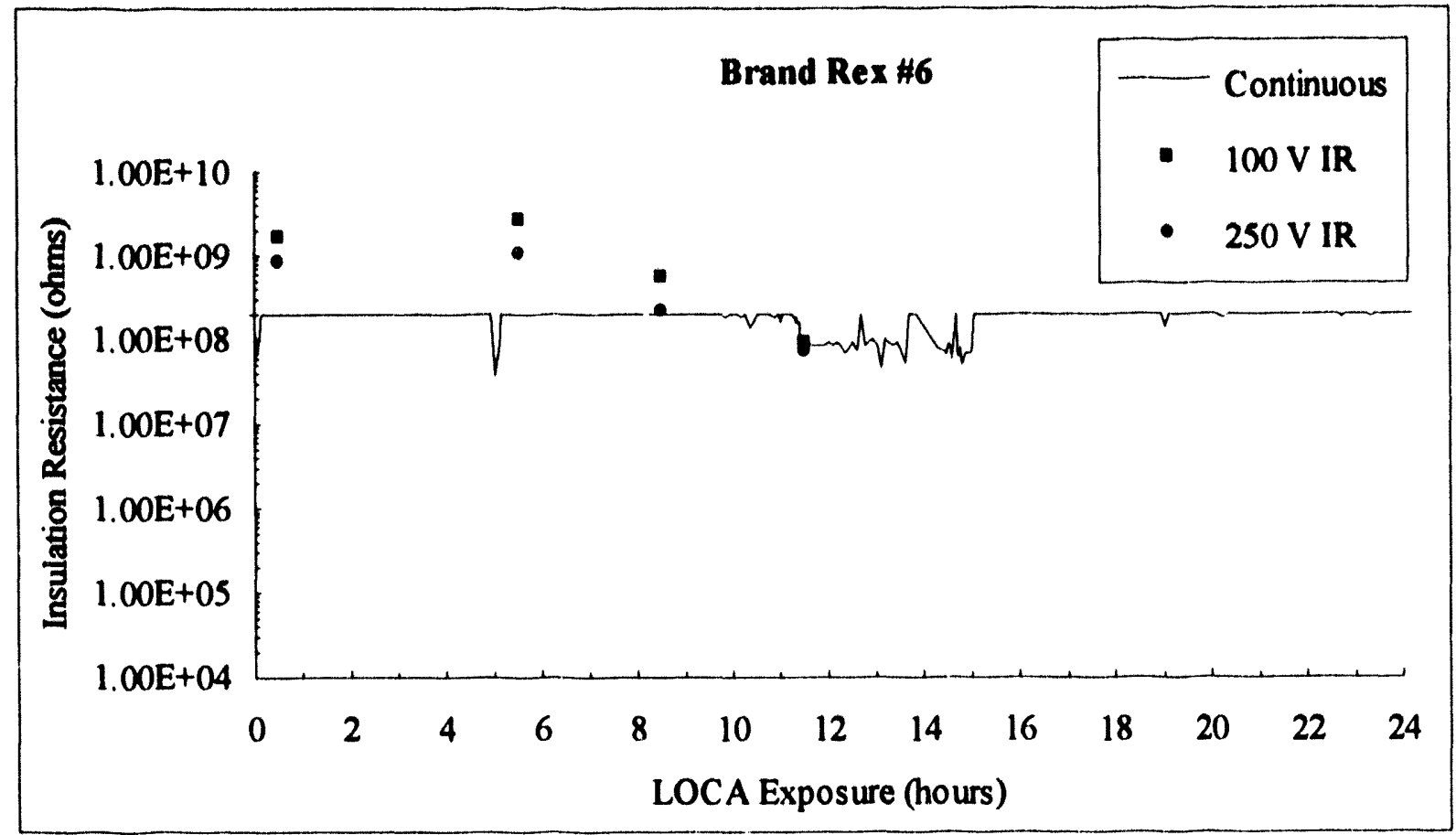

Figure A-11 Insulation Resistance for Brand Rex Sample \#6 during the first 24 hours.

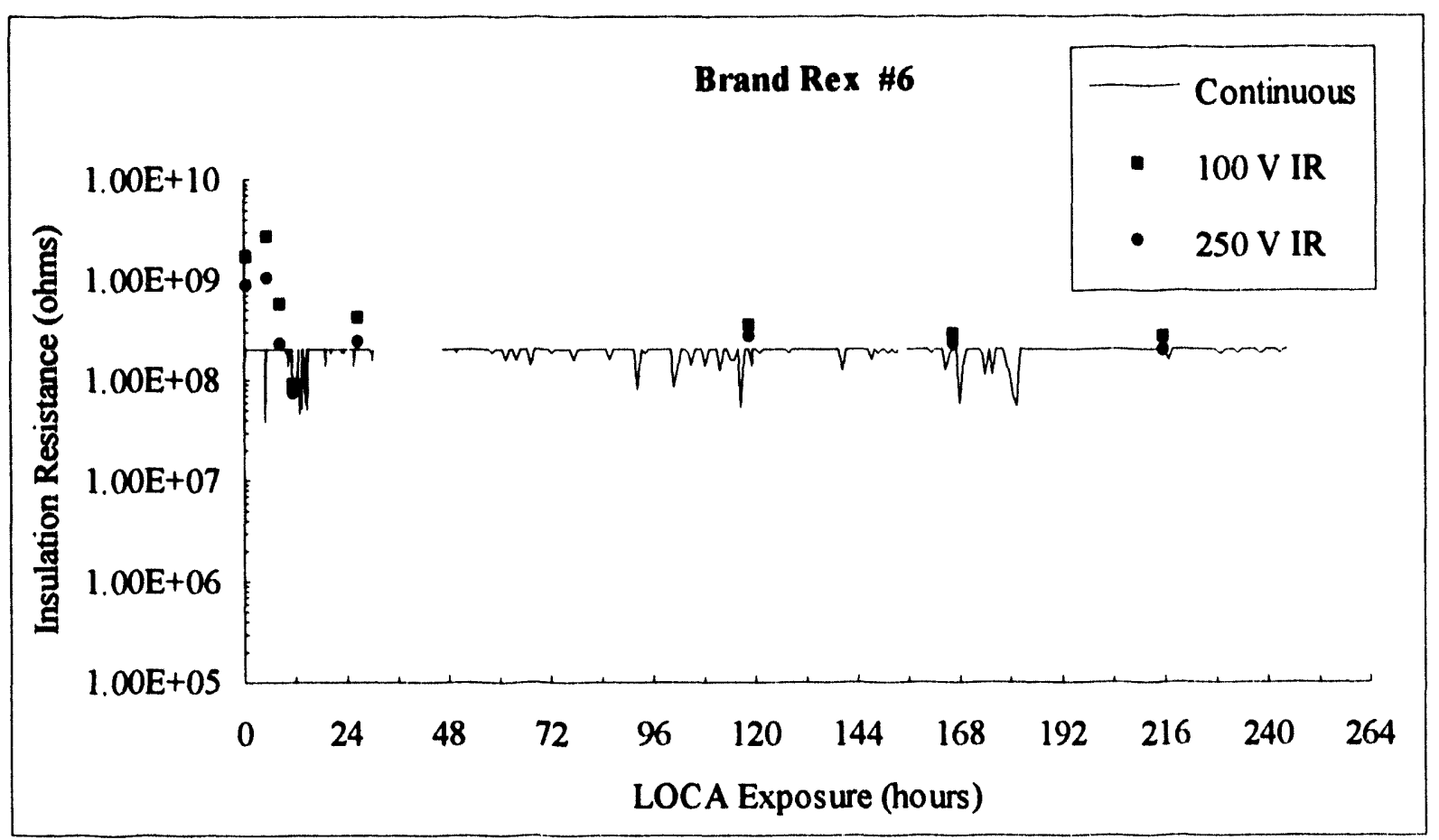

Figure A-12 Insulation Resistance for Brand Rex Sample \#6. 


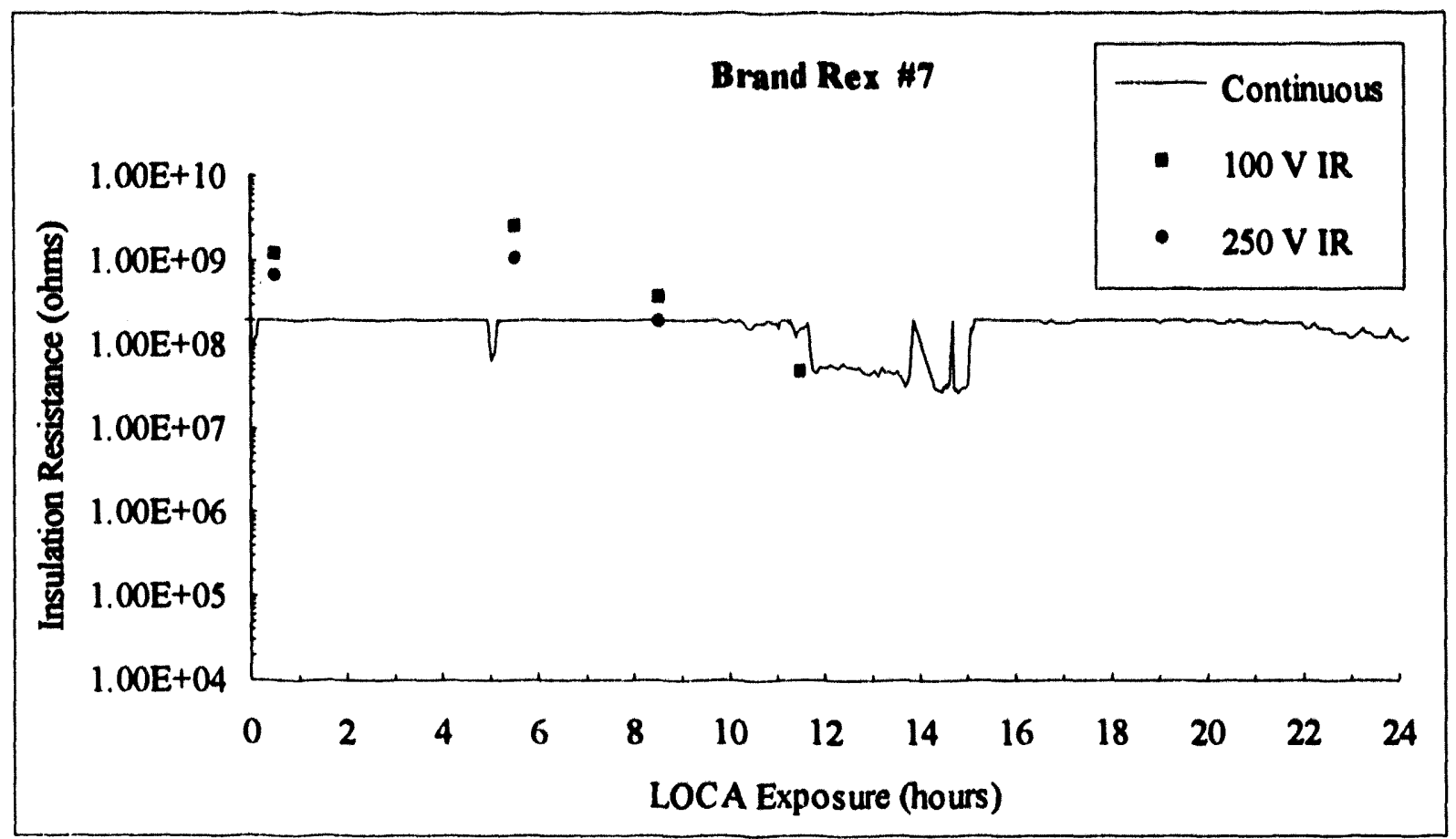

Figure A-13 Insulation Resistance for Brand Rex Sample \#7 during the first 24 hours.

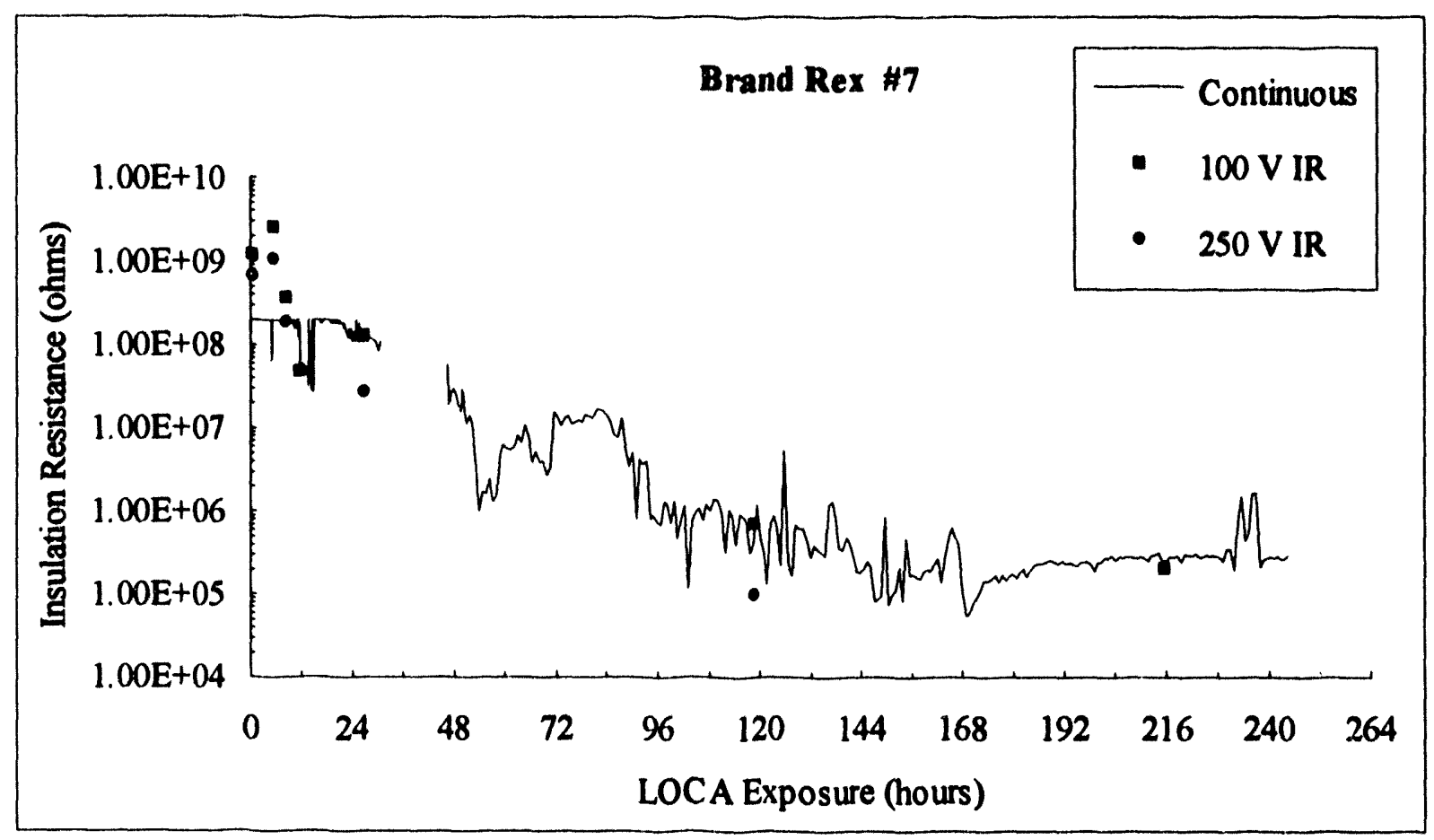

Figure A-14 Insulation Resistance for Brand Rex Sample \#7. 


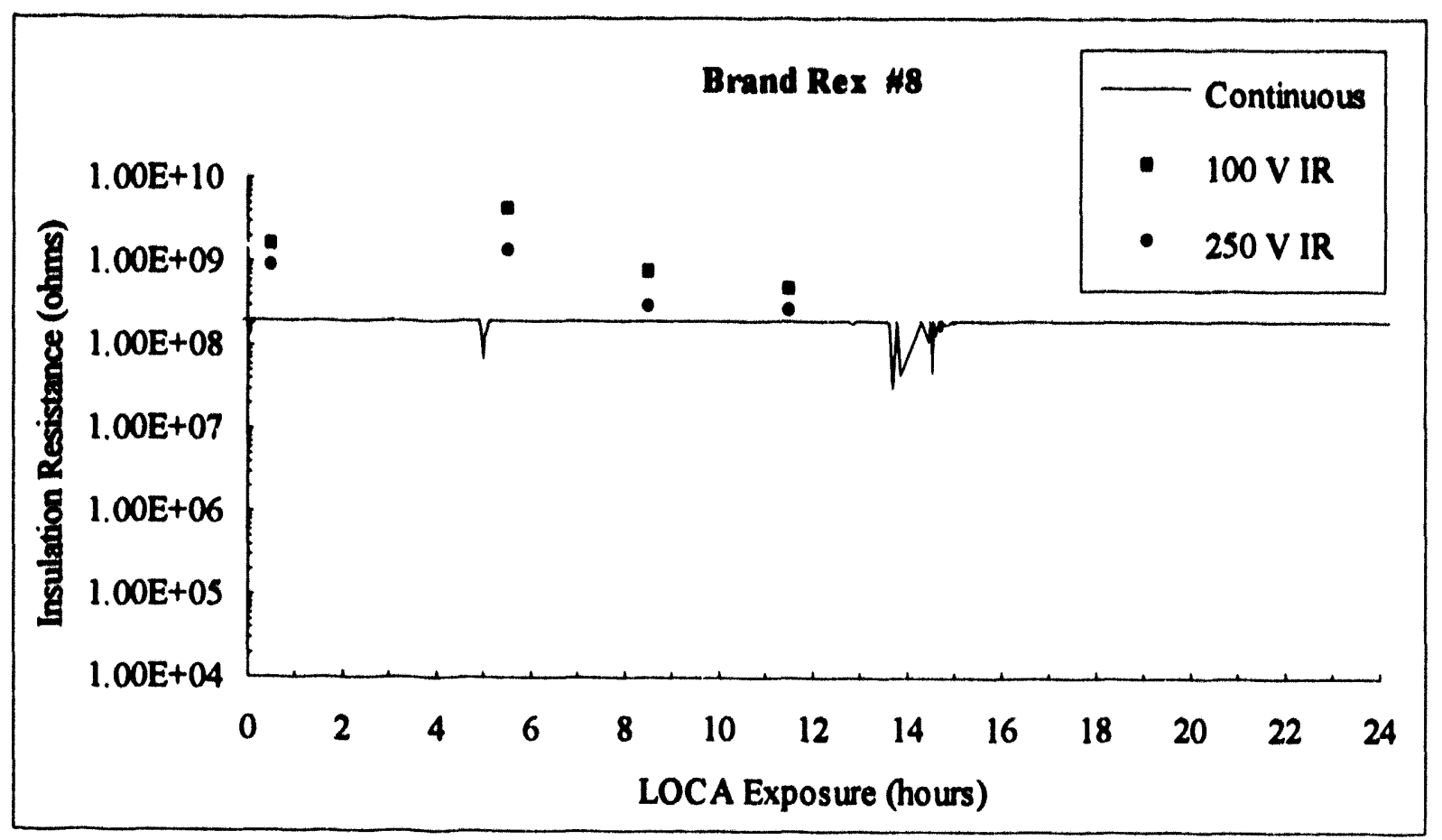

Figure A-15 Insulation Resistance for Brand Rex Sample \#8 during the first 24 hours.

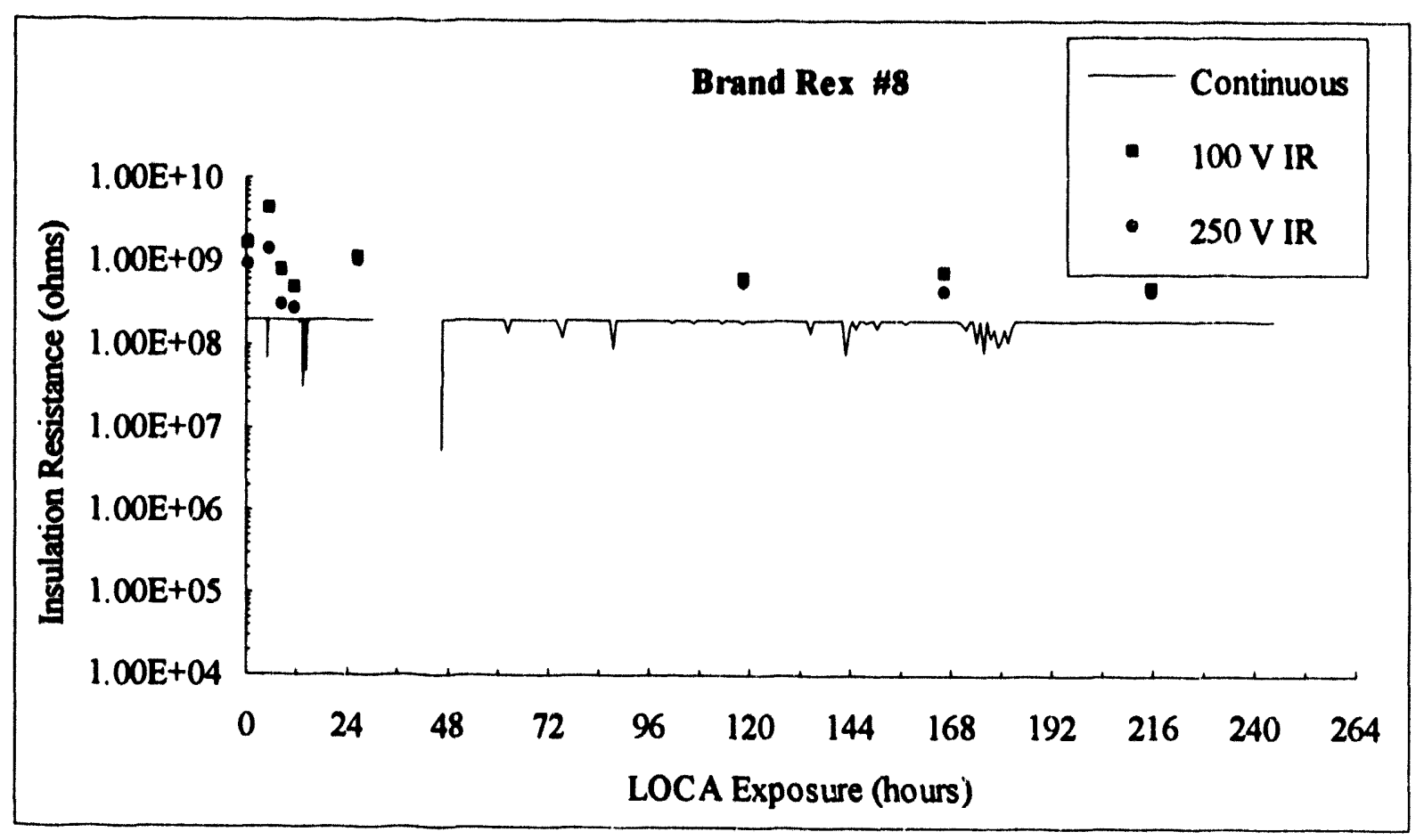

Figure A-16 Insulation Resistance for Brand Rex Sample \#8. 


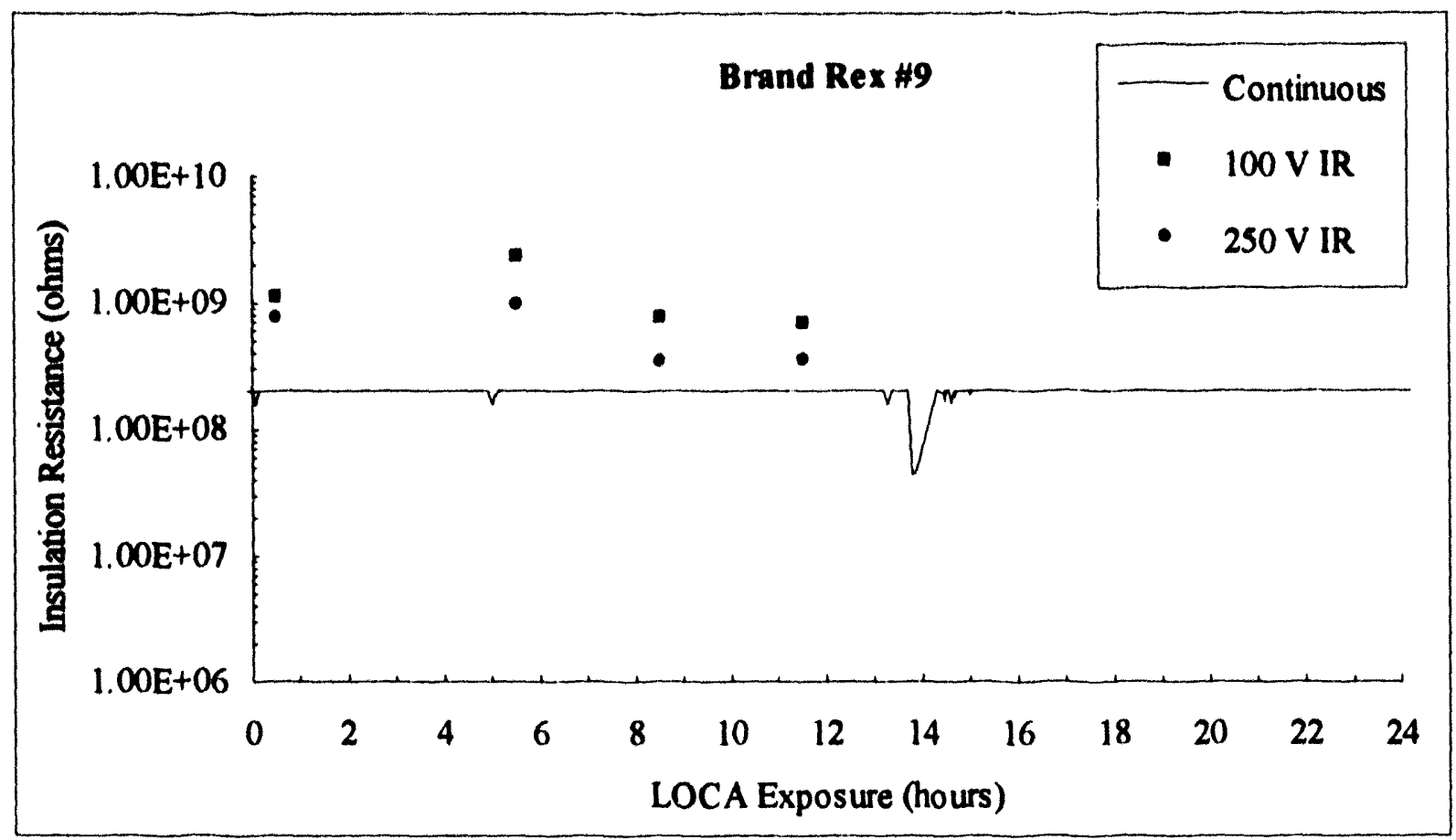

Figure A-17 Insulation Resistance for Brand Rex Sample \#9 during the first 24 hours.

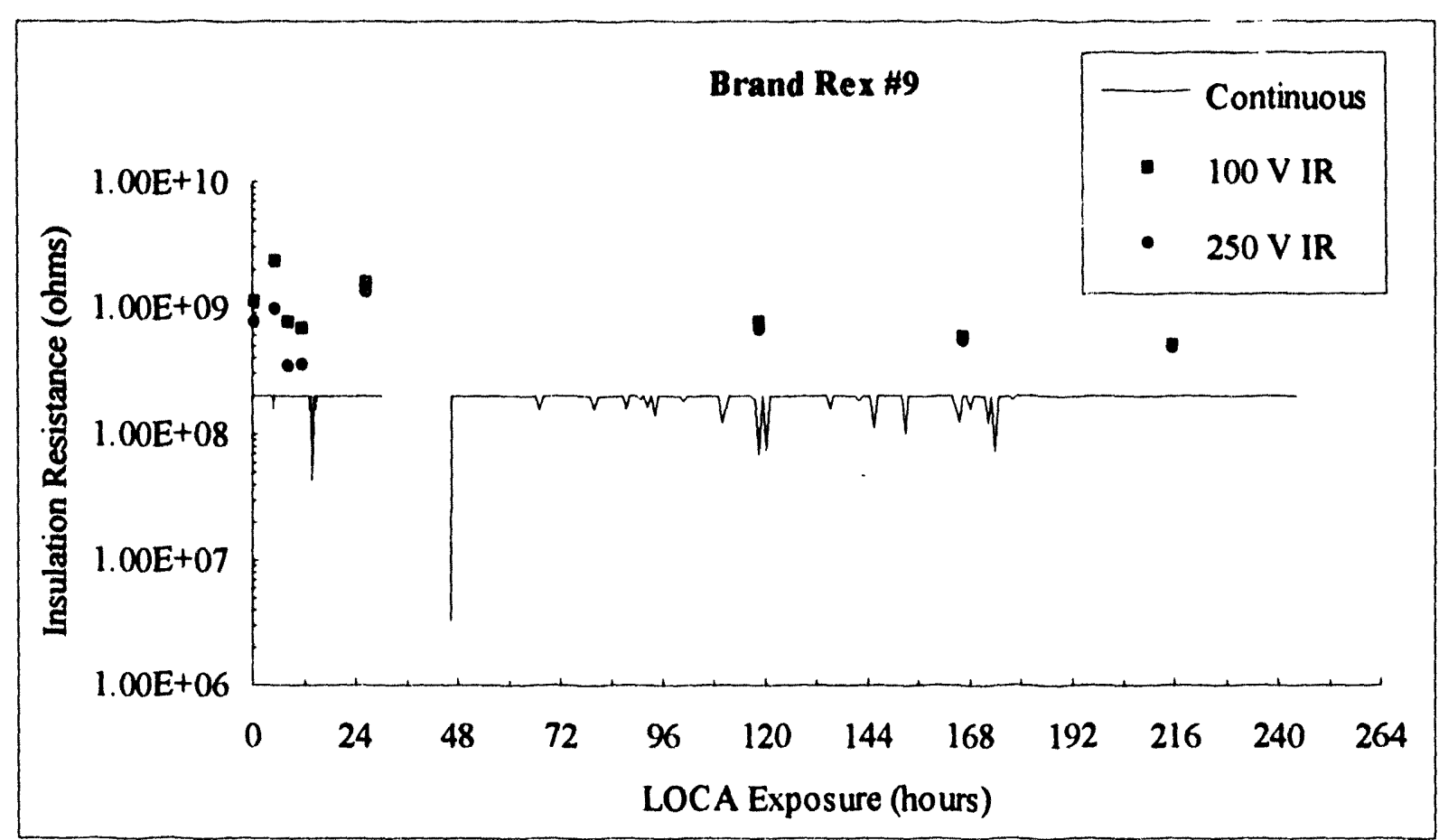

Figure A-18 Insulation Resistance for Brand Rex Sample \#9. 


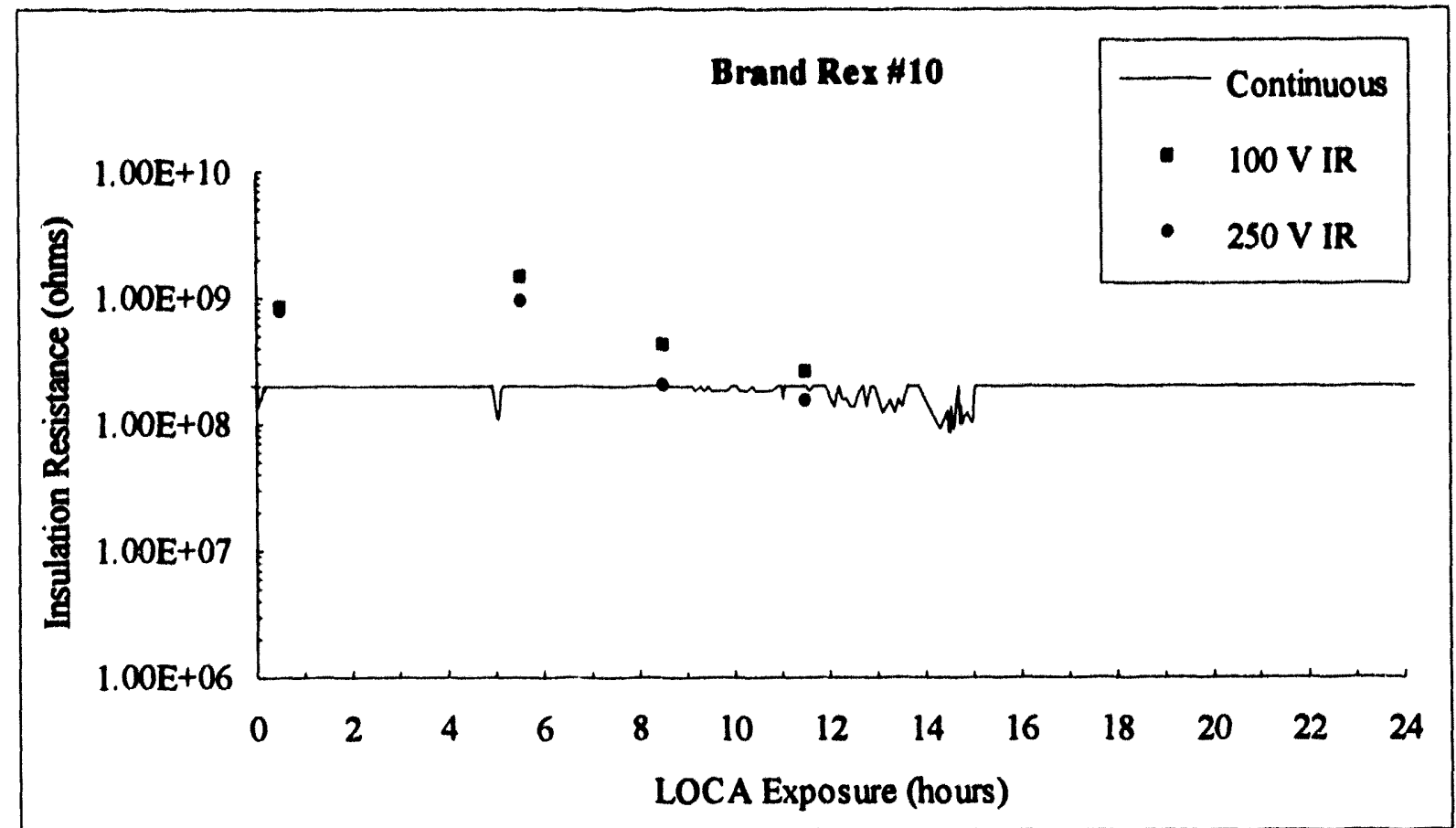

Figure A-19 Insulation Resistance for Brand Rex Sample \#10 during the first 24 hours.

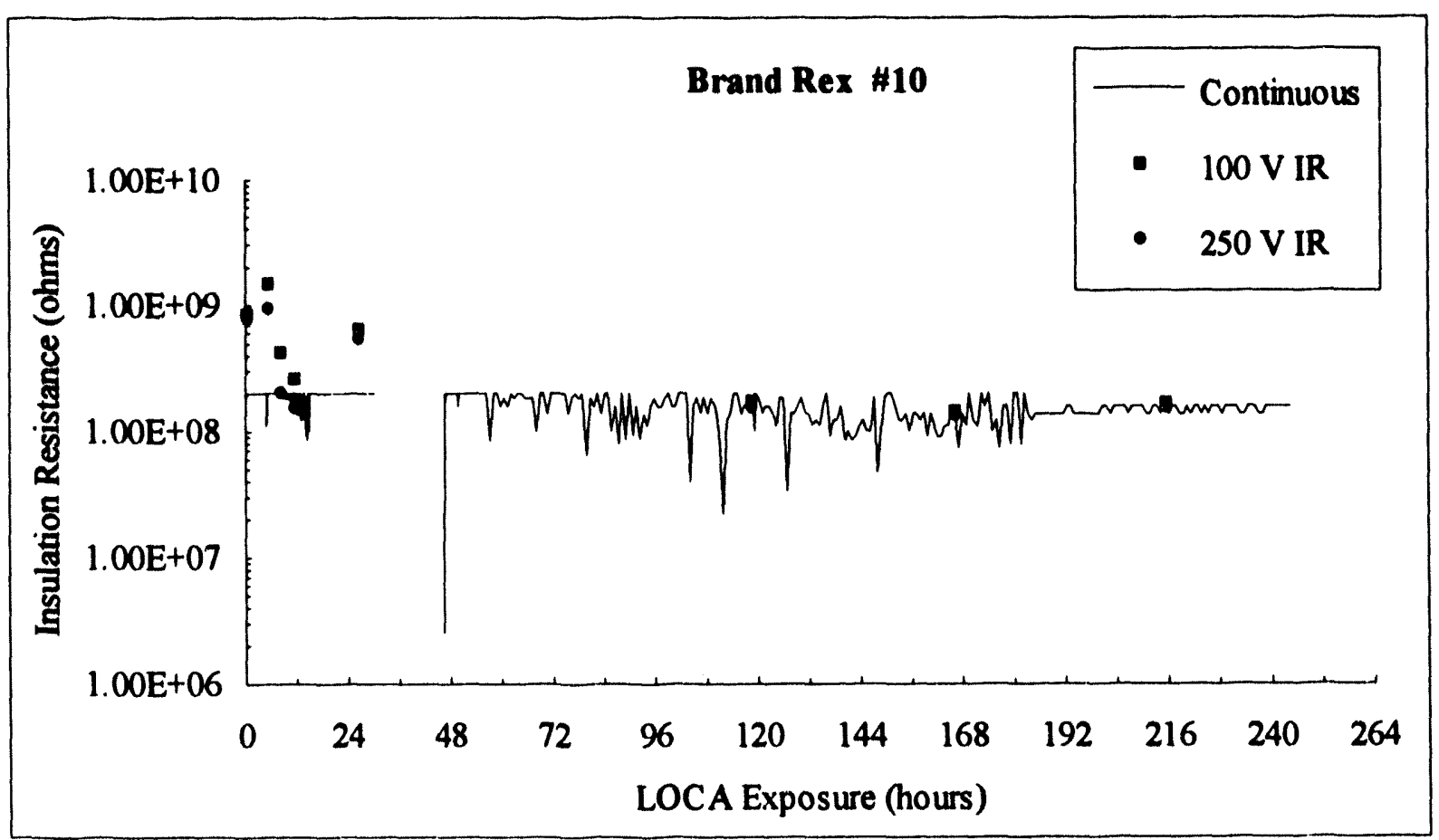

Figure A-20 Insulation Resistance for Brand Rex Sample \#10 . 


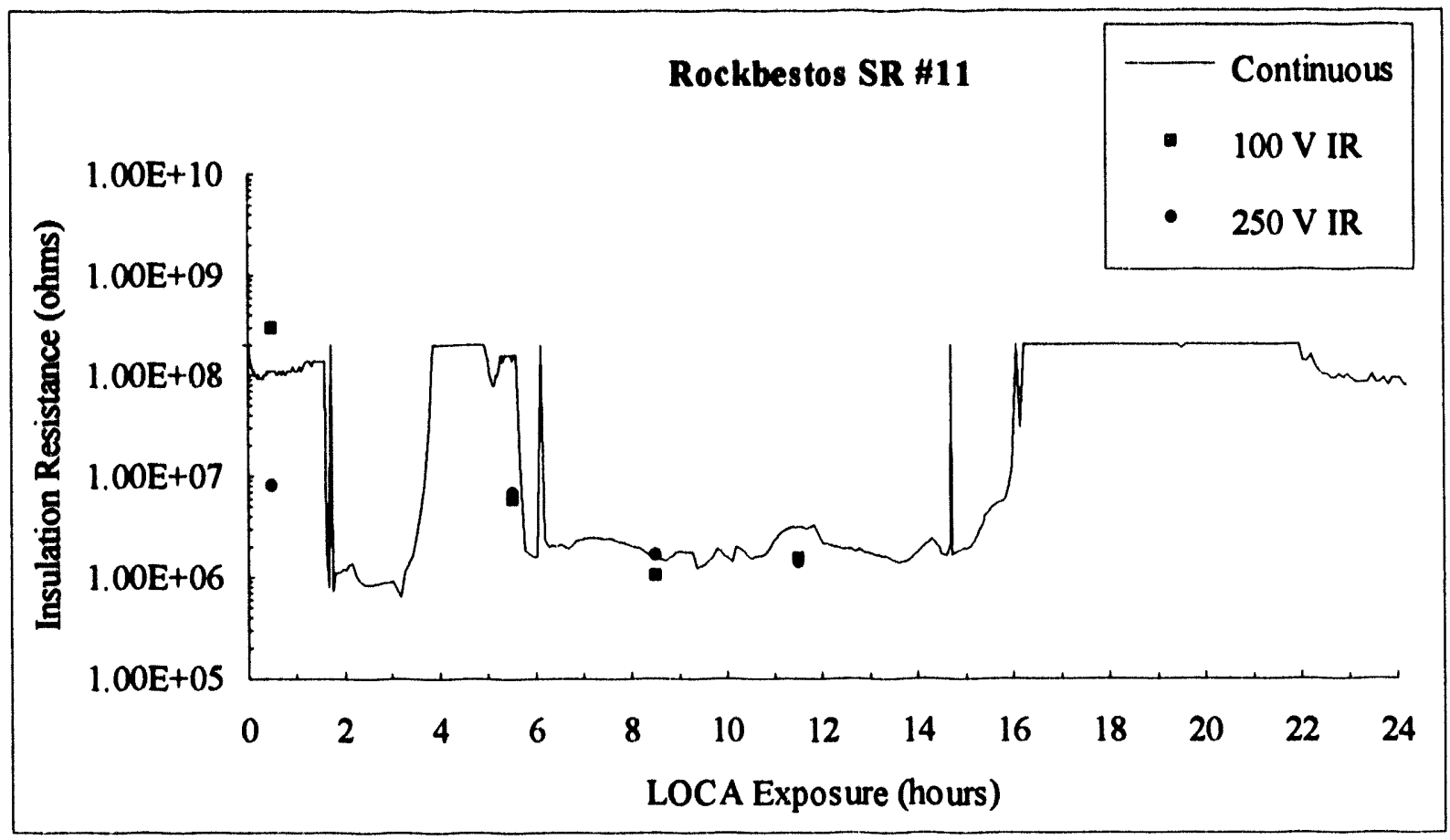

Figure A-21 Insulation Resistance for Rockbestos SR Sample \# 11 during the first 24 hours.

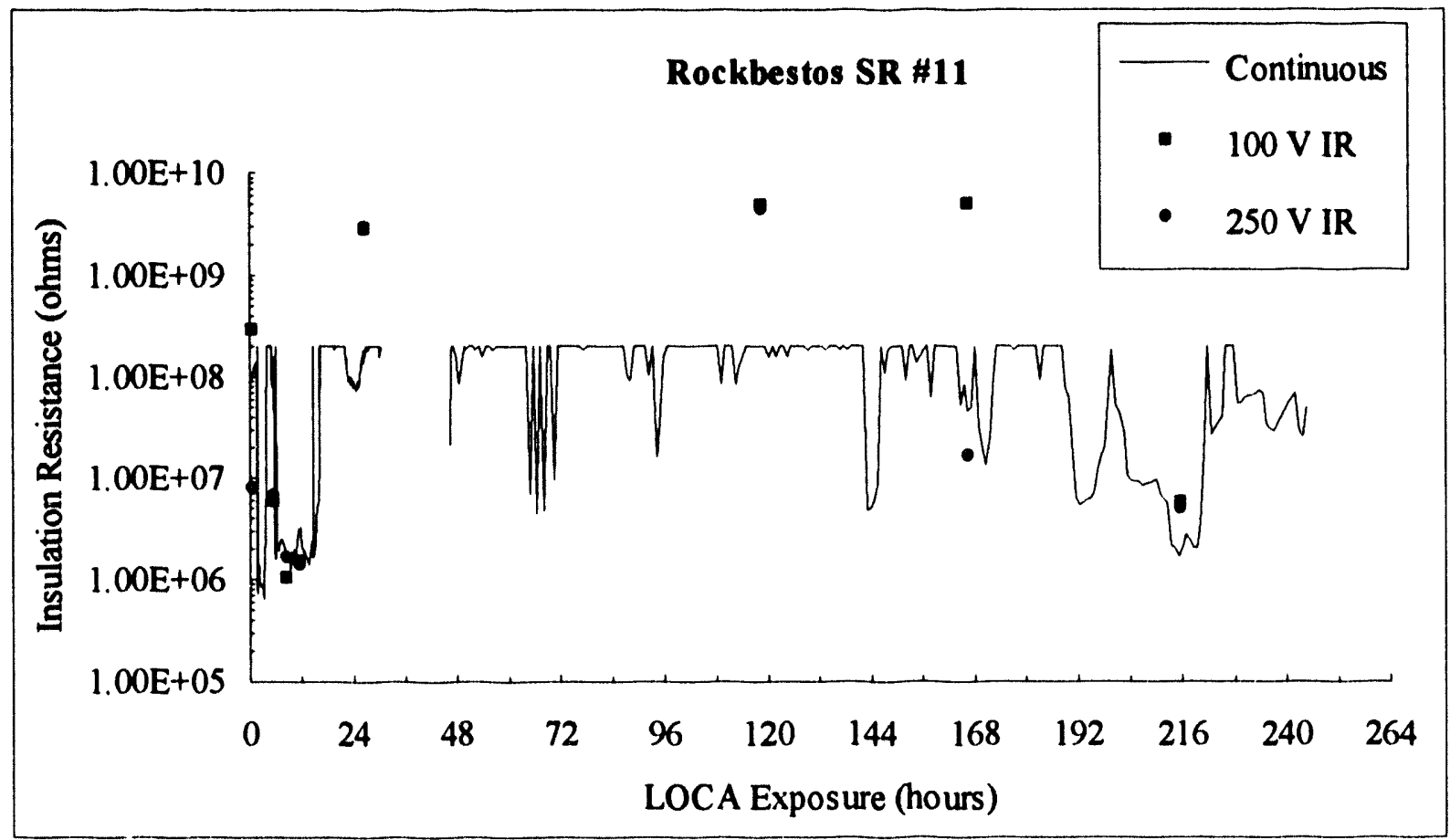

Figure A-22 Insulation Resistance for Rockbestos SR Sample \#11. 


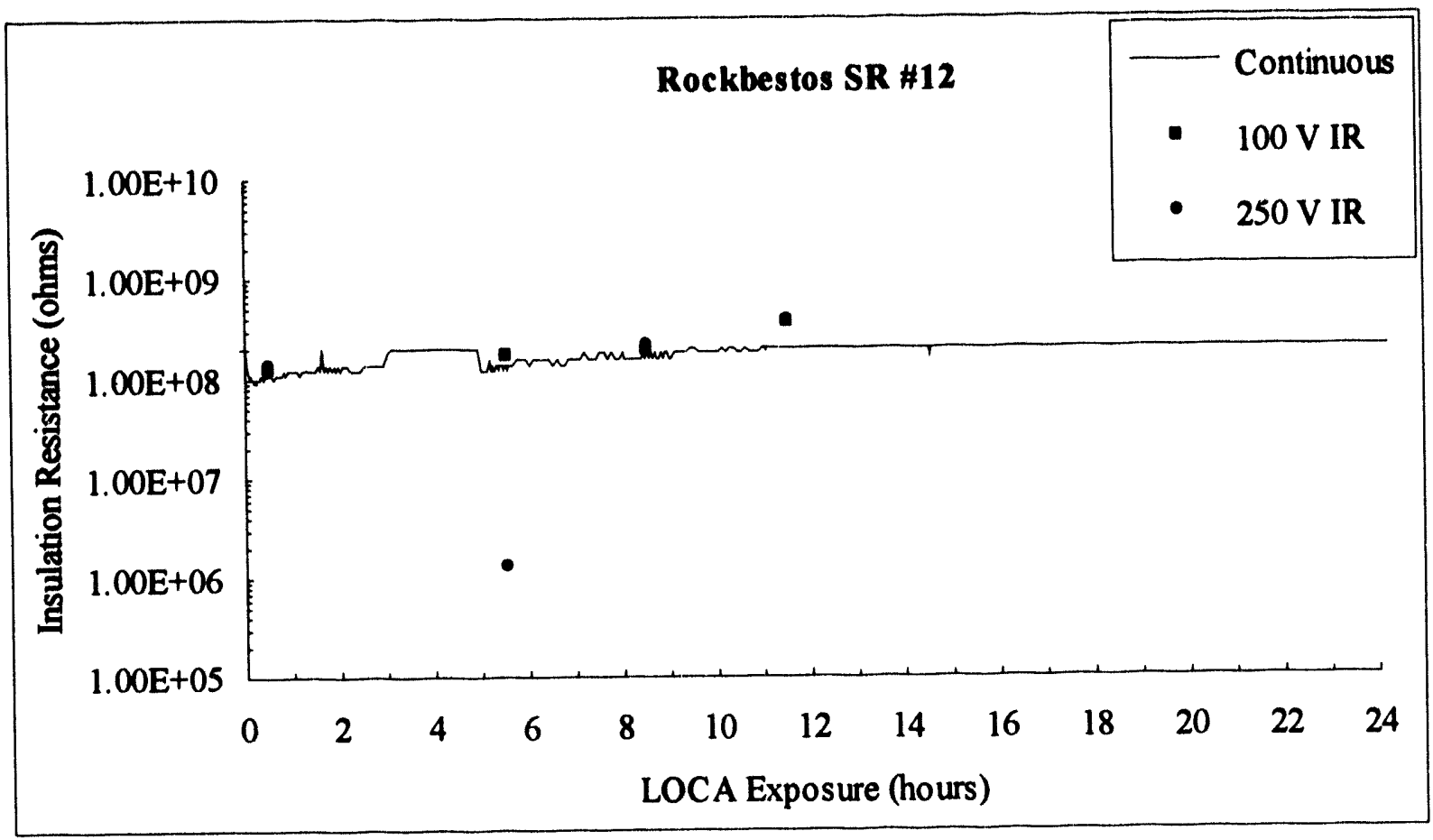

Figure A-23 Insulation Resistance for Rockbestos SR Sample \#12 during the first 24 hours.

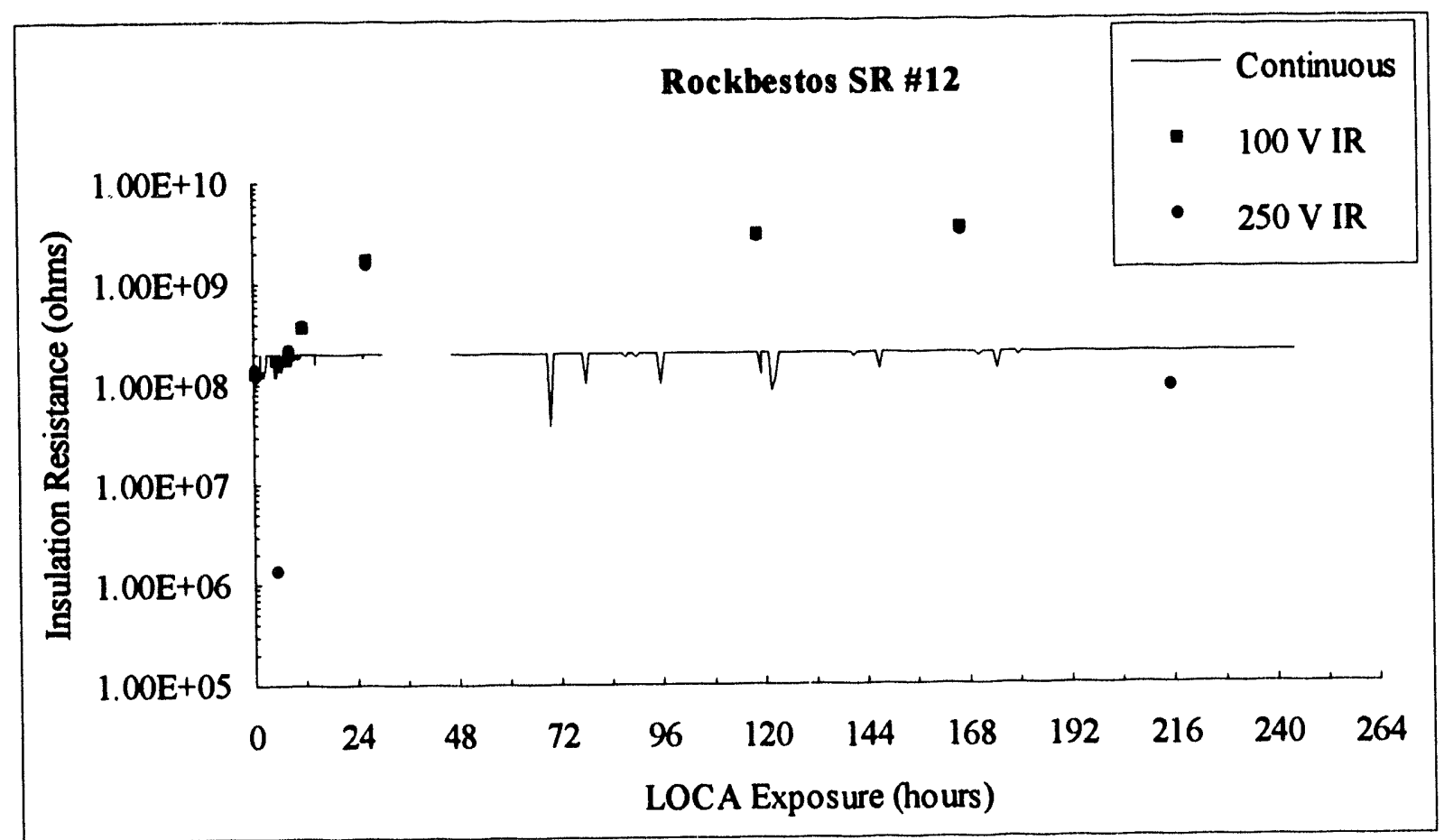

Figure A-24 Insulation Resistance for Rockbestos SR Sample \#12. 


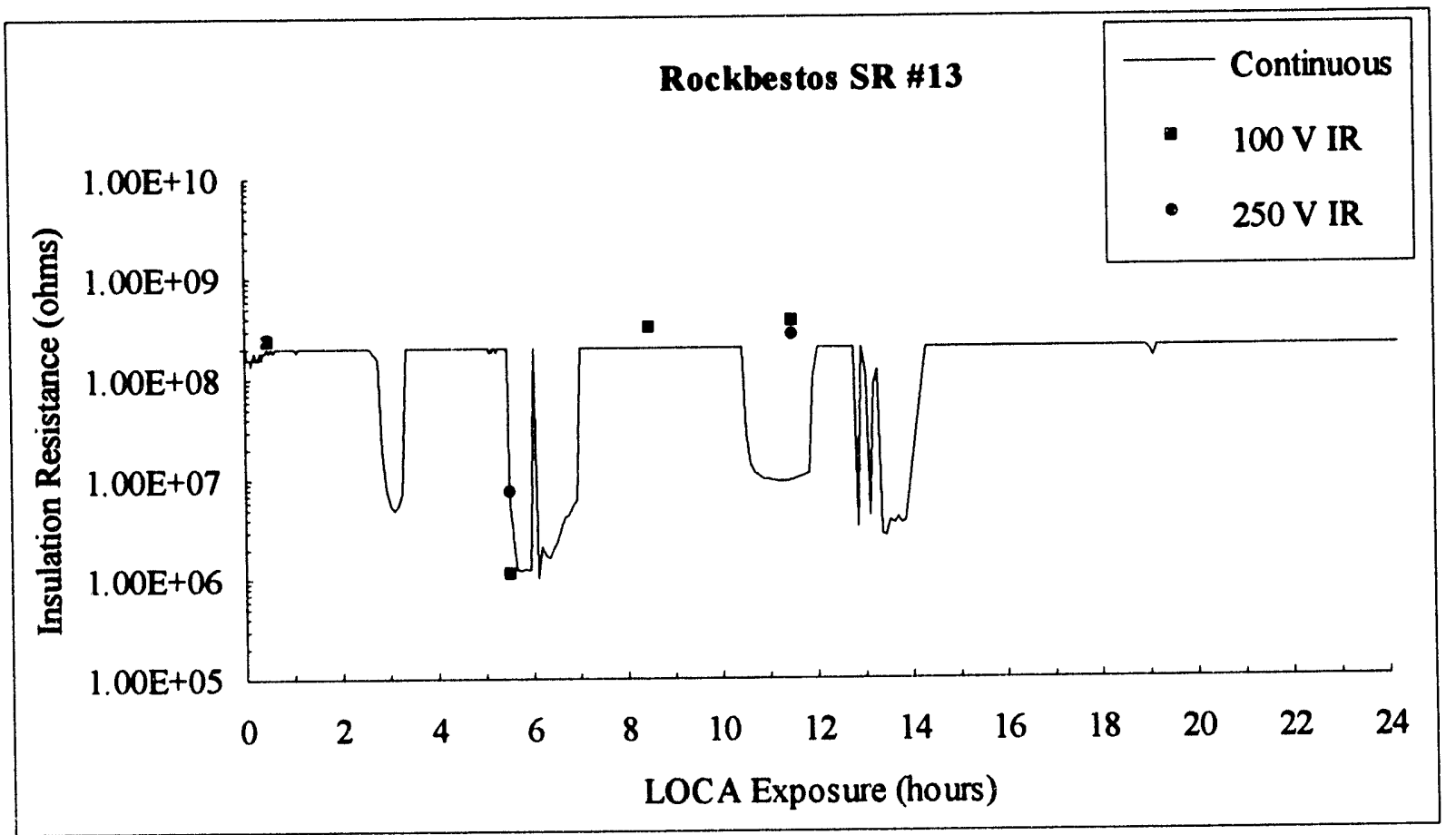

Figure A-25 Insulation Resistance for Rockbestos Sample \#13 during the first 24 hours.

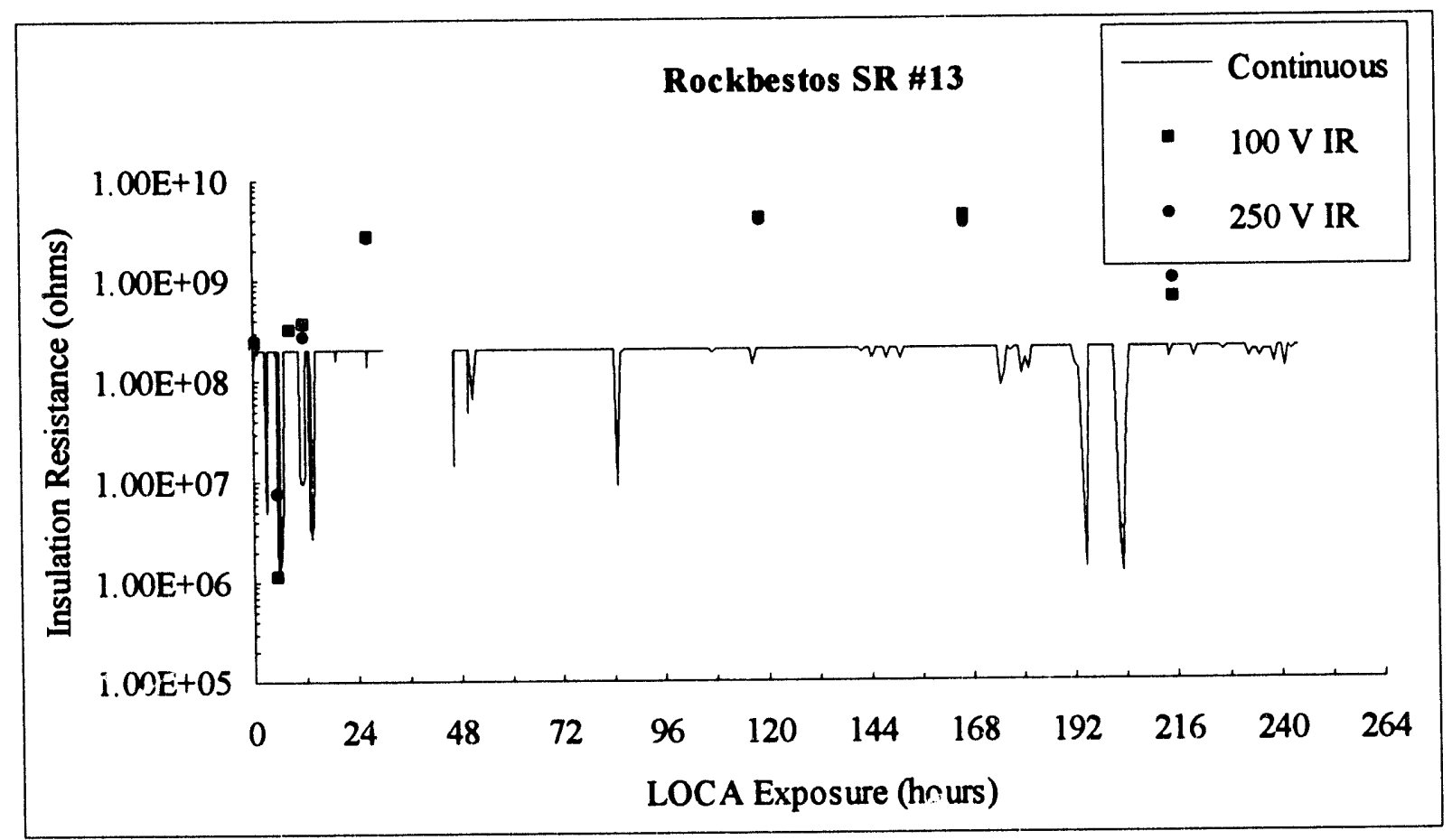

Figure A-26 Insulation Resistance for Rockbestos SR Sample \#13. 


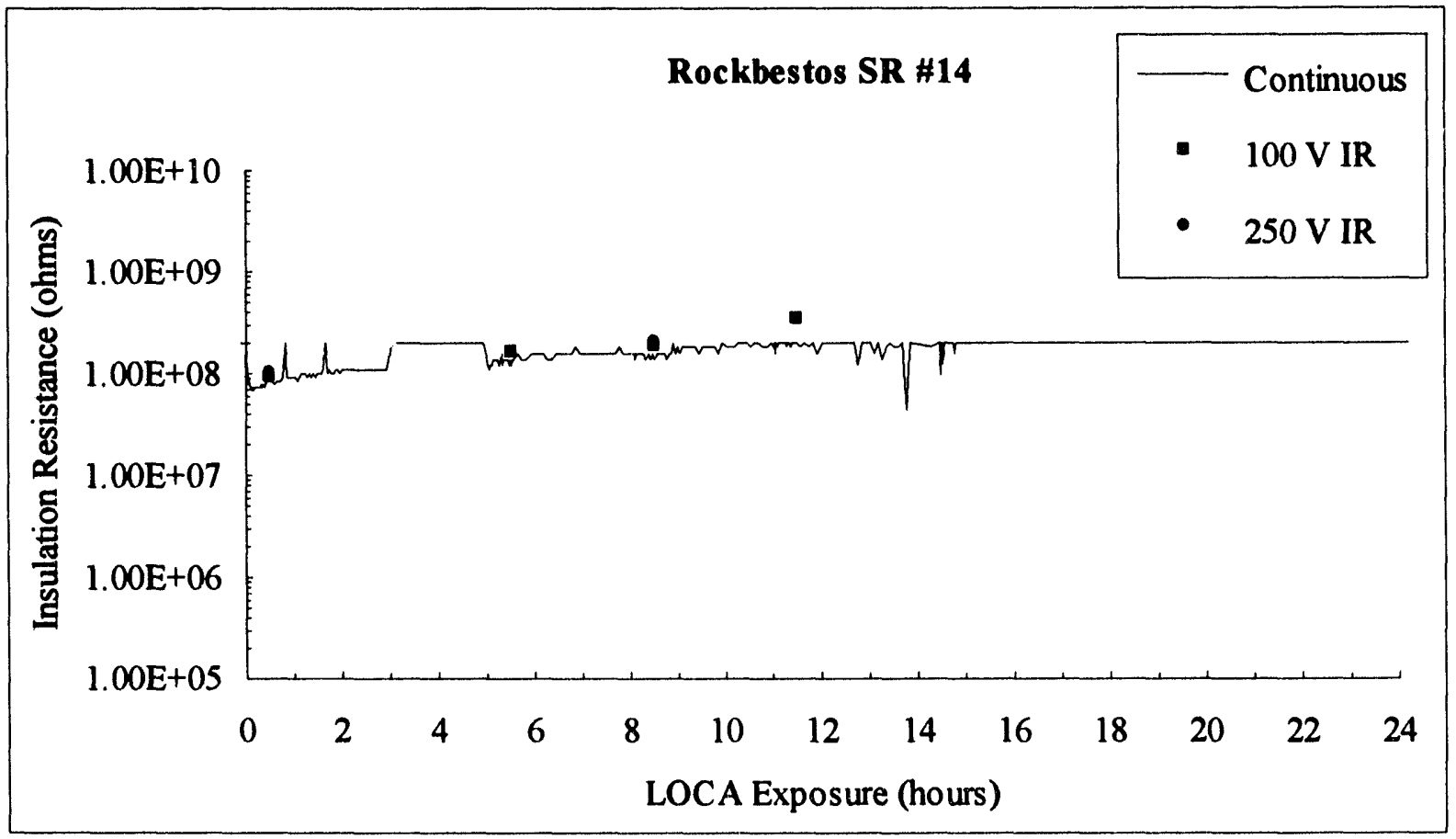

Figure A-27 Insulation Resistance for Rockbestos Sample \#14 during the first 24 hours.

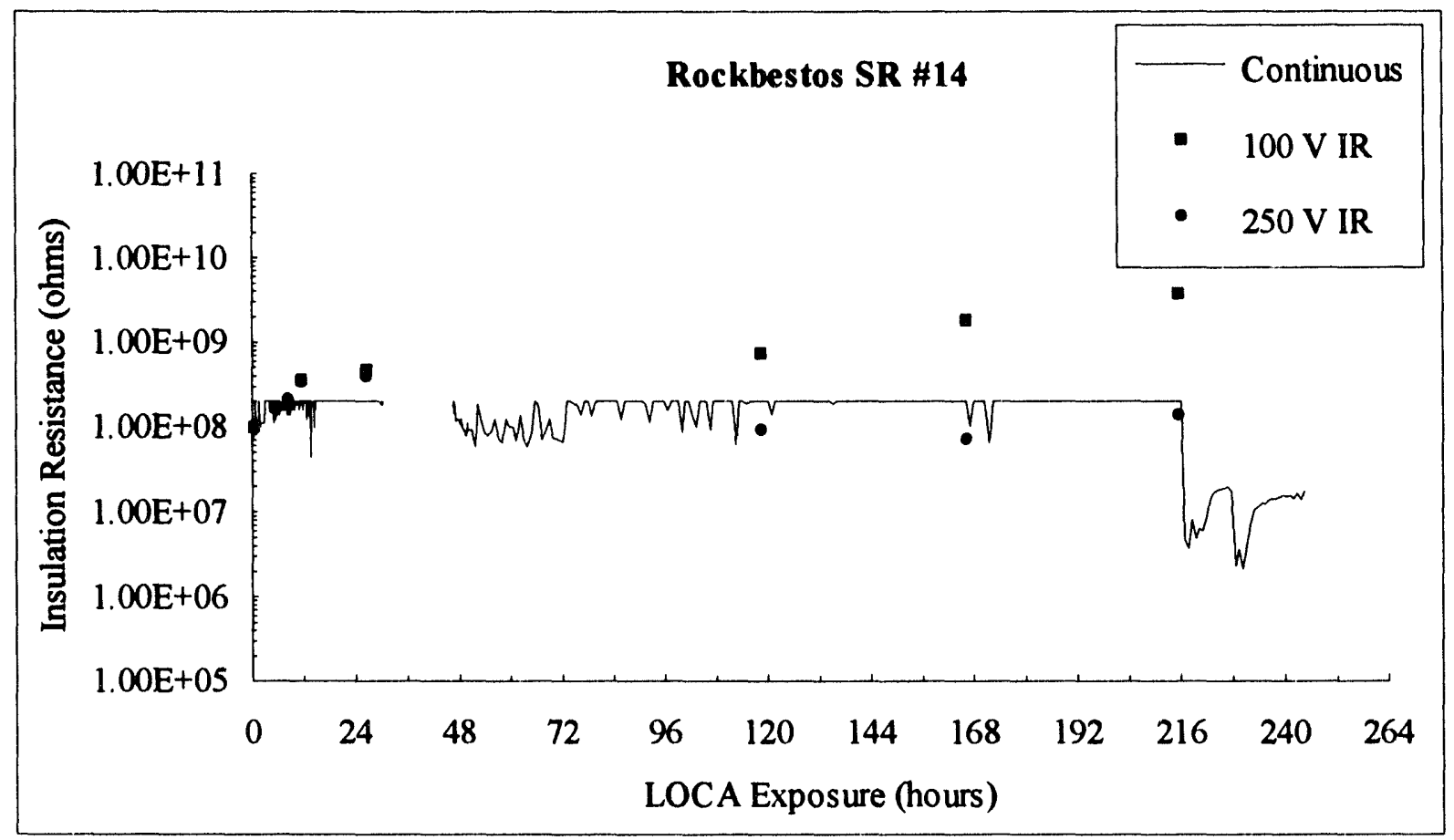

Figure A-28 Insulation Resistance for Rockbestos SR Sample \#14. 


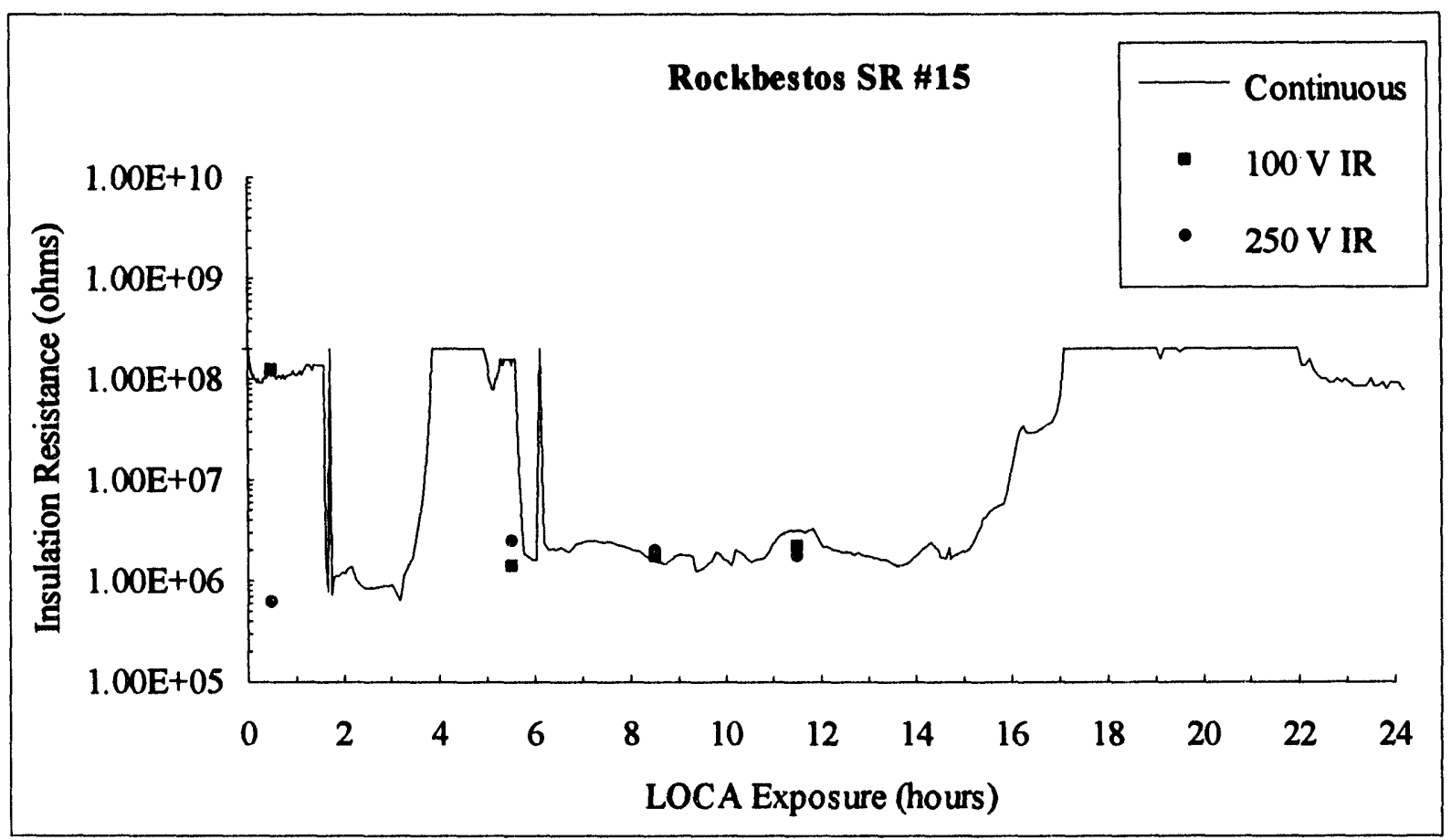

Figure A-29 Insulation Resistance for Rockbestos Sample \#15 during the first 24 hours.

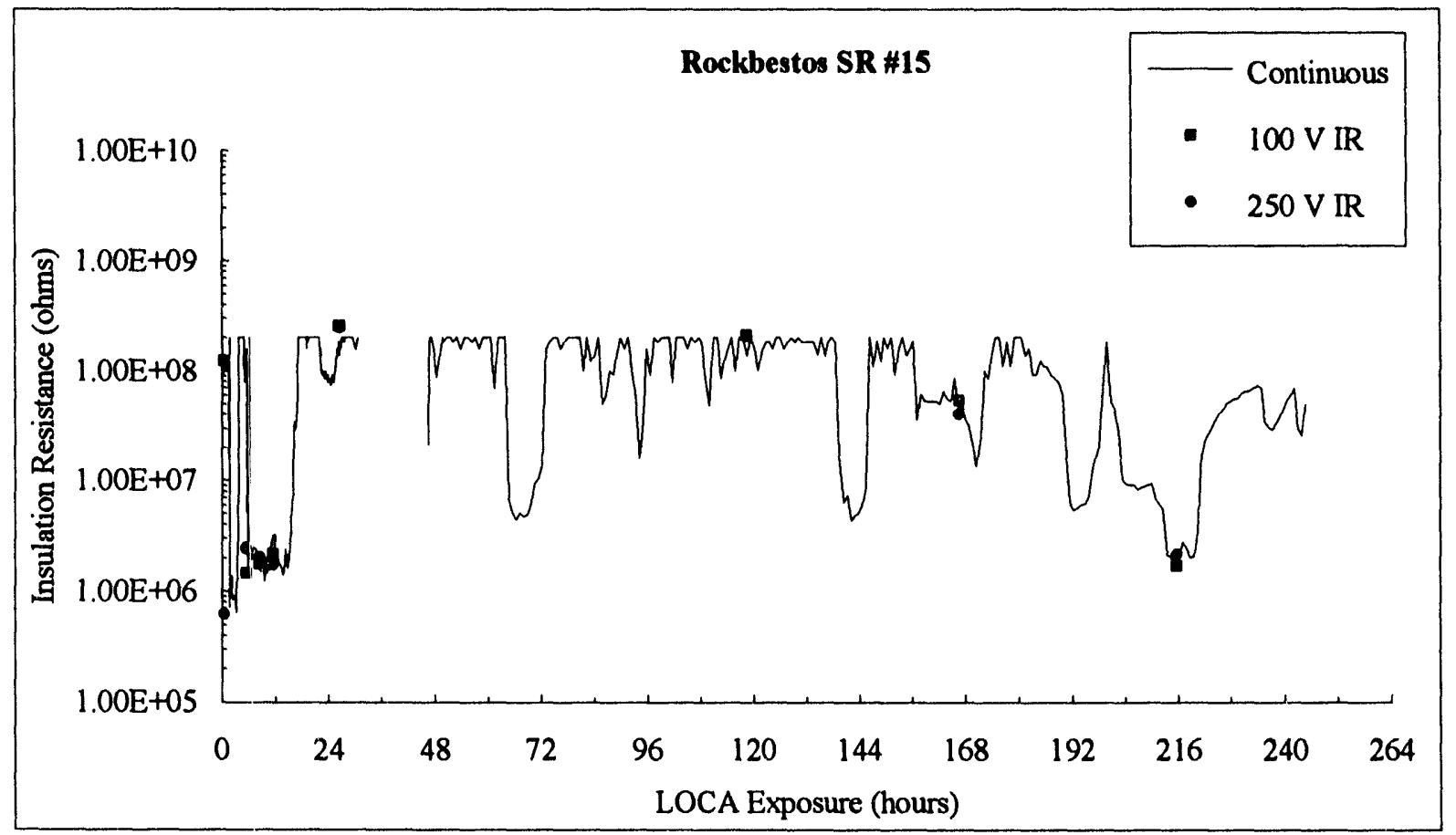

Figure A-30 Insulation Resistance for Rockbestos SR Sample \#15. 


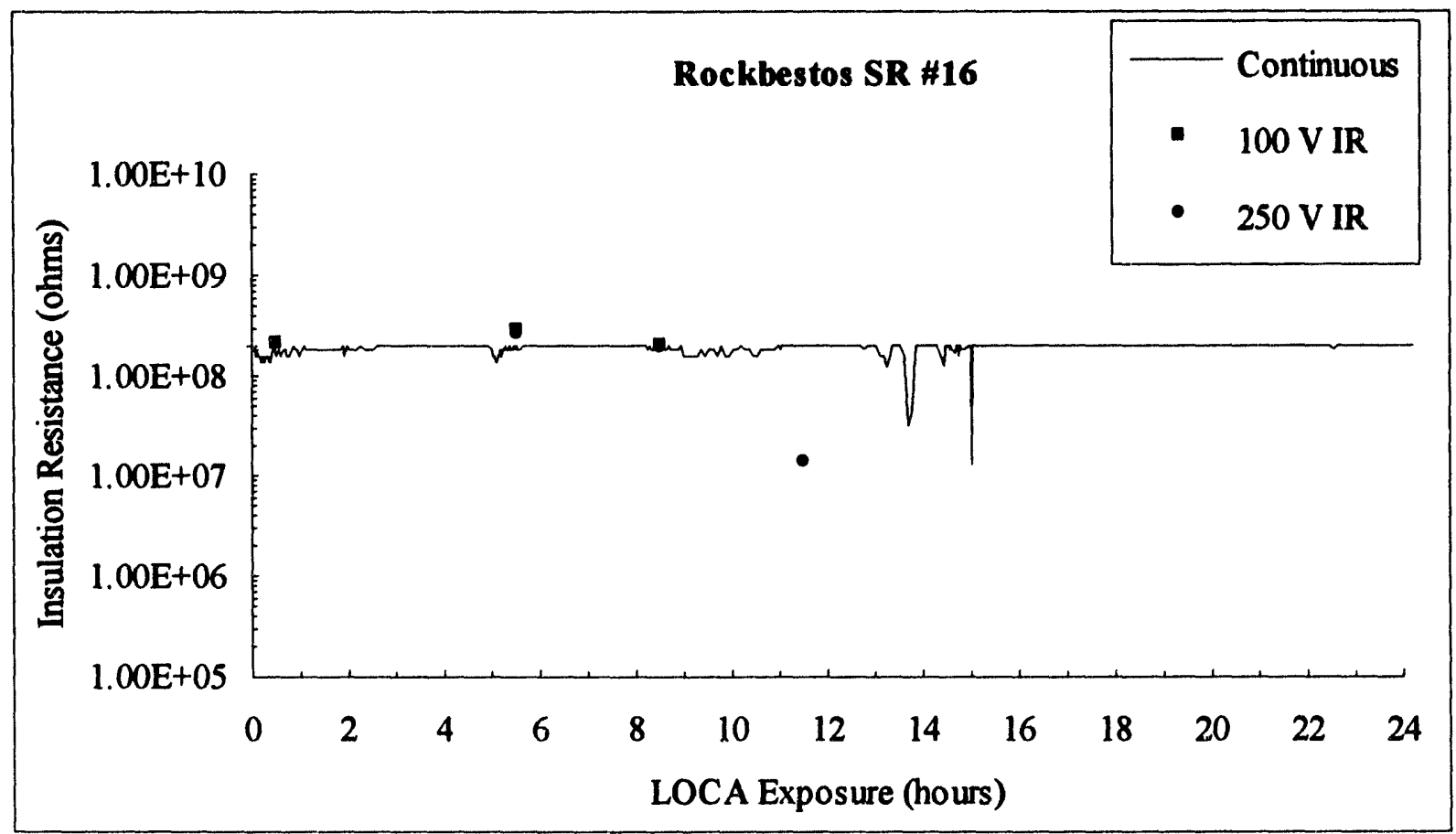

Figure A-31 Insulation Resistance for Rockbestos Sample \#16 during the first 24 hours.

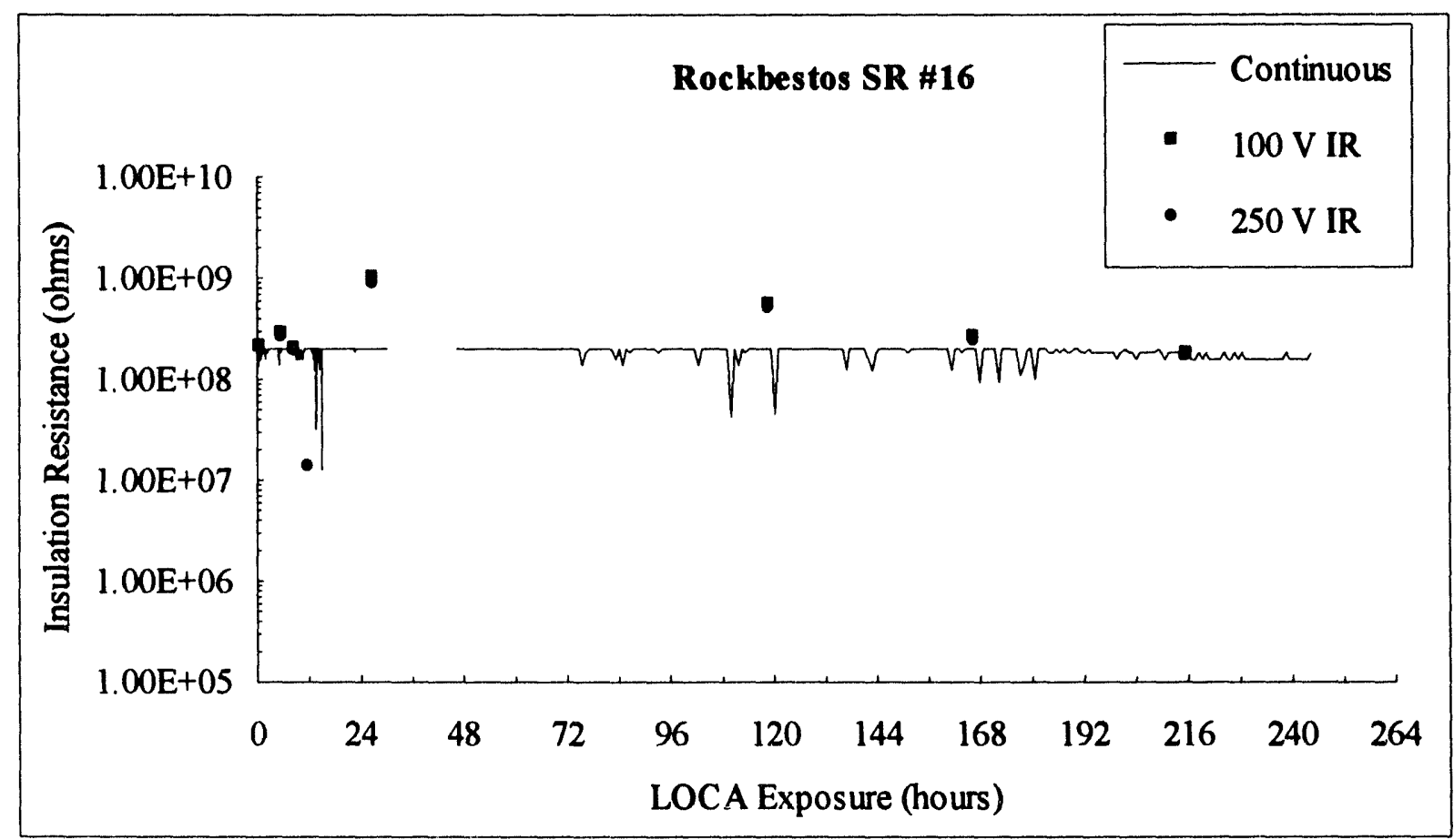

Figure A-32 Insulation Resistance for Rockbestos SR Sample \#16. 


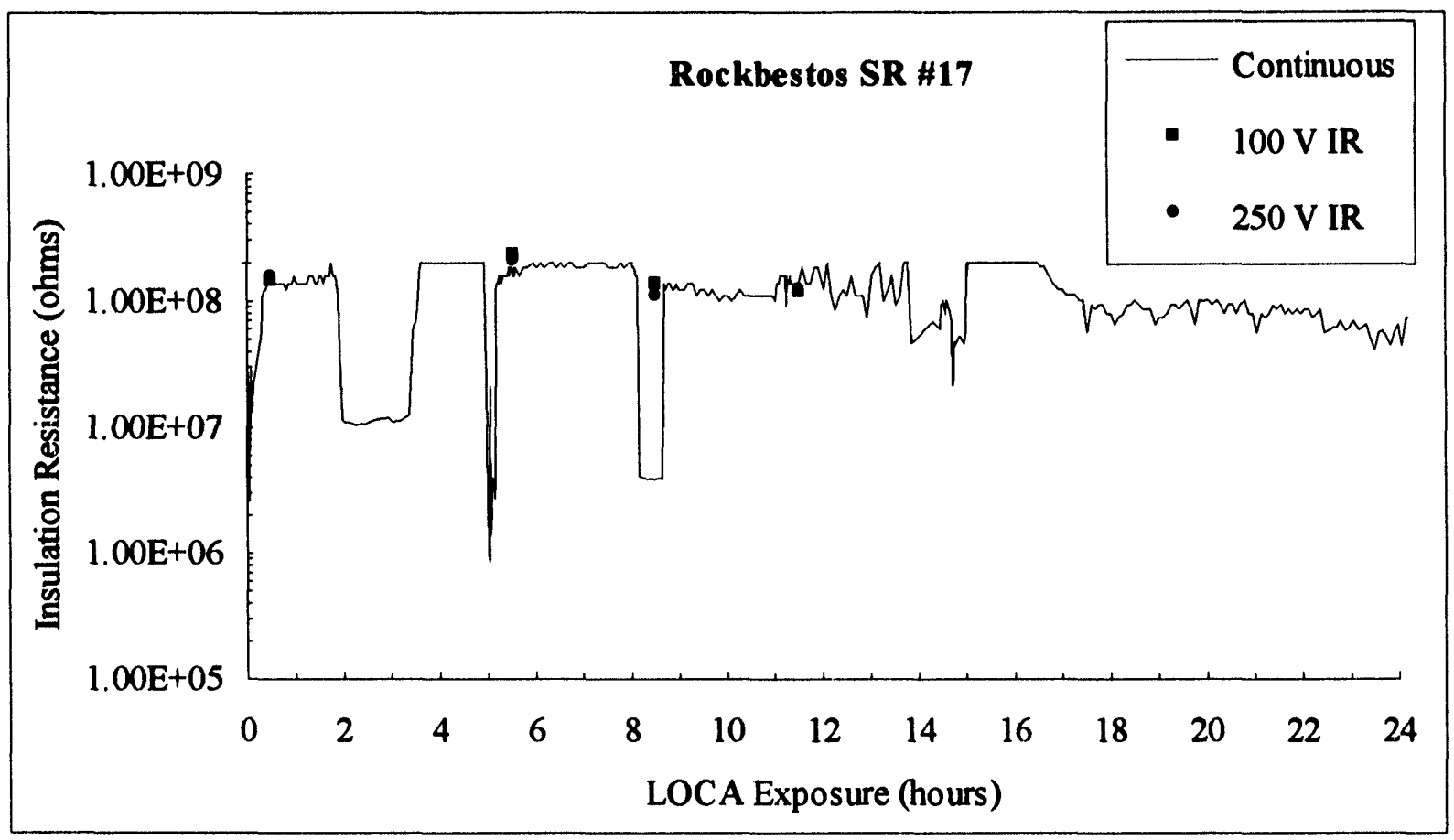

Figure A-33 Insulation Resistance for Rockbestos Sample \#17 during the first 24 hours.

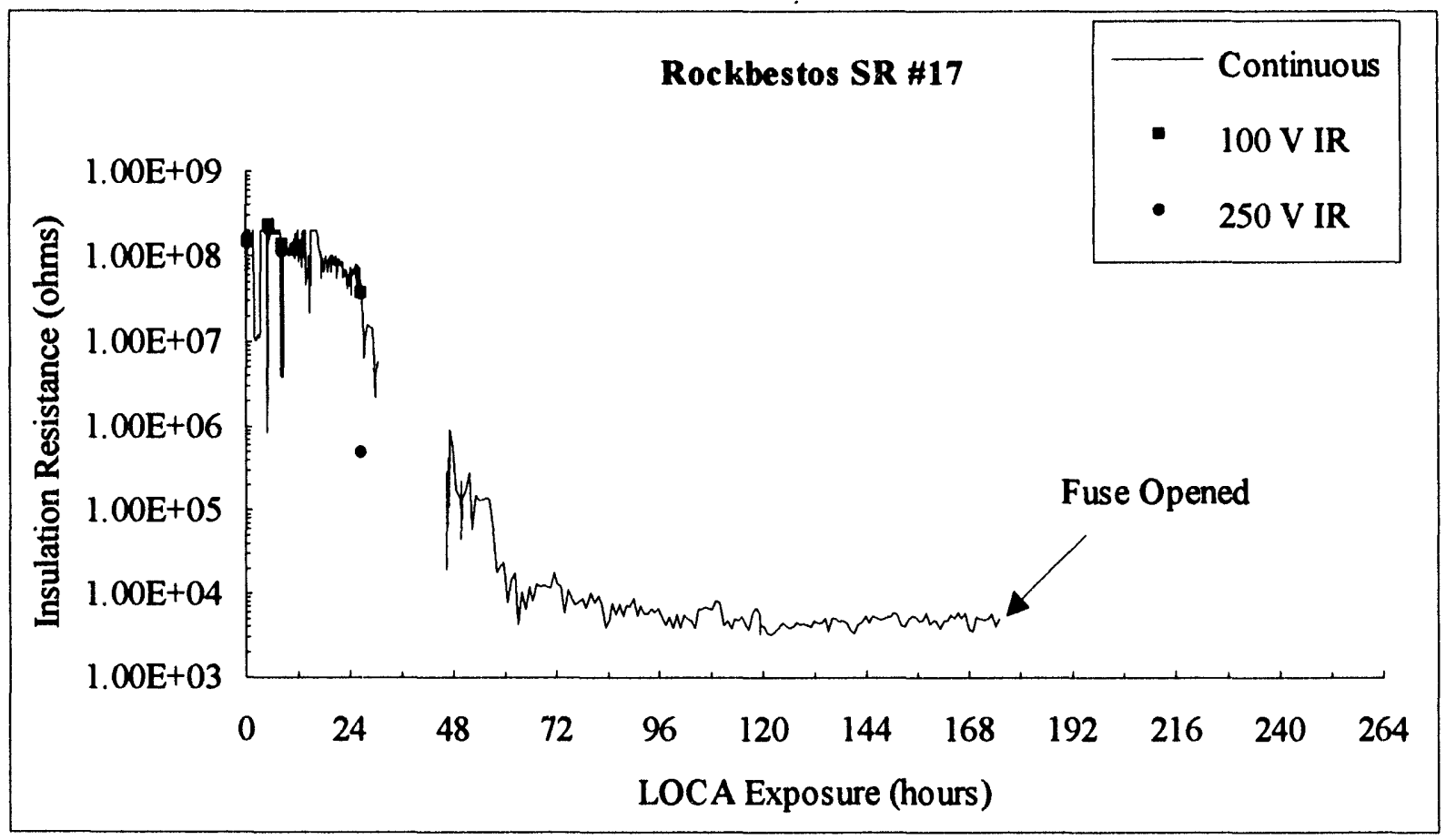

Figure A-34 Insulation Resistance for Rockbestos SR Sample \#17. 


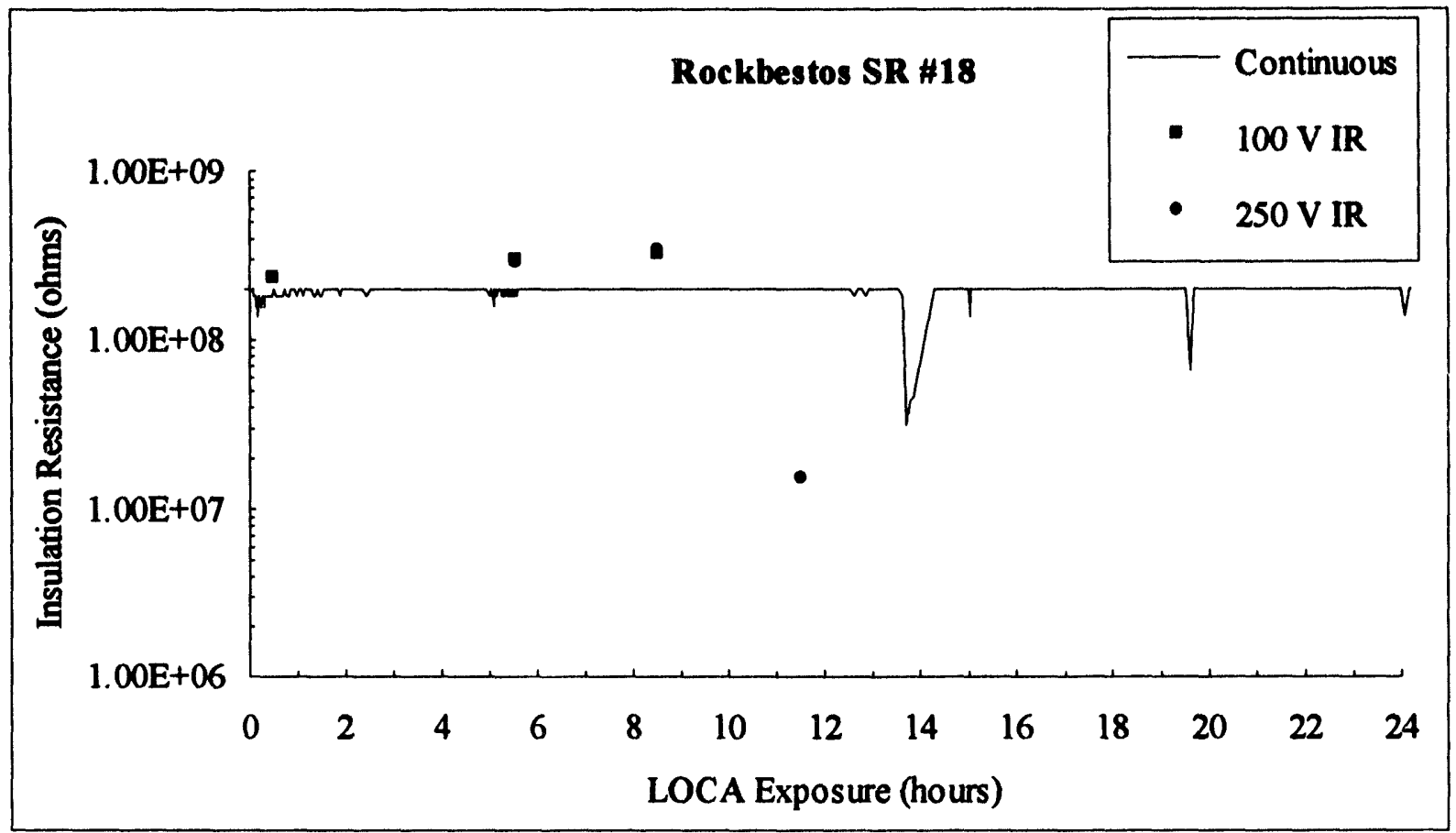

Figure A-35 Insulation Resistance for Rockbestos Sample \#18 during the first 24 hours.

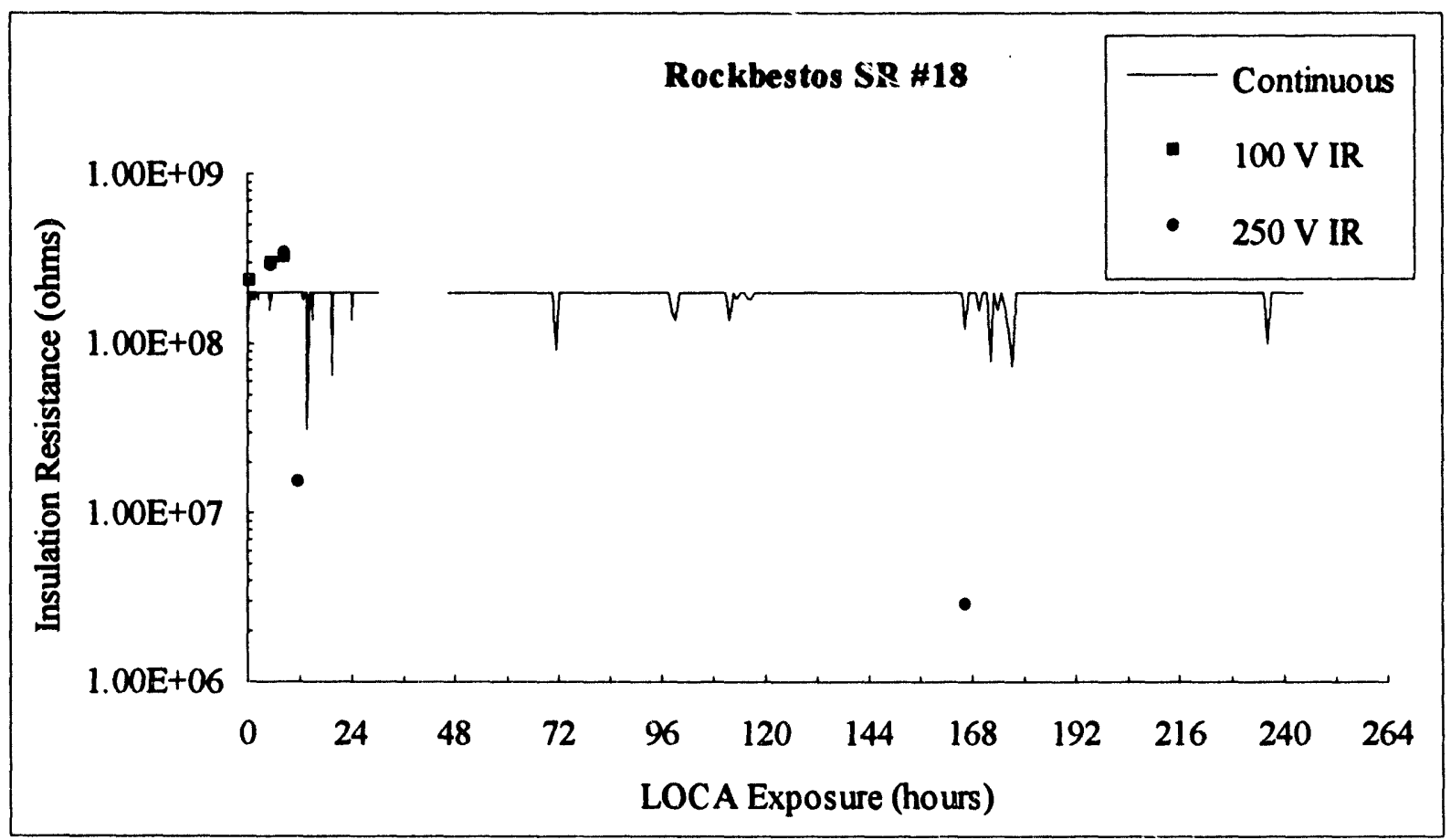

Figure A-36 Insulation Resistance for Rockbestos SR Sample \#18. 


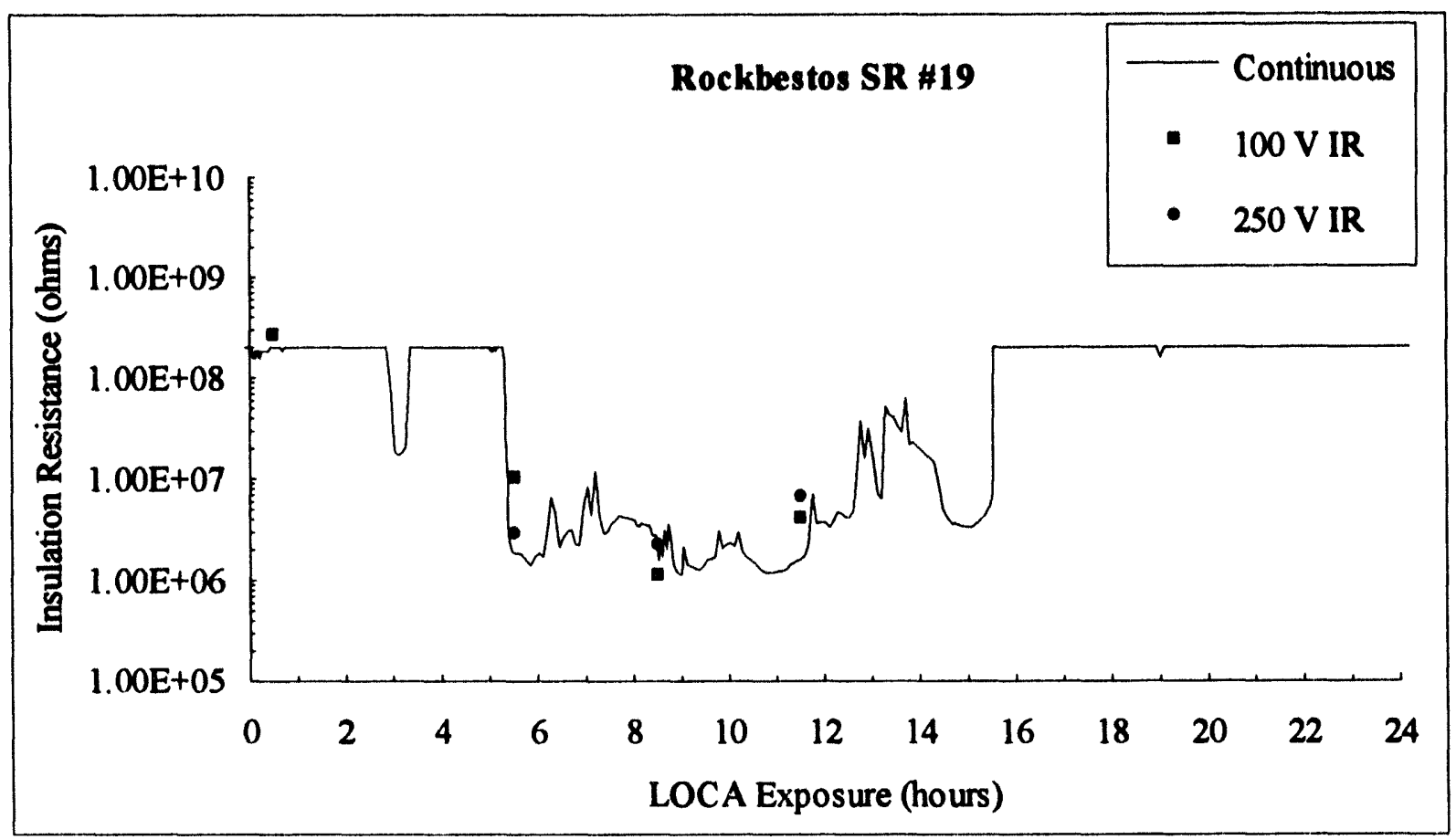

Figure A-37 Insulation Resistance for Rockbestos Sample \#19 during the first 24 hours.

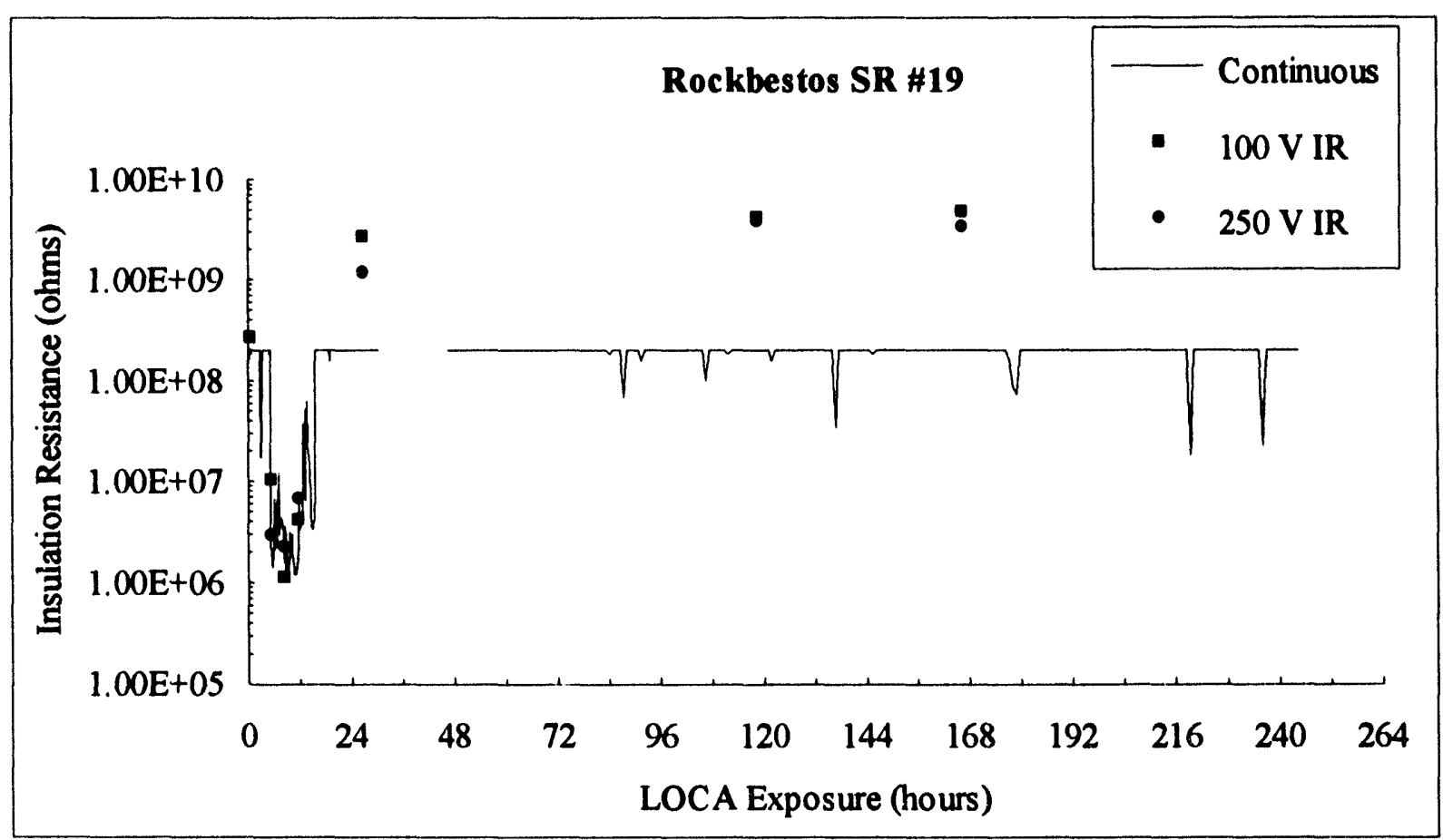

Figure A-38 Insulation Resistance for Rockbestos SR Sample \#19. 


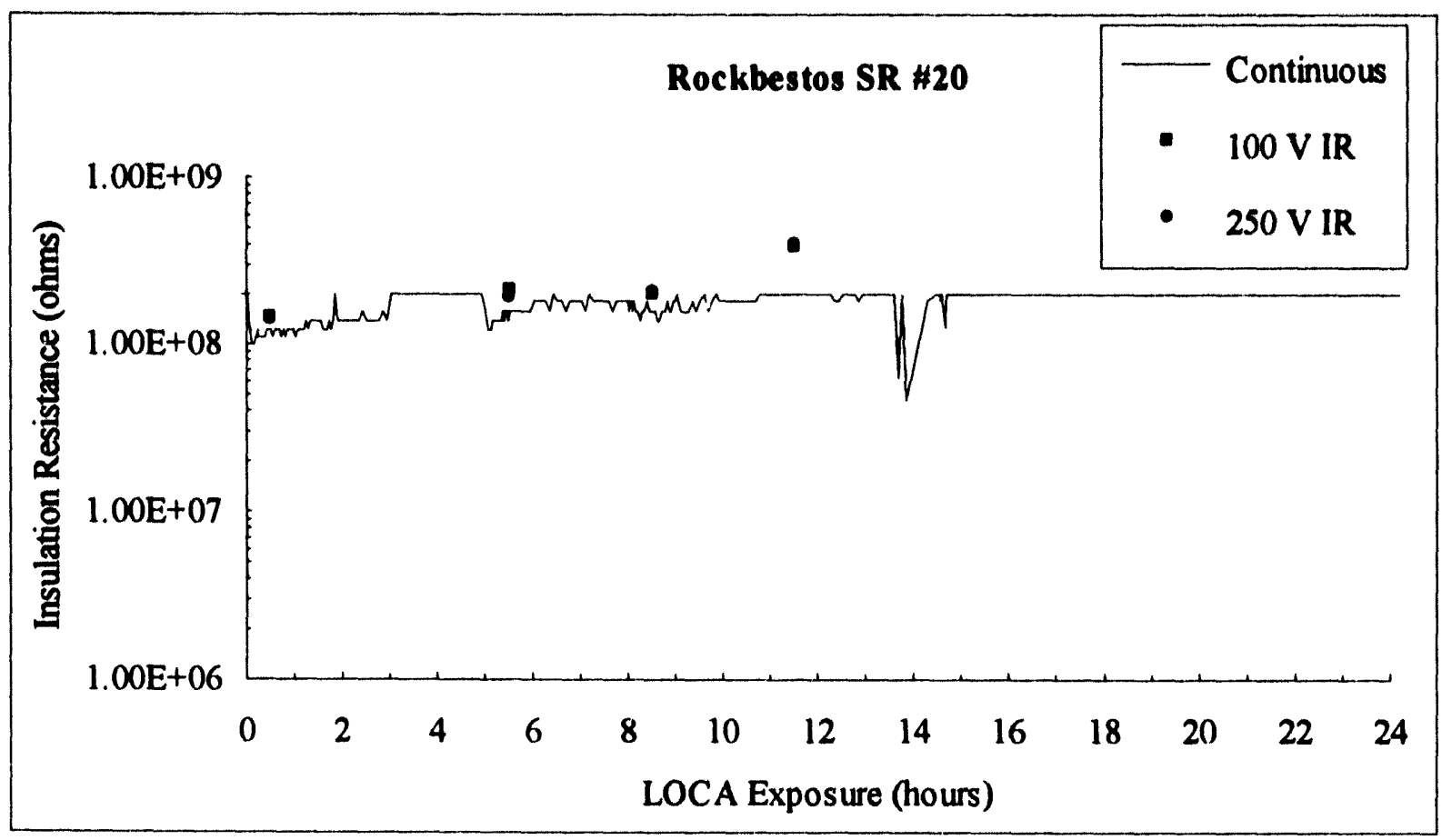

Figure A-39 Insulation Resistance for Rockbestos SR Sample $\$ 20$ during the first 24 hours.

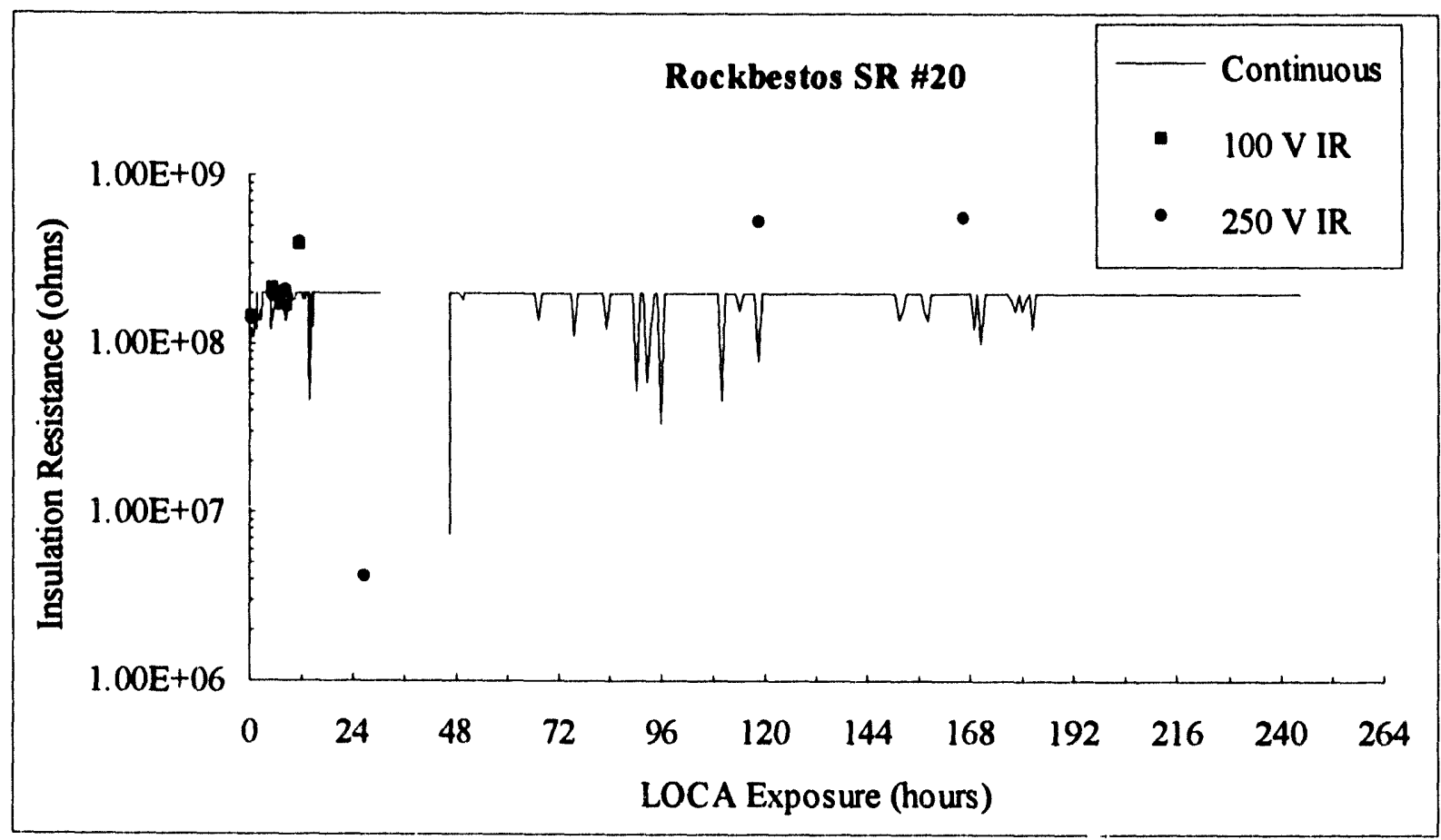

Figure A-40 Insulation Resistance for Rockbestos SR Sample \#20. 


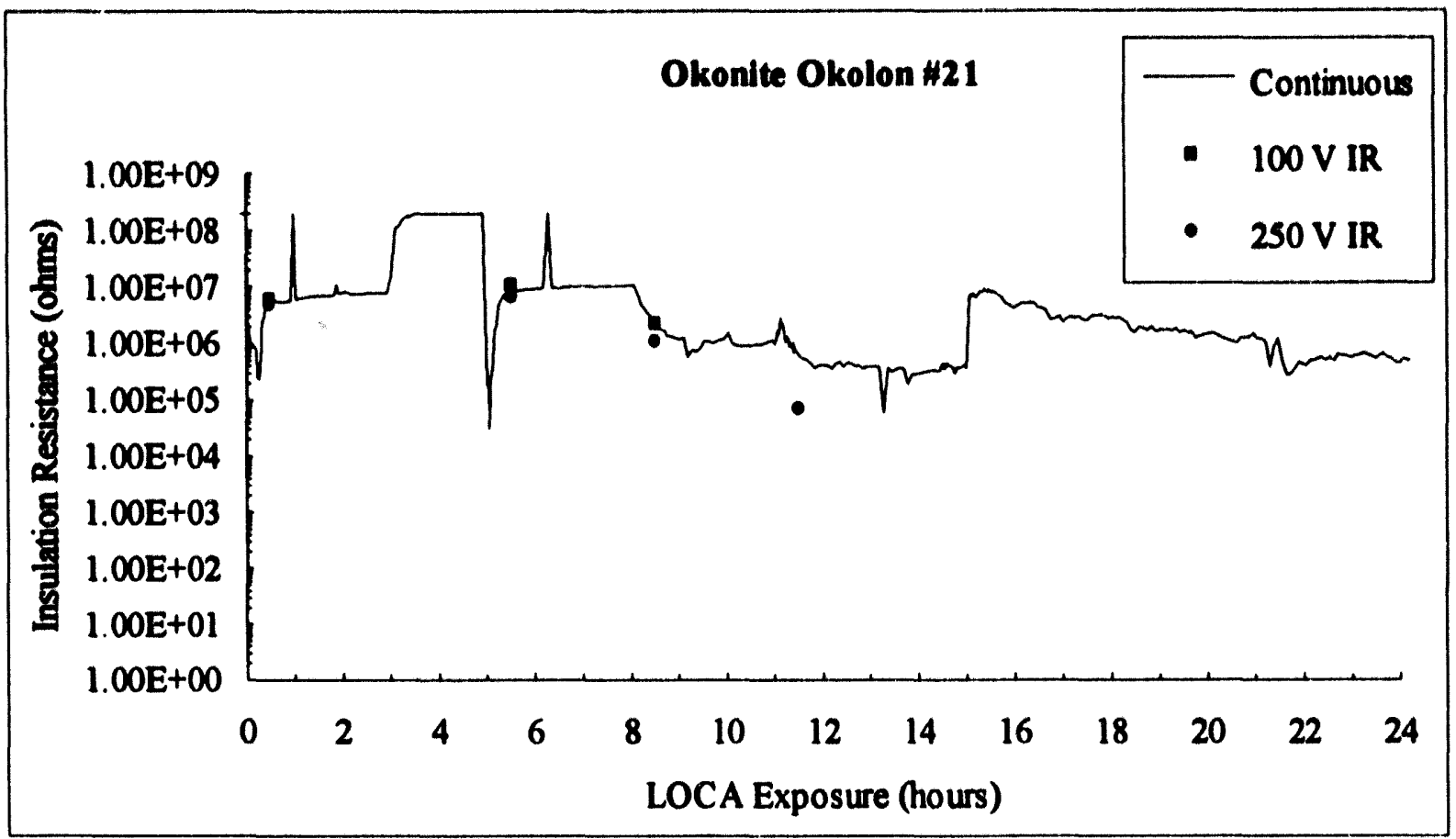

Figure A-41 Insulation Resistance for Okonite Okolon Sample \#21 during the first 24 hours.

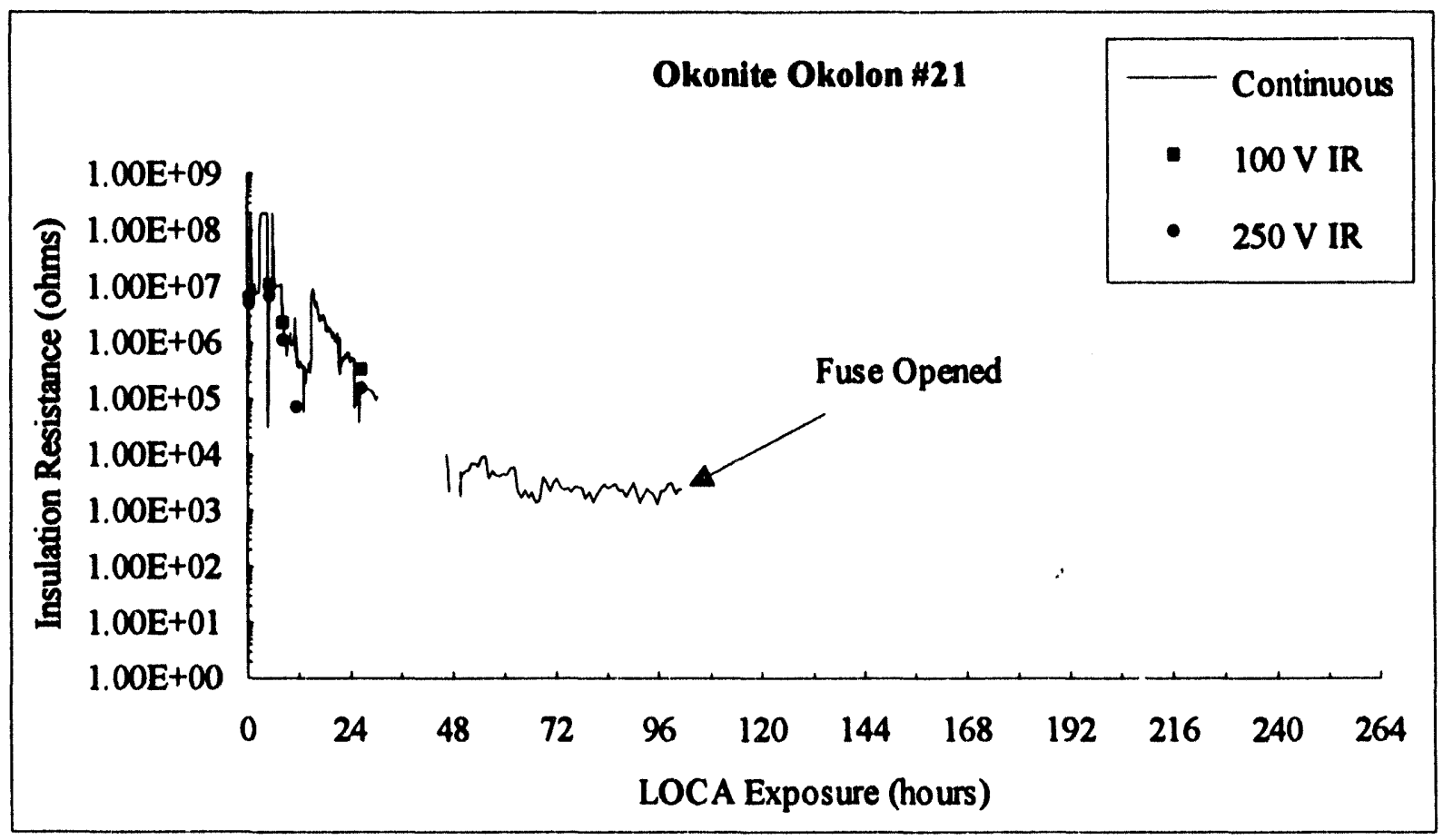

Figure A-42 Insulation Resistance for Okonite Okolon Sample \#21. 


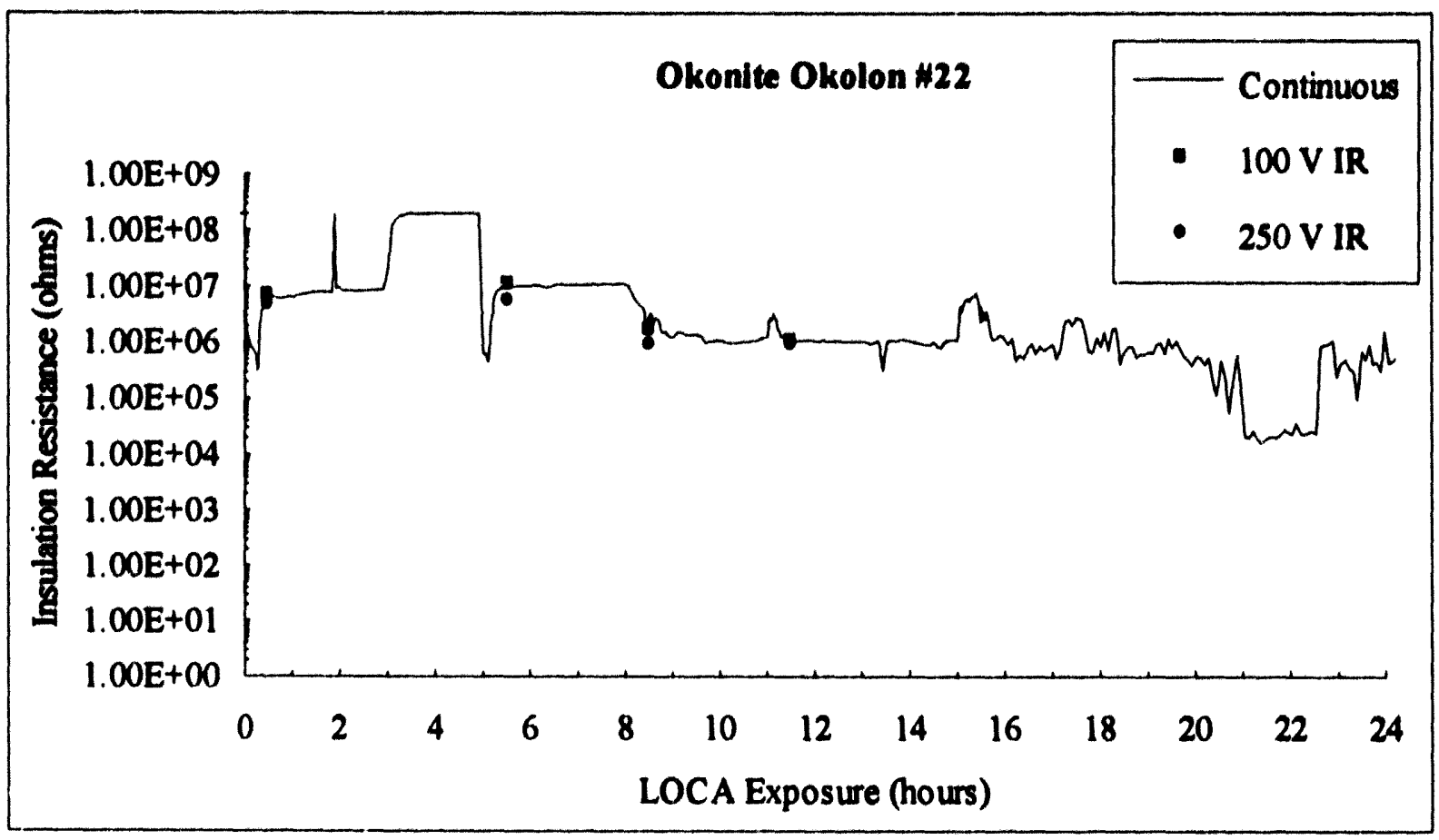

Figure A-43 Insulation Resistance for Okonite Okolon Sample $\$ 22$ during the first 24 hours.

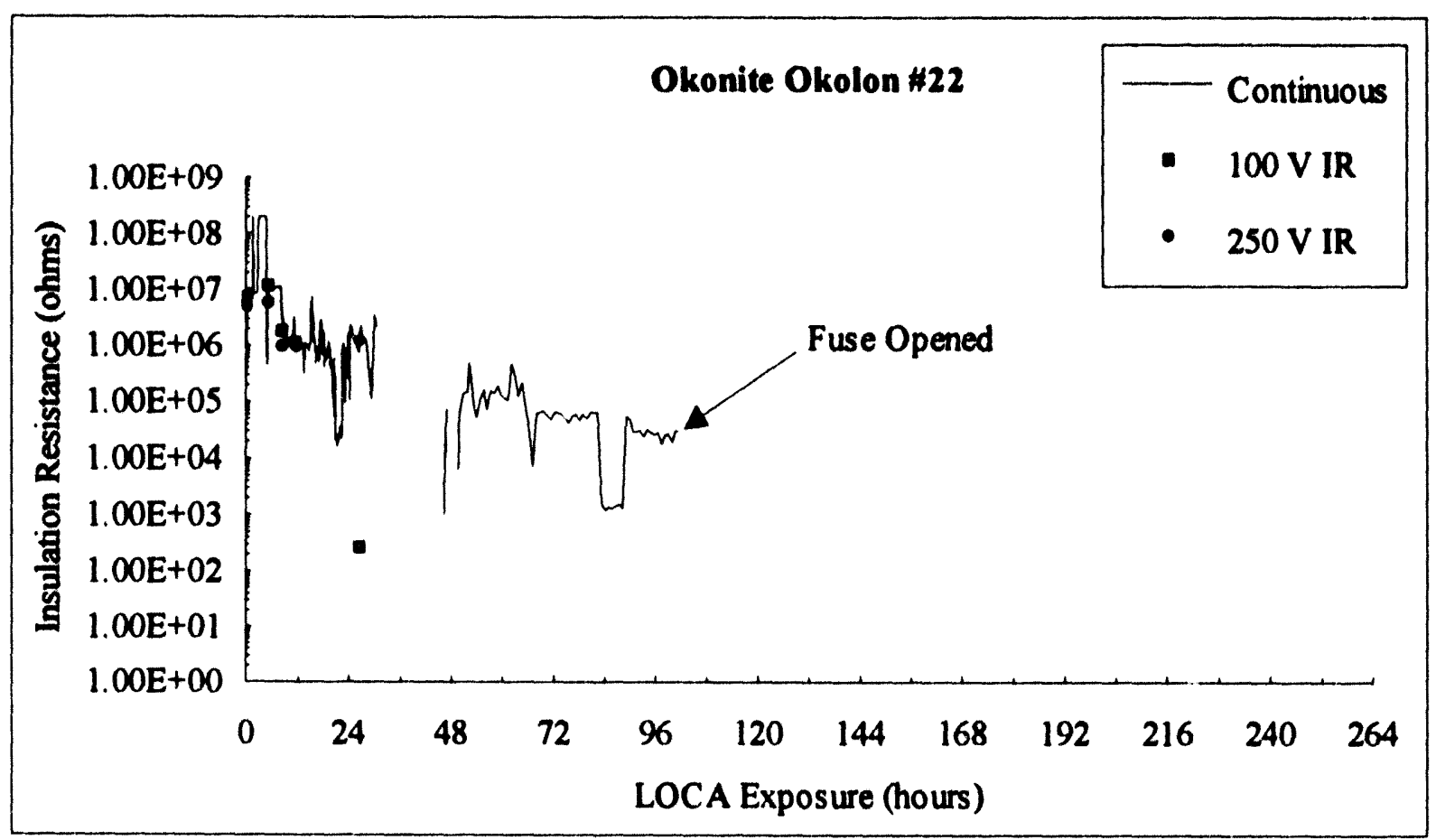

Figure A-44 Insulation Resistance for Okonite Okolon Sample \#22. 


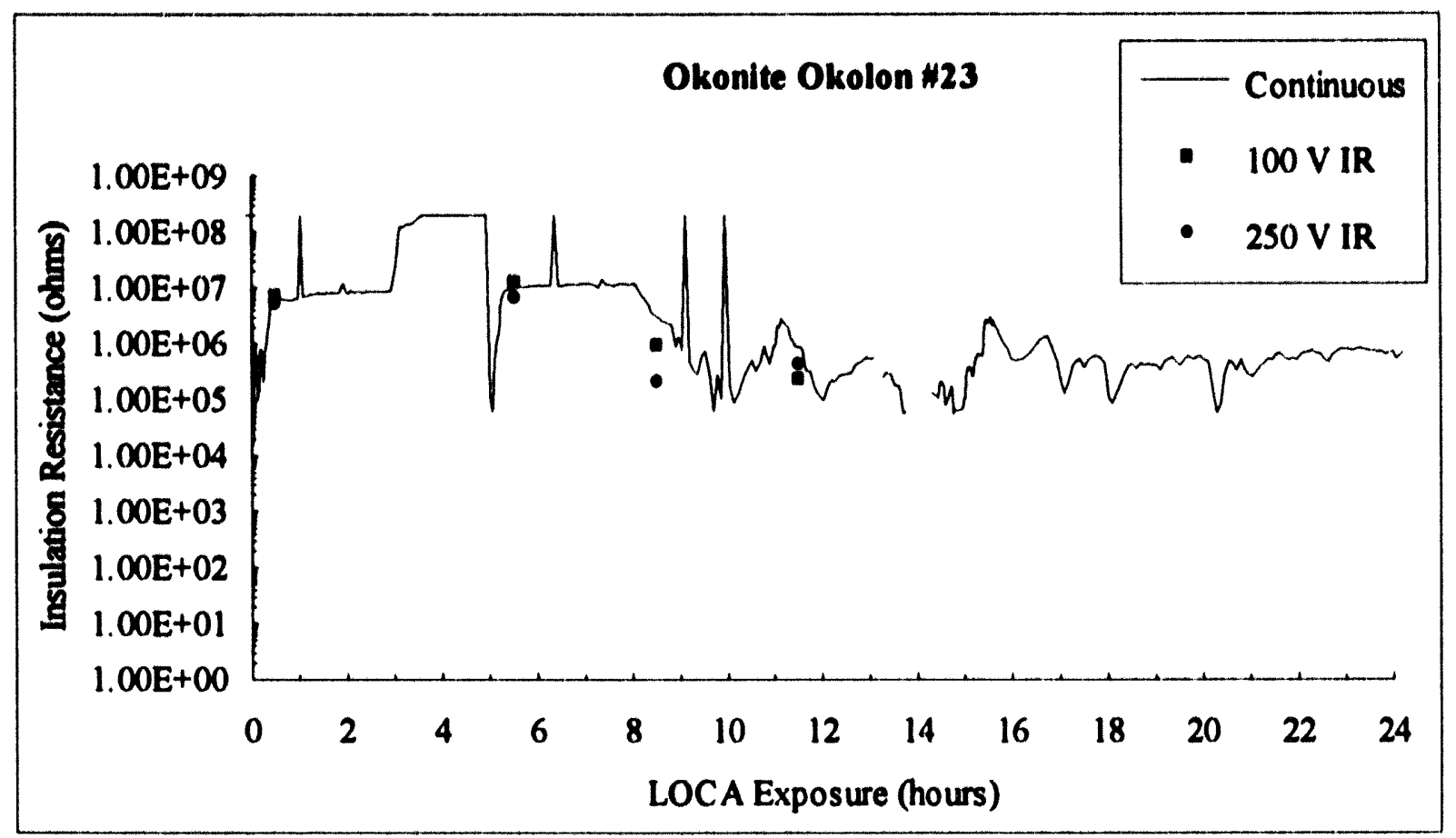

Figure A-45 Insulation Resistance for Okonite Okolon Sample $\$ 23$ during the first 24 hours.

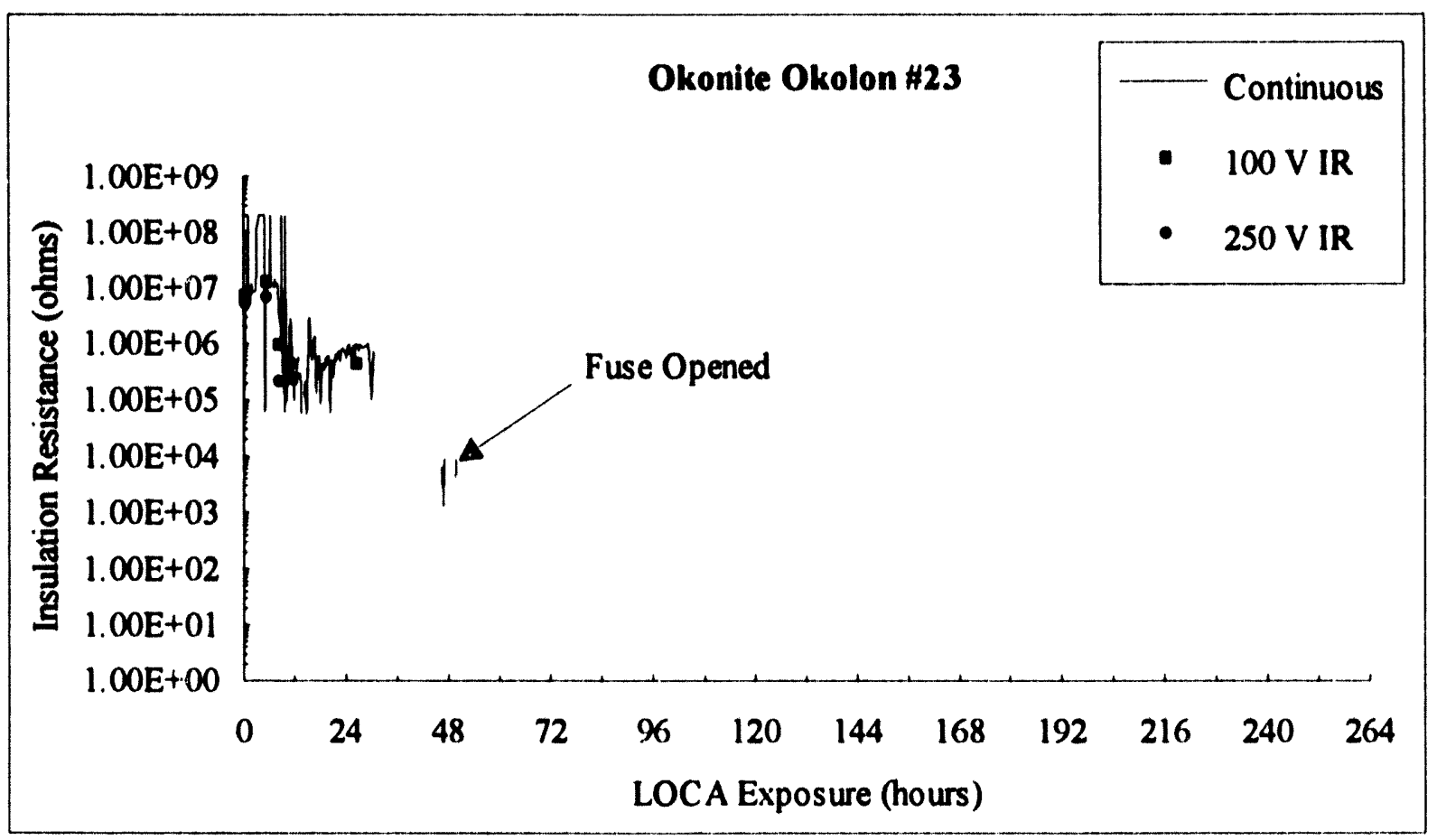

Figure A-46 Insulation Resistance for Okonite Okolon Sample \#23. 


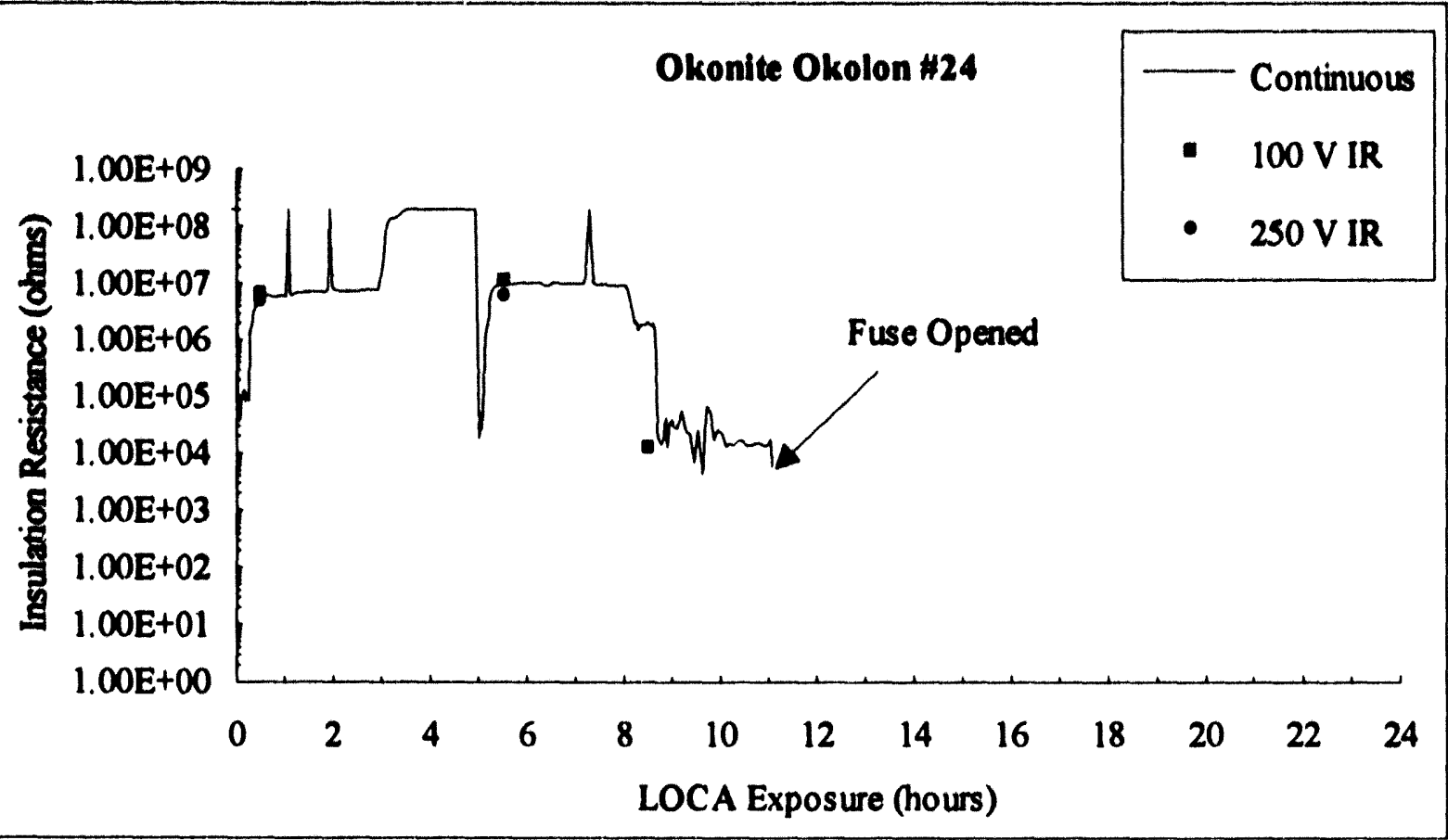

Figure A-47 Insulation Resistance for Okonite Okolon Sample $\$ 24$ during the first 24 hours.

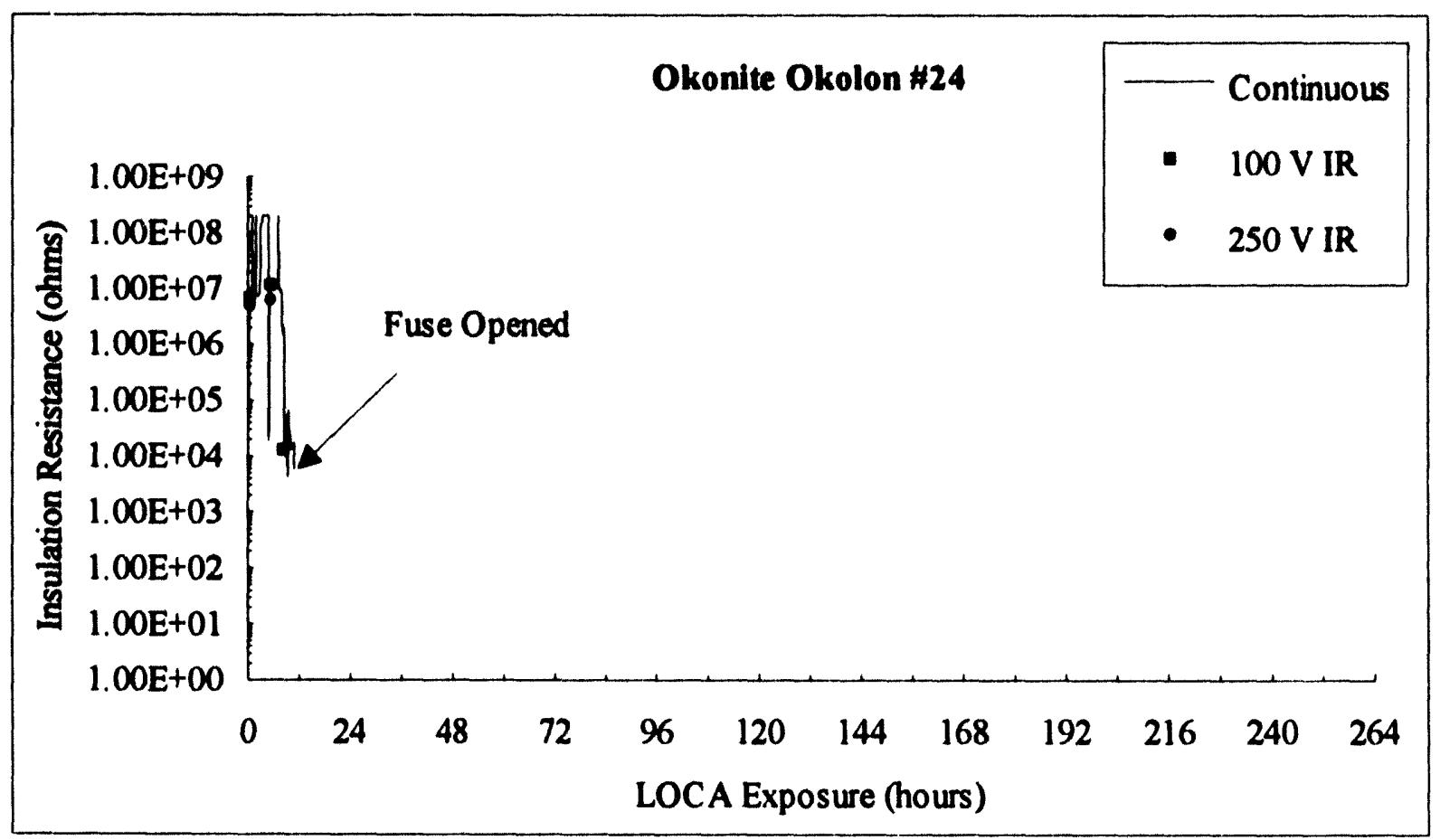

Figure A-48 Insulation Resistance for Okonite Okolon Sample \#24. 


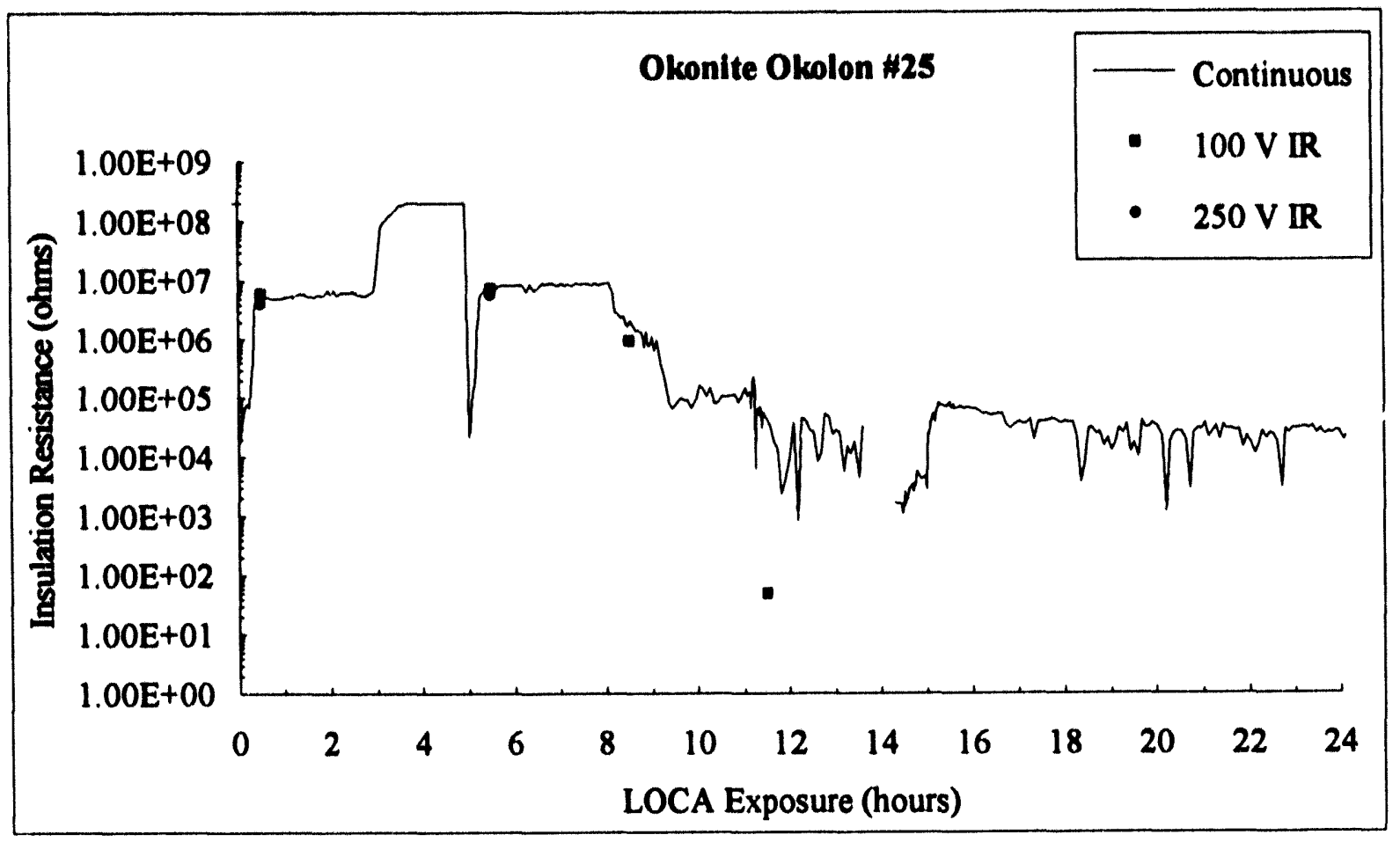

Figure A-49 Insulation Resistance for Okonite Okolon Sample \#25 during the first 24 hours.

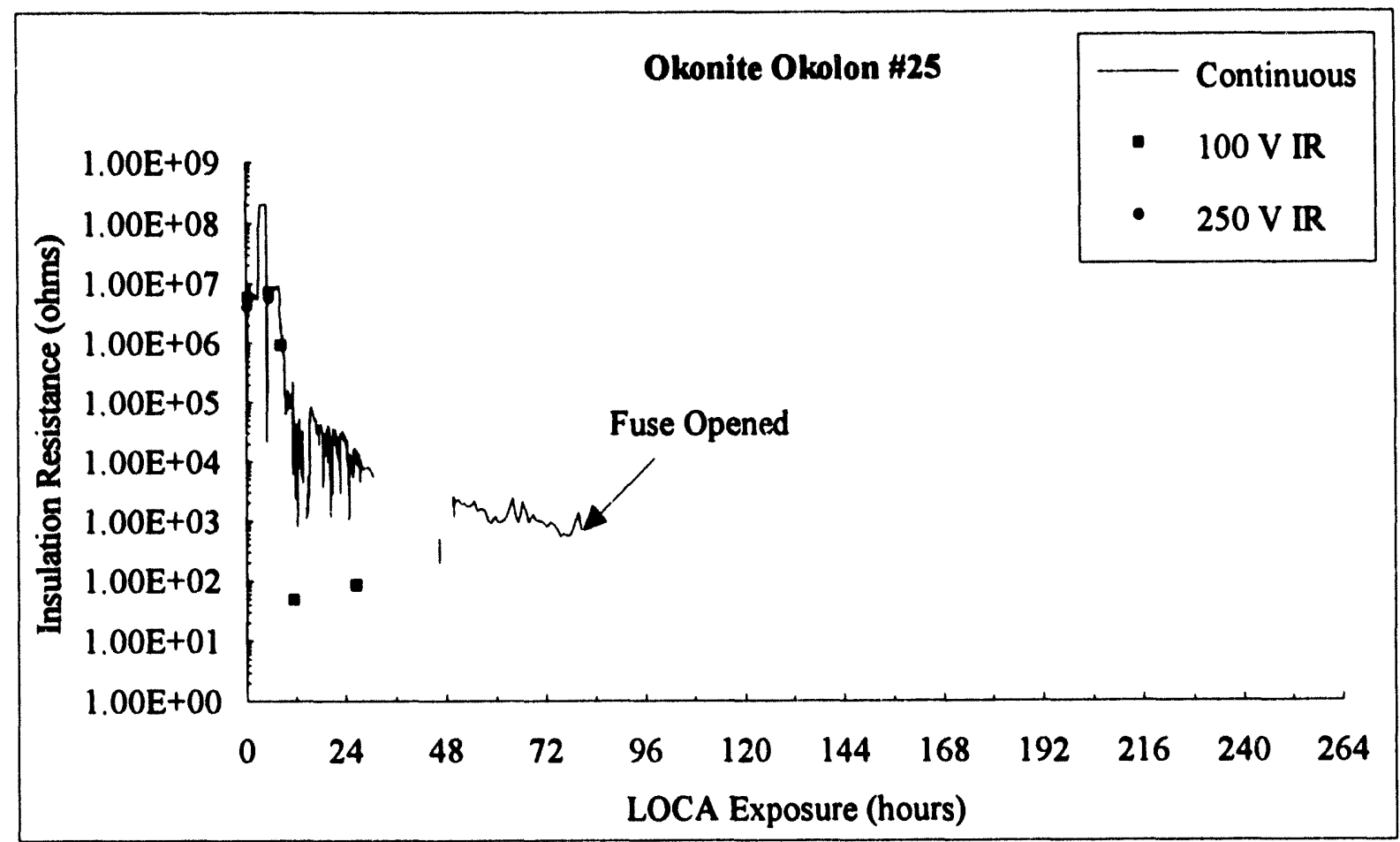

Figure A-50 Insulation Resistance for Okonite Okolon Sample \#25 . 


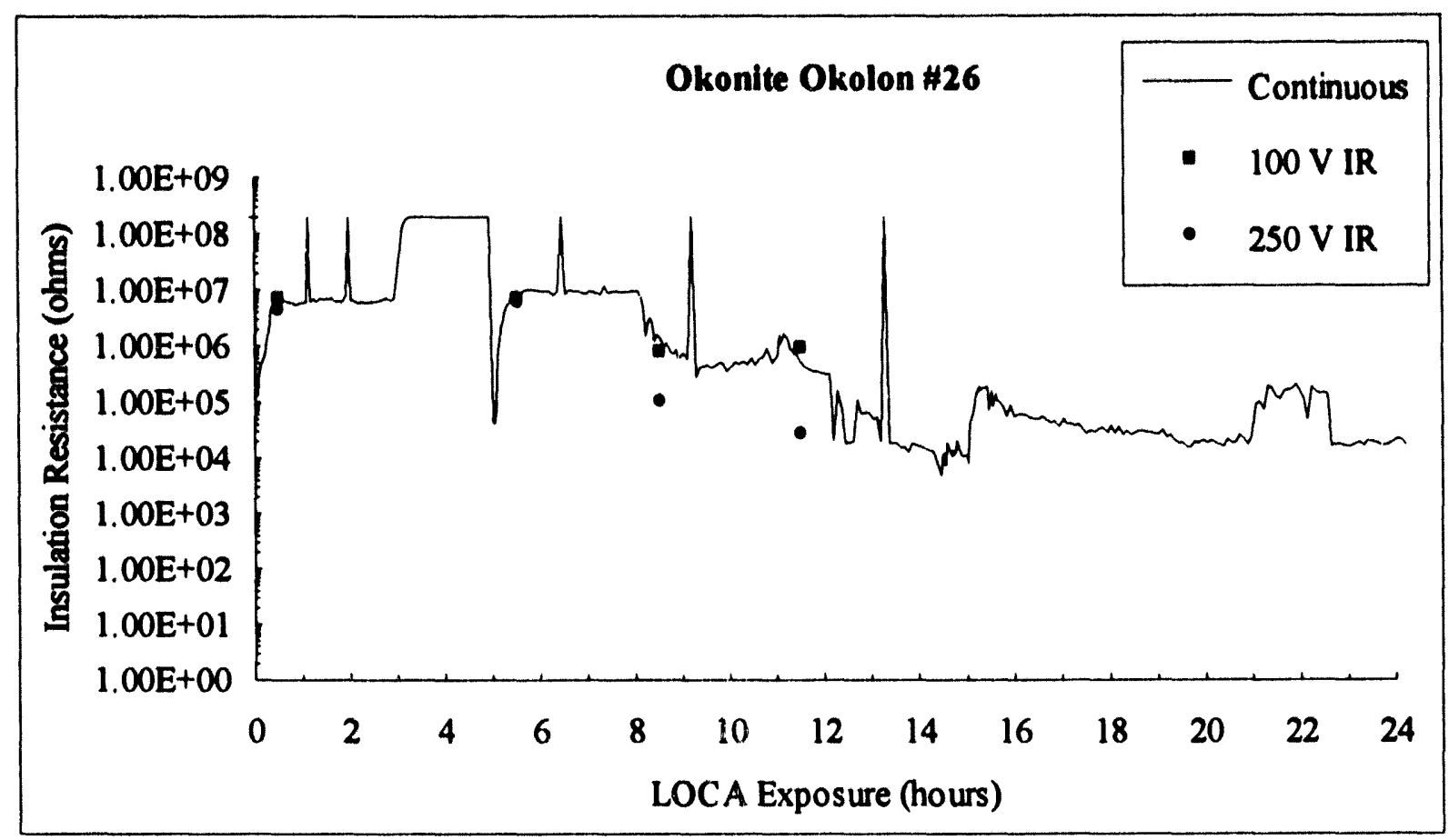

Figure A-51 Insulation Resistance for Okonite Okolon Sample \#26 during the first 24 hours.

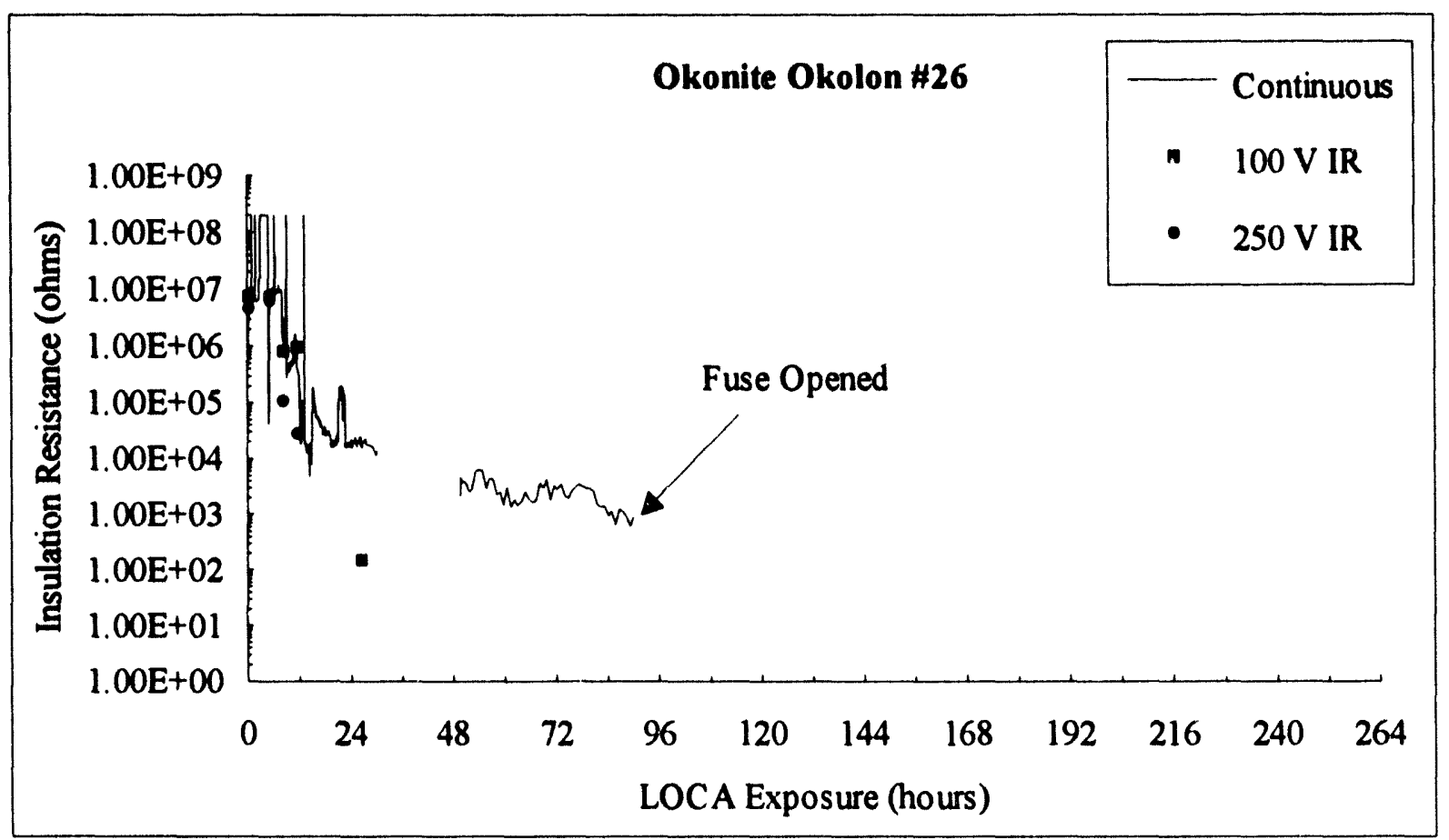

Figure A-52 Insulation Resistance for Okonite Okolon Sample \#26. 


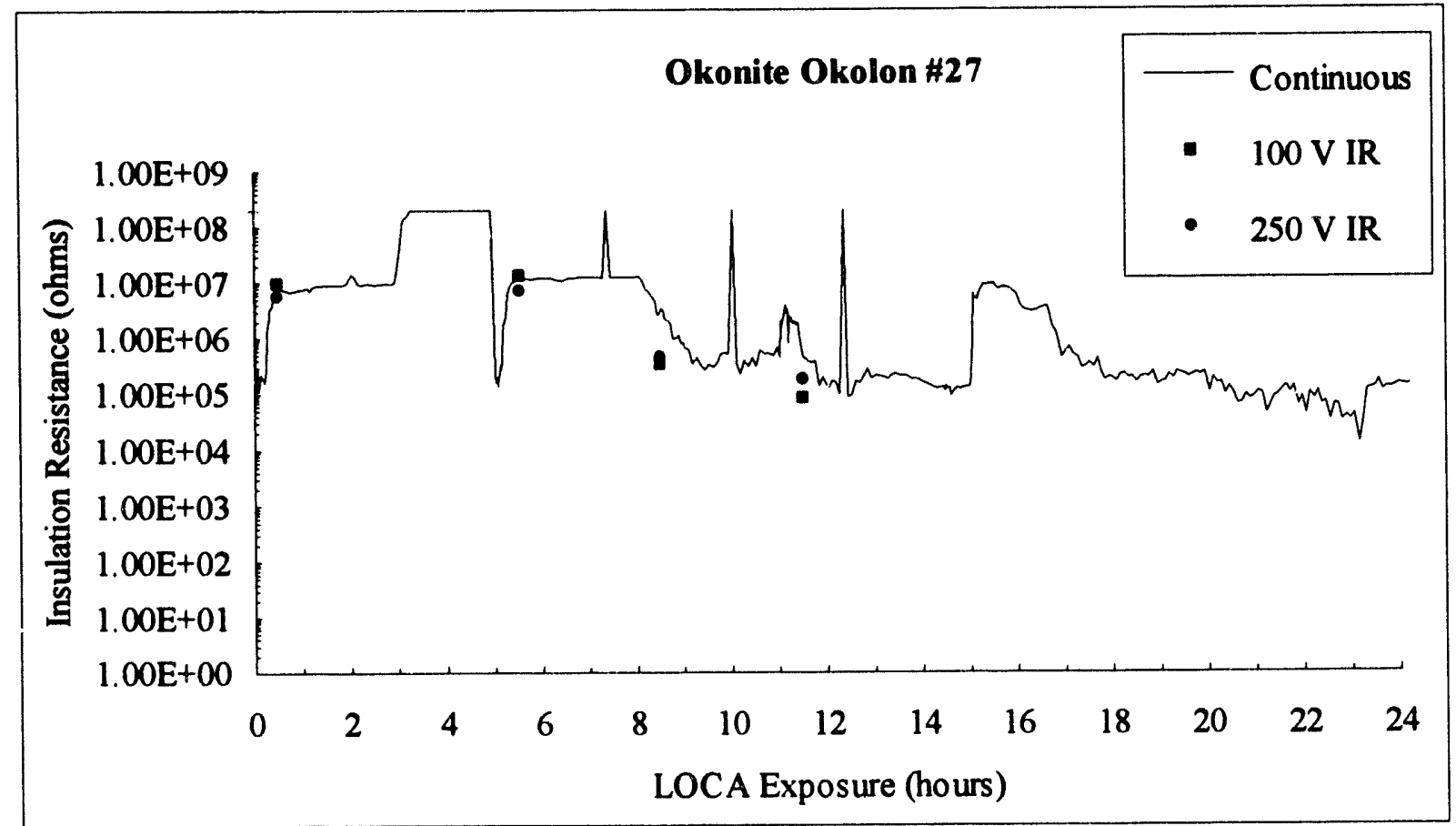

Figure A-53 Insulation Resistance for Okonite Okolon Sample \#27 during the first 24 hours.

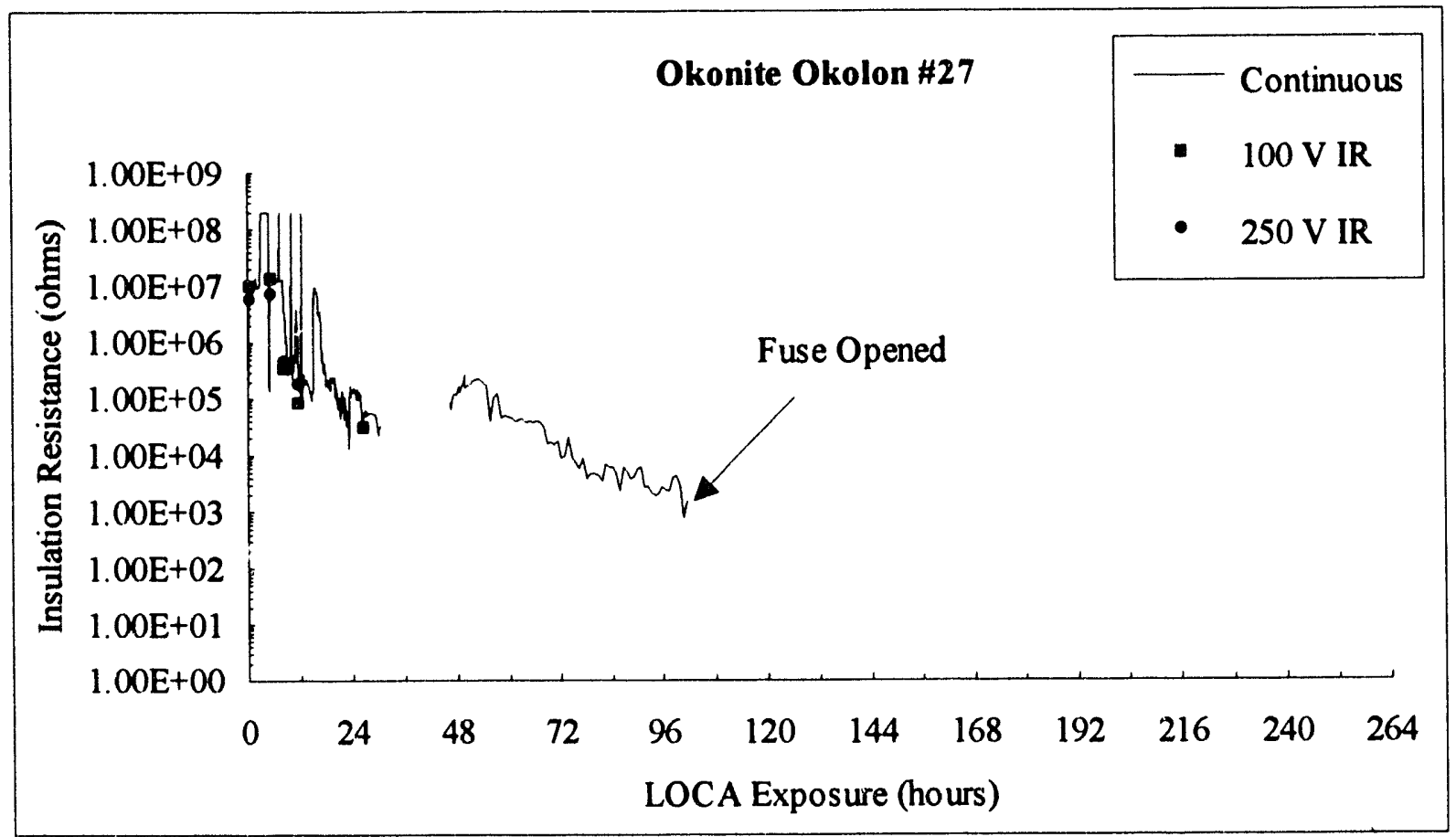

Figure A-54 Insulation Resistance for Okonite Okolon Sample \#27. 


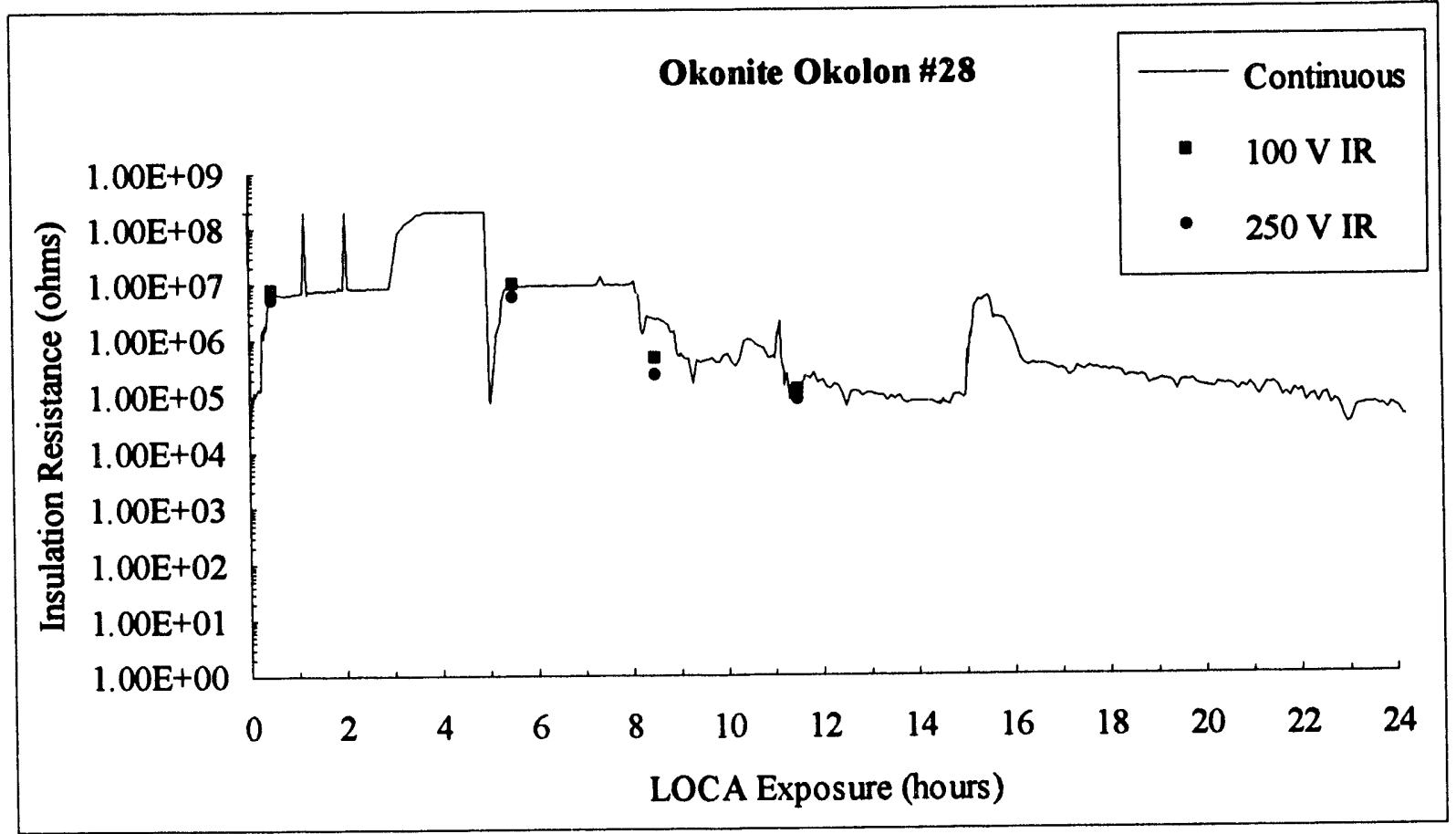

Figure A-55 Insulation Resistance for Okonite Okolon Sample \#28 during the first 24 hours.

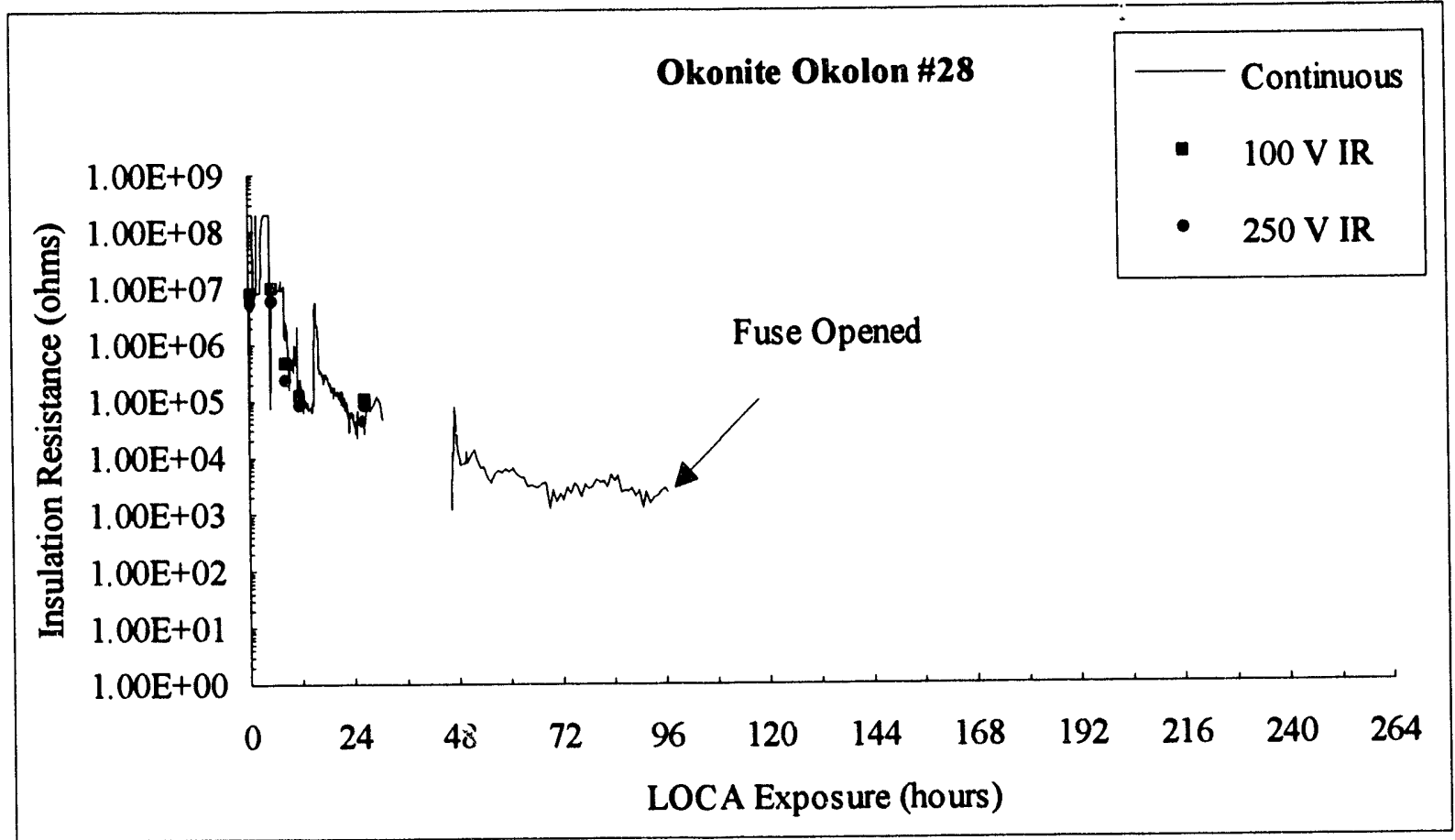

Figure A-56 Insulation Resistance for Okonite Okolon Sample \#28. 


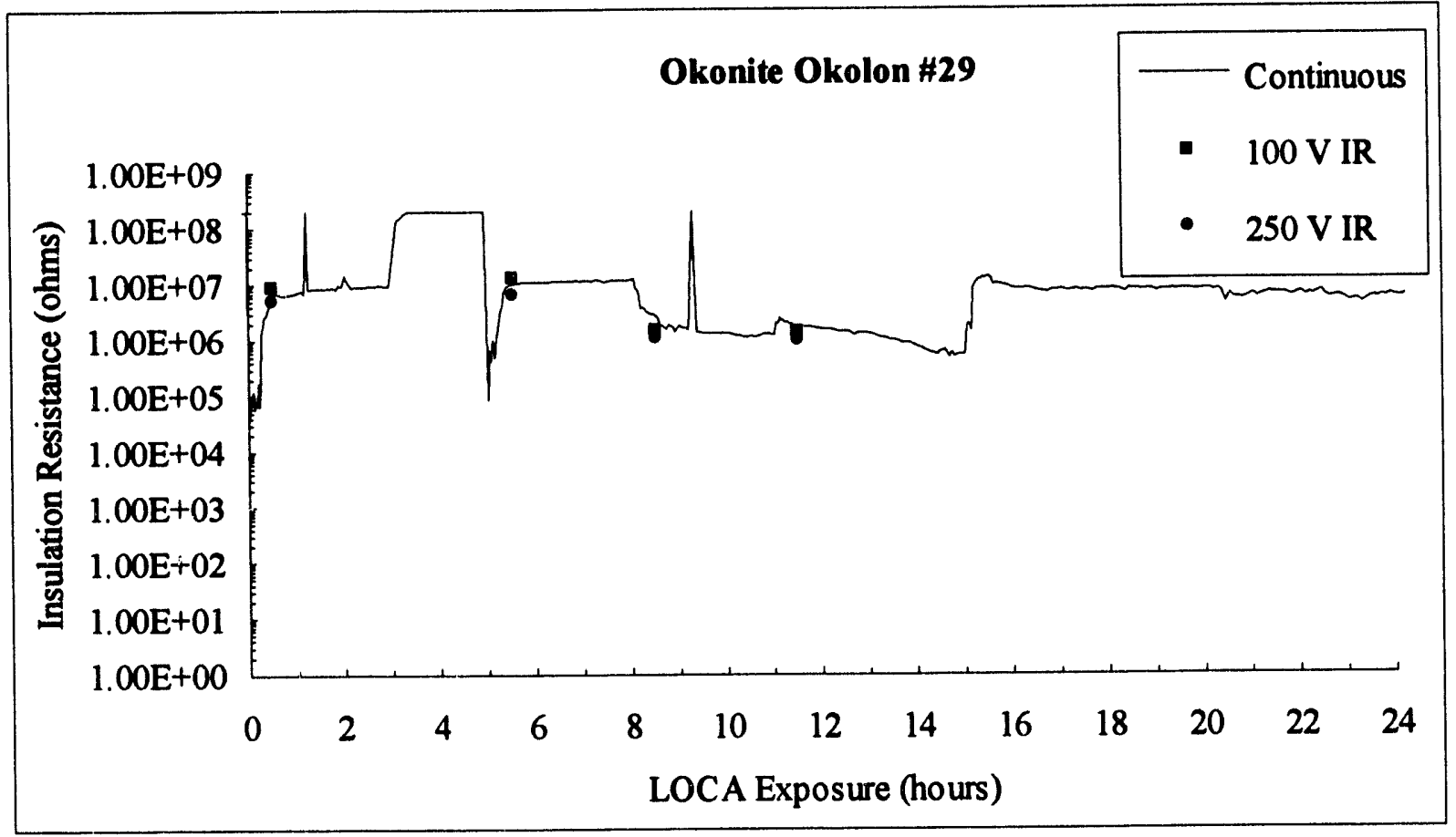

Figure A-57 Insulation Resistance for Okonite Okolon Sample \#29 during the first 24 hours.

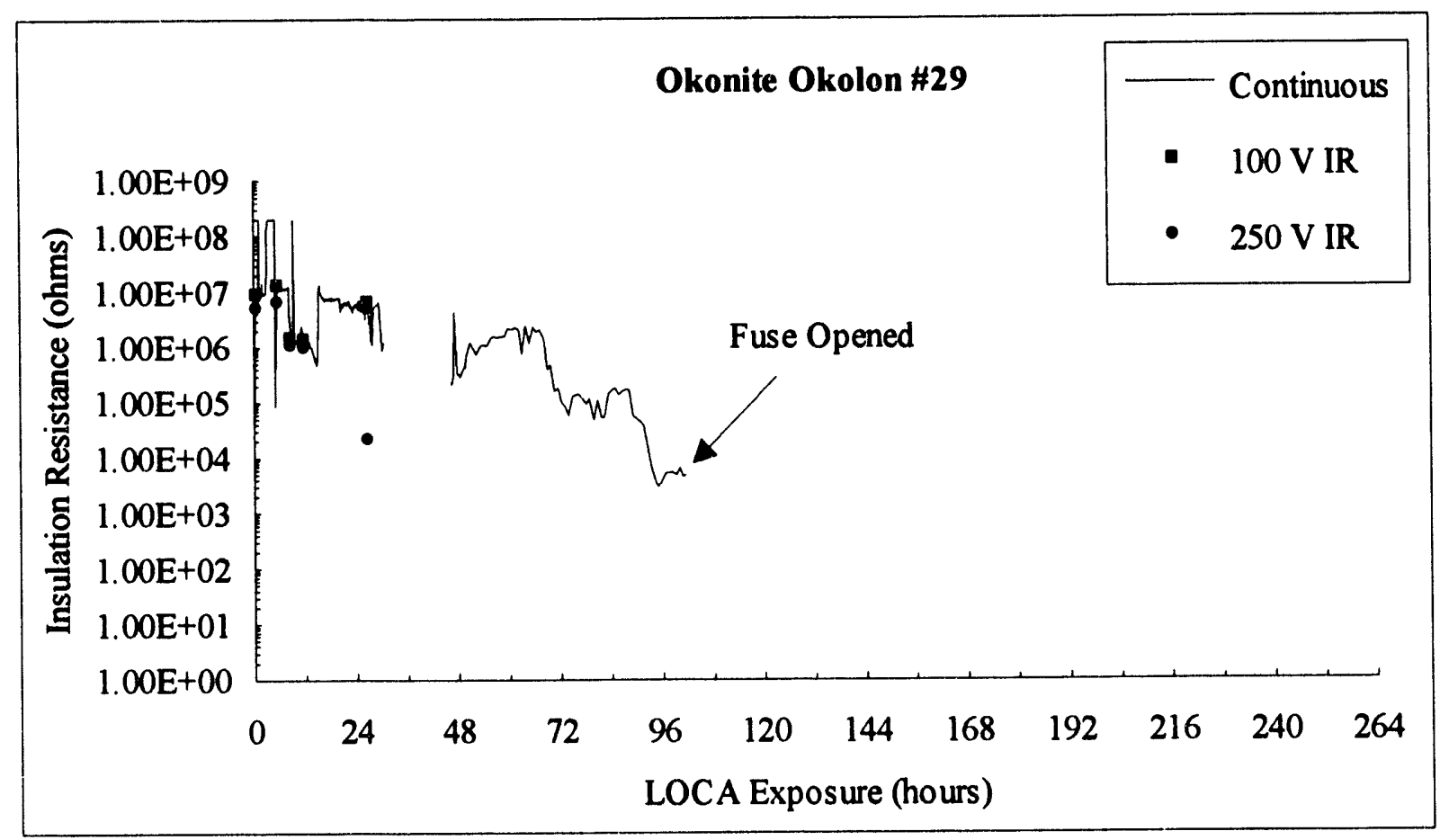

Figure A-58 Insulation Resistance for Okonite Okolon Sample \#29. 


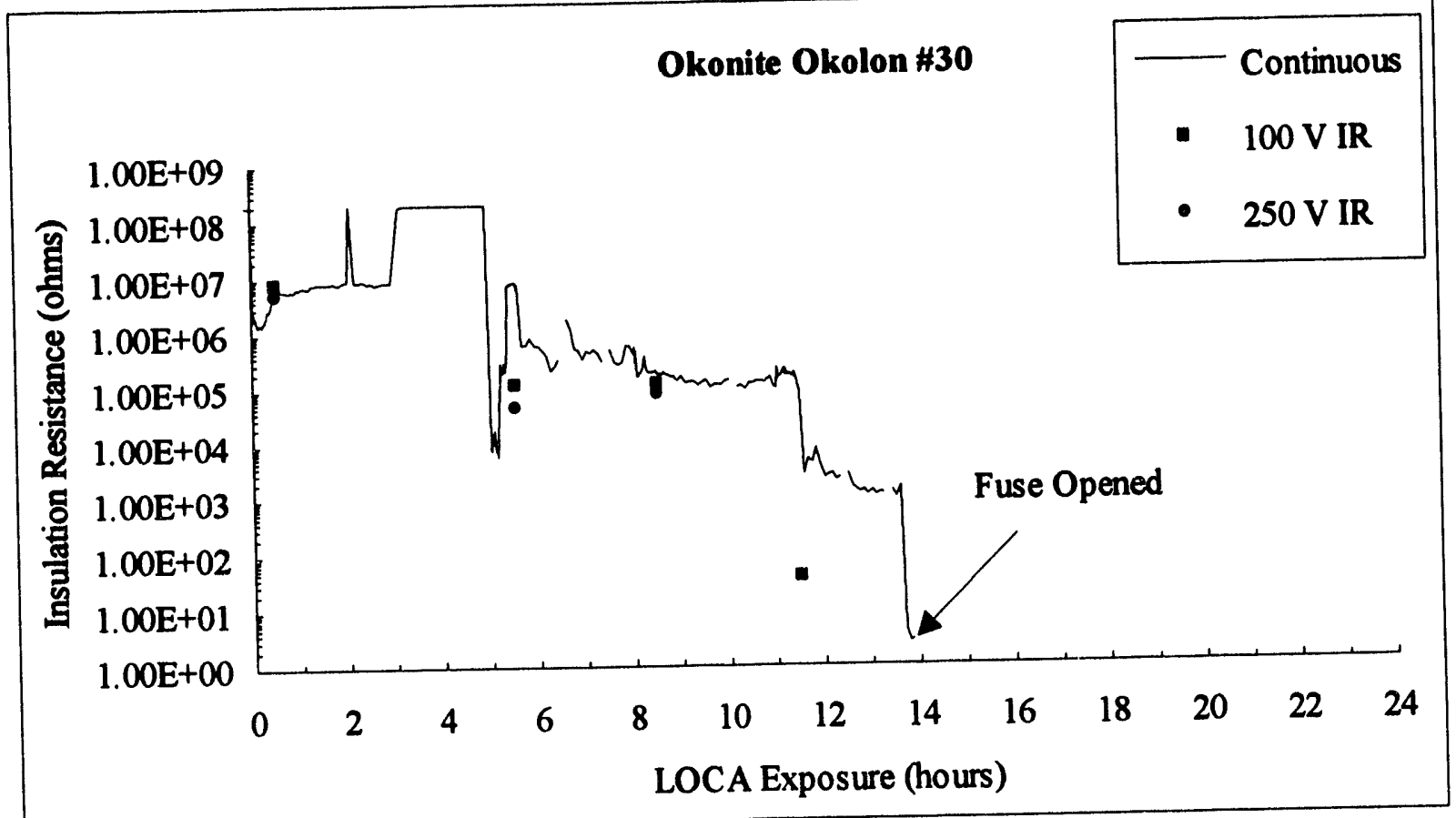

Figure A-59 Insulation Resistance for Okonite Okolon Sample \#30 during the first 24 hours.

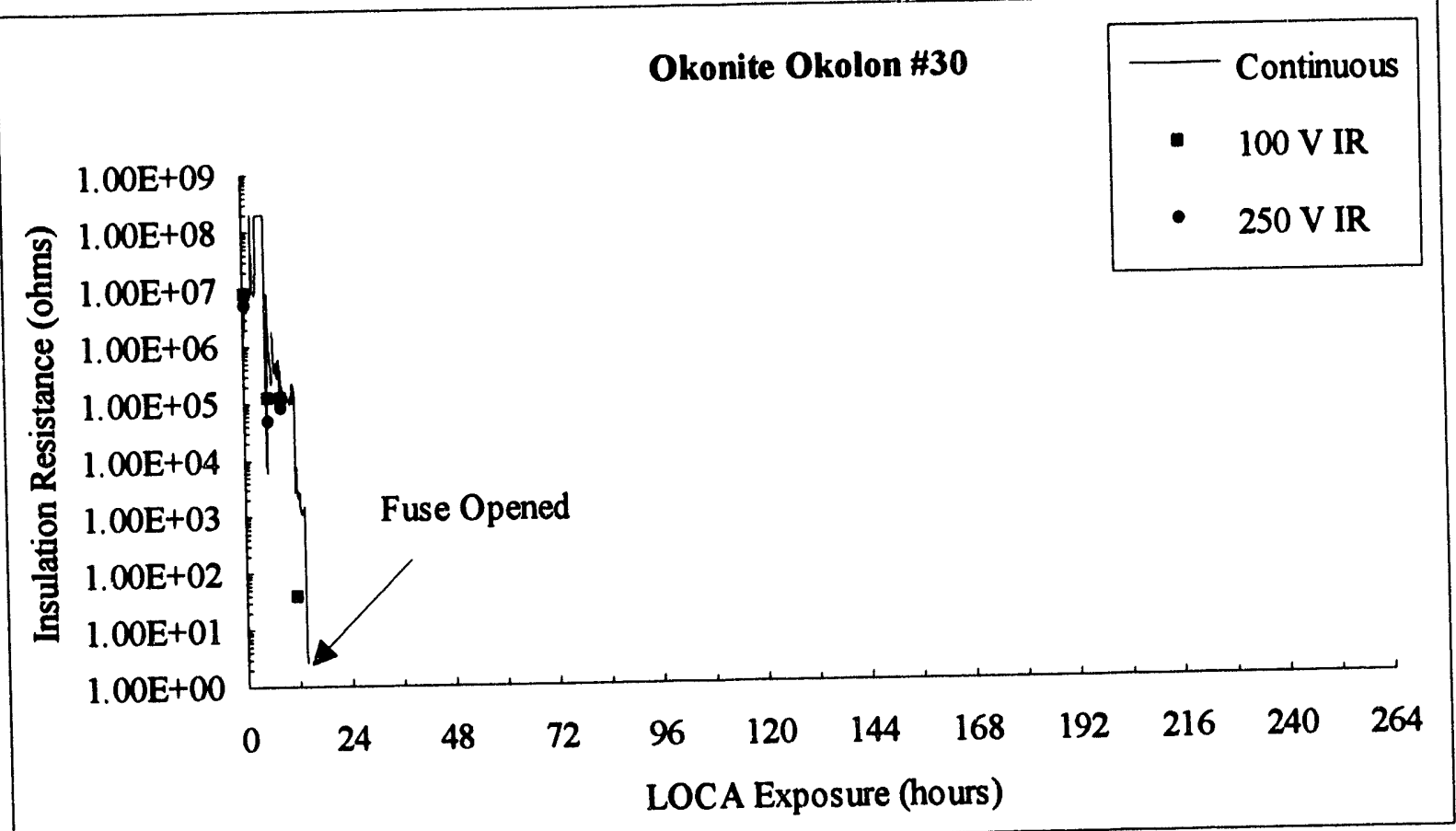

Figure A-60 Insulation Resistance for Okonite Okolon Sample \#30. 


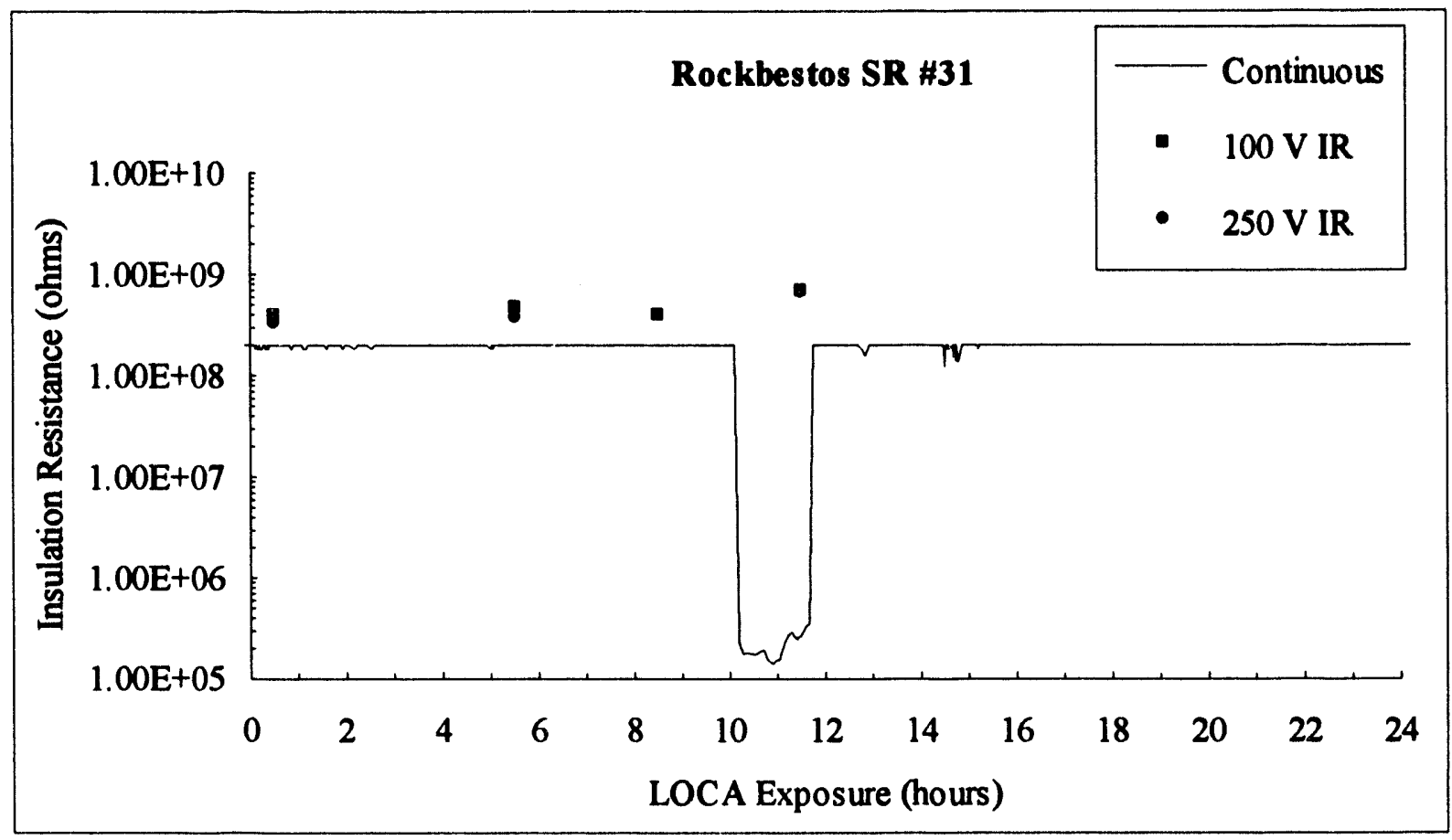

Figure A-61 Insulation Resistance for Rockbestos SR Sample \#31 during the first 24 hours.

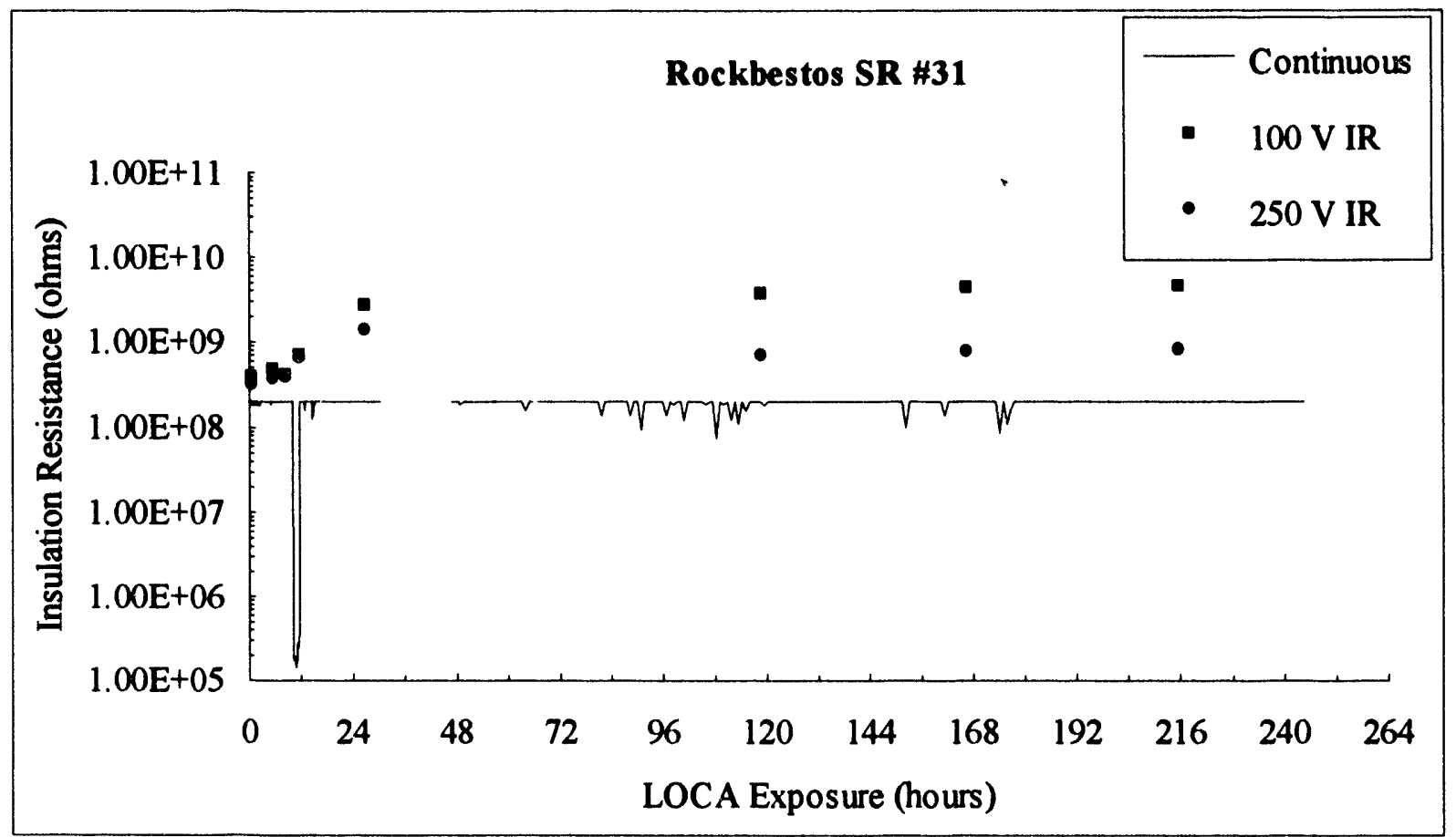

Figure A-62 Insulation Resistance for Rockbestos SR Sample \#31. 


\section{Appendix B Test Sequence Considerations}

Many reviewers of this report commented that the test sequence of applying the total radiation dose prior to thermal aging was unrealistic and/or extremely conservative and that it was not clear that the only significant difference between this test program and previous Sandia testing was the level of thermal aging. This appendix addresses these concerns. 


\section{Appendix B Test Sequence Considerations}

Many reviewers of this report commented that the test sequence of applying the total radiation dose prior to thermal aging was unrealistic and/or extremely conservative and that it was not clear that the only significant difference between the Reference B-1 testing and this test program was the level of thermal aging. This appendix demonstrates why we believe that the test sequence is irrelevant to the test results obtained in this test program. Because the comments were in particular relative to the failures of the Okonite cables, this appendix will focus on those cables. In addition, because we believe that aging of the CSPE jacket material was a dominant factor in the failures, we will focus on the jacket. This belief is supported by the manufacturer's qualification test, which included an unjacketed cable insulated with the same material as in our tests. Their testing had comparable thermal aging, $50 \%$ higher total radiation dose, and a similar accident profile, without any evidence of failures. In contrast, our testing resulted in extensive longitudinal splitting of ten separate samples plus two additional cable segments that were used as cable ties.

Table B-1 summarizes the test conditions and failures from the 6- and 9-month aging exposures from Reference B-1 along with the test conditions and failures from this test program. All exposures are for the Okonite cables in the test programs, which were of the same materials and construction. Note that in addition to the 6- and 9-month exposures in the previous testing, 3-month and 0-month (unaged) exposures were included. One Okonite cable was included in the unaged exposure and three were included in the 3-month exposure. In both cases, no failures were observed.

Figure B-1 shows the Okonite cable failure that occurred in the Reference B-1 testing. Note the similarity to the failures shown in Figure 6 of this report. In both cases, extensive longitudinal cracking existed along significant portions of the cable. This similarity in appearance between the test failures shown in Figures 6 and B-l suggests a similar failure mechanism.

The simulations that were used in Reference B-1 are obviously the most realistic in that the aging radiation and thermal aging were applied simultaneously and at quite low acceleration factors relative to typical testing. Note that the total dose in the 9-month exposure from Reference B-1 was significantly higher than in the current program and that the radiation aging was applied at a much lower acceleration factor.

The 9-month simultaneous exposure $\left(56 \mathrm{Mrad}\right.$ at $\left.98^{\circ} \mathrm{C}\right)$ can be equated to other conditions using time-temperature-dose rate superposition [B-2]. Using an activation energy of $1.08 \mathrm{eV}$ for CSPE (for comparison with Figure 11 in Reference $\mathrm{B}-2$ ), a thermal exposure for 9 months at $98^{\circ} \mathrm{C}$ is equivalent to $206 \mathrm{yr}^{\prime}$ at $45^{\circ} \mathrm{C}$. The aging dose of $56 \mathrm{Mrad}$ is matched by a dose rate of $30 \mathrm{rad} / \mathrm{hr}(0.30 \mathrm{~Gy} / \mathrm{hr})$ over 206 years. From the e/ $e_{0}$ curve on Figure 11 in Reference $\mathrm{B}-2$, the $45^{\circ} \mathrm{C}, 30 \mathrm{rad} / \mathrm{hr}(0.30 \mathrm{~Gy} / \mathrm{hr})$ point causes the same damage as a thermal-only exposure three times longer in duration. This means that the 9-month simultaneous radiation and thermal exposure is equivalent to a thermal-only exposure of roughly 620 years $(=3 \times 206$ years $)$ at $45^{\circ} \mathrm{C}$, or about $69^{\circ} \mathrm{C}$ for $40 \mathrm{yr}$.

The thermal exposure of $158^{\circ} \mathrm{C}$ for $336 \mathrm{hr}$ that was used in this program equates to about $1180 \mathrm{yr}$ at $45^{\circ} \mathrm{C}$, or about $75^{\circ} \mathrm{C}$ for $40 \mathrm{yr}$, again using an activation energy of $1.08 \mathrm{eV}$. Note that this thermal exposure, by itself, is 1.9 times ( 1180 years/620 years) as severe as the combined radiation and thermal aging in the previous 9-month exposure.

If we assume that the radiation and thermal aging in the current program were applied simultaneously rather than sequentially, we can again employ time-temperature-dose rate superposition. The total dose of $130 \mathrm{Mrad}$ (including the accident radiation dose) over 1180 years gives an equivalent of $13 \mathrm{rad} / \mathrm{hr}(0.13 \mathrm{~Gy} / \mathrm{hr})$. Again using Figure 11 from Reference B-2, the thermal aging only line represents a time that is about a factor of 2.2 higher than the $45^{\circ} \mathrm{C}$ and $13 \mathrm{rad} / \mathrm{hr}(0.13 \mathrm{~Gy} / \mathrm{hr})$ point. Thus, the combined thermal and radiation aging (including the accident radiation exposure as additional radiation aging), if they had been applied simultaneously, would have equated to roughly 2600 years $\left(2.2 \times 1180\right.$ years) at $45^{\circ} \mathrm{C}$, or $83^{\circ} \mathrm{C}$ for 40 years, with no radiation exposure ${ }^{2}$. It should be noted that this cable is claimed to be qualified for $40 \mathrm{yr}$ at $90^{\circ} \mathrm{C}$ plus $200 \mathrm{Mrad}$ of radiation exposure.

To get an idea of the mechanical properties expected in the CSPE after various amount of aging, we will refer to Figure 10 in Reference B-2. In that figure, it is evident that after the equivalent of about $350 \mathrm{yr}$ at $45^{\circ} \mathrm{C}\left(2.6 \mathrm{yr}\right.$ at $\left.90^{\circ} \mathrm{C}\right)$, the CSPE material has a retained elongation of about $10 \%$

\footnotetext{
${ }^{1}$ Note that some equivalent aging times at $45^{\circ} \mathrm{C}$ are very long. The $45^{\circ} \mathrm{C}$ reference temperature is used solely as a means to compare data between this program and previous work. It must be recalled that very long lifetimes at $45^{\circ} \mathrm{C}$ translate to much shorter lifetimes at higher temperatures. For example, 3260 yr at $45^{\circ} \mathrm{C}$ corresponds to about 40 yr at $85^{\circ} \mathrm{C}$ for an activation energy of $1.08 \mathrm{eV}$.

2 We expect that the actual equivalent thermal aging would be less than that calculated since simultaneous exposure of CSPE to high temperature and radiation was shown to be more severe than sequential exposure of radiation at ambient temperature followed by thermal aging [B-3]. In Reference B-3, p. 60, curve $\mathrm{E}$ gives retained elongation of about 0.15 for simuitaneous exposure, while curve $B$ gives retained elongation of about 0.20 for sequential exposure to radiation at ambient temperature followed by thermal aging equivalent to the thermal aging used in the simultaneous exposure.
} 
Table B-1 Comparison of Testing Conditions to Reference B-1 Conditions

\begin{tabular}{|c|c|c|c|}
\hline Parameter & $\begin{array}{l}\text { Reference B-1 6-Month } \\
\text { Exposure }\end{array}$ & $\begin{array}{l}\text { Reference B-1 9-Month } \\
\text { Exposure }\end{array}$ & Current Test Program \\
\hline Radiation Aging & $29 \mathrm{Mrad}$ & $56 \mathrm{Mrad}$ & $20 \mathrm{Mrad}$ \\
\hline $\begin{array}{c}\text { Radiation Aging Dose } \\
\text { Rate }\end{array}$ & $6.4 \mathrm{krad} / \mathrm{hr}$ & $8.4 \mathrm{krad} / \mathrm{hr}$ & $300 \mathrm{krad} / \mathrm{hr}$ \\
\hline Thermal Aging & $98^{\circ} \mathrm{C}$ for 6 months & $98^{\circ} \mathrm{C}$ for 9 months & $158^{\circ} \mathrm{C}$ for $336 \mathrm{hr}$ \\
\hline $\begin{array}{c}\text { Nominal Aging } \\
\text { Acceleration Factor for } \\
\text { 40-Year Life } \\
\end{array}$ & 80 & 53 & $\begin{array}{l}1000 \text { for Thermal, } 5300 \\
\text { for Radiation }\end{array}$ \\
\hline Accident Dose & $110 \mathrm{Mrad}$ & $110 \mathrm{Mrad}$ & $110 \mathrm{Mrad}$ \\
\hline $\begin{array}{l}\text { Accident Radiation Dose } \\
\text { Rate }\end{array}$ & $570 \mathrm{krad} / \mathrm{hr}$ & $570 \mathrm{krad} / \mathrm{hr}$ & $300 \mathrm{krad} / \mathrm{hr}$ \\
\hline Total Radiation Dose & $139 \mathrm{Mrad}$ & $166 \mathrm{Mrad}$ & $130 \mathrm{Mrad}$ \\
\hline Steam Profile & \multicolumn{3}{|c|}{$\begin{array}{l}\text { All tests used essentially the same profile } \\
\text { (see Figures } 4 \text { and } 5 \text { in this report) }\end{array}$} \\
\hline Test Sequence & \multicolumn{2}{|c|}{$\begin{array}{l}\text { Simultaneous thermal and radiation aging followed } \\
\text { by accident radiation followed by steam }\end{array}$} & $\begin{array}{c}\text { Aging + accident } \\
\text { radiation followed by } \\
\text { thermal aging followed } \\
\text { by steam }\end{array}$ \\
\hline Test Failures & 0 of 3 & 1 of 4 & 10 of $10^{*}$ \\
\hline $\begin{array}{l}\text { Failure Appearance After } \\
\text { LOCA }\end{array}$ & None & \multicolumn{2}{|c|}{ Extensive longitudinal cracking } \\
\hline
\end{tabular}

* Although initial failure occurred during thermal aging on the damaged cables (circumferential cracking), all cables also suffered extensive longitudinal cracking during the accident steam exposure (including identical cables that were used as cable ties). Thus, it is evident that all the cables would have failed the steam exposure even if they had been undamaged.

absolute. After the equivalent of $620 \mathrm{yr}$ at $45^{\circ} \mathrm{C}$ (equivalent thermal-only exposure for 9-month simultaneous exposure of Reference B-1), the CSPE would be expected to have virtually no residual elongation. This was in fact the case [B-1]. After an accident radiation exposure of another 110 Mrad of radiation, the CSPE is certainly in very poor mechanical condition. Thus, if the jacket is important to cable survival during the accident steam exposure, it is not too surprising that a cable would fail after preconditioning as in the 9-month aging. Despite this, three of four cables tested with the 9-month aging exposure survived the accident radiation and steam exposures. However, all were extremely brittle following the steam exposure. The extensive longitudinal splitting observed in the failed sample indicated that the failure was not a simple random statistical failure.
Because the sample that failed was aged to the maximum extent and a significant number of samples were less severely aged and did not fail, a connection with the degree of aging is strongly suggested.

Based on the analysis of equivalent thermal aging times, the fact that all of the cables had identical longitudinal cracking during the steam exposure is not very surprising. Since there is an almost certain connection between the failures and the degree of aging, we would expect the Okonite cables to fail a test where the thermal aging that was used in this test program was combined with no radiation aging and followed by a $110 \mathrm{Mrad}$ accident exposure and the steam profile used in this test. Thus, although the application of the total radiation dose prior to thermal aging is perhaps more 


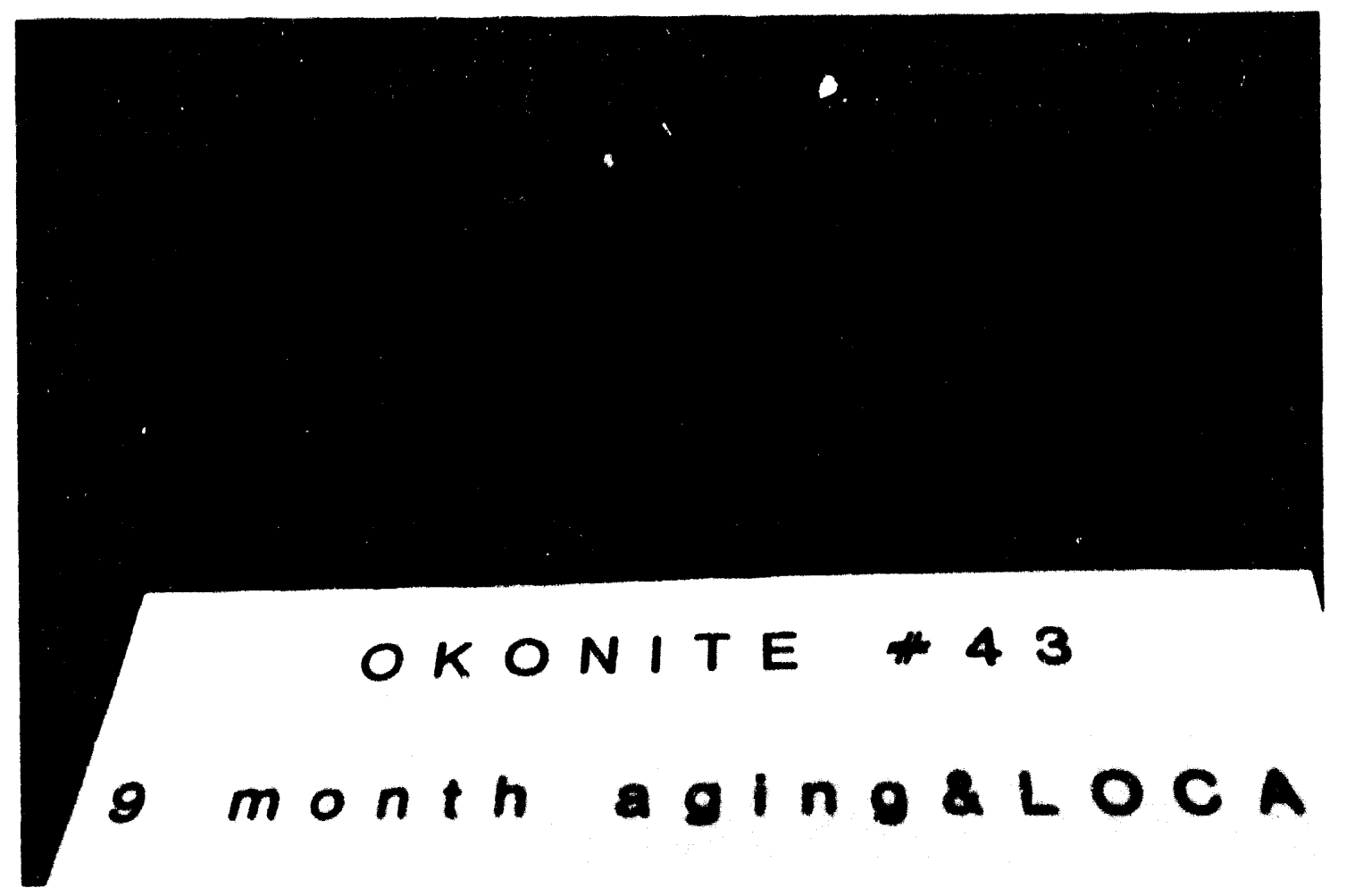

Figure B-1 Failure of Okonite Cable Sample from Reference B-1 Test Program

severe than a different aging sequence, the evidence clearly indicates that the sequence was irrelevant in this test.

However, the sequence may become important if testing at lower levels of thermal aging is conducted.

Some direct evidence that the application of the accident radiation exposure prior to thermal aging was not overly important comes from the parts of the samples that were located in the test chamber head. While we do not have precise exposure data, these samples were exposed to lower radiation doses than the samples on the test mandrel. Some portions of the samples that were in the test chamber head had longitudinal cracking just as the portions of the samples on the mandrels did. These portions of the samples were exposed to thermal aging (although the temperatures in the head were not monitored) as well as full accident steam, but reduced radiation. The splitting of these cables that were exposed to reduced radiation levels also lends support to the conclusion that thermal aging was the major factor (as compared to the previous testing) responsible for the failures observed in this test program. It should be noted that the level of thermal aging received by the cables up close to the penetrations, where the total radiation dose should have been very small, was not sufficient to cause the cables to crack during the steam exposure. However, because the temperature in the vicinity of the penetrations was not monitored, there is no way to know how much thermal aging the cables in the head actually received.

\section{References}

B-1. M. J. Jacobus, Aging, Condition Monitoring, and Loss-of-Coolant (LOCA) Tests of Class IE Electrical Cables, NUREG/CR-5772, SAND911766/2, Sandia National Lahoratories, November 1992.

B-2. K. T. Gillen and R. L. Clough, Predictive Aging Results for Cable Materials in Nuclear Power Plants, SAND90-2009, Sandia National Laboratories, November 1990

B-3. L. D. Bustard, et al., The Effect of Alternative Aging and Accident Simulations on Polymer Properties. NUREG/CR-4091, SAND84-2291, Sandia National Laboratories, May 1985. 
DISTRIBUTION:

Edward H. Aberbach Brand Rex Company 1600 West Main Street

Willimantic, CT 06226-1128

Thamir J. Al-Hussaini

Duke Power Company

P.O. Box 33189

Charlotte, NC 28242

Atomic Energy of Canada, Ltd.

Attn: E. C. Davey

If. "rument and Control Branch

Chalk River Nuclear Laboratories

Chalk River, Ontario K0J 1J0

CANADA

Atomic Energy of Canada, Ltd.

Attn: S. Nish

1600 Dorchester Boulevard West

Montreal, Quebec H3H 1P9

CANADA

Vince Bacanskas

Gulf States Utilities

River Bend Station

MA-3, P.O. Box 220

St. Franscisville, LA 70775

Asok Biswas

Southern California Edison Co.

San Onofre Nuclear Generating Station

5000 Pacific Coast Highway

San Clemente, CA 92672

Kenneth Baker

Raychem Corporation

300 Constitution Place

Menlo Park, CA 94025

Michael G. Bayer

Dow Chemical Company

Building B129

Freeport, TX 77541

Bruce Bernstein

EPRI

1019 19th St. NW

Washington, DC 20036
Premnath Bhatia

Baltimore Gas \& Electric

P.O. Box 1475, FSRC

Baltimore, MD 21203

John Billing

ERA Technology Ltd.

Cleeve Road

Leatherhead KT22 75A

UNITED KINGDOM

William Z. Black

Georgia Tech

School of Mechanical Engineering

Atlanta, GA 30332

Bruce P. Bolbat

Pennsylvania Power \& Light

2 North Ninth Street

Allentown, PA 18101

Paul Boucher

GPU

1 Upper Pond Road

Parsippany, NJ 07974

K. W. Brown

Tennessee Valley Authority

Electrical and Technical Services

W11C110

400 W. Summit Hill Drive

Knoxville, TN 37902

Robert J. Brunner

Pennsylvania Power \& Light

2 N. Ninth Street

Allentown, PA 18101

Daniel O. Bye

Southern California Edison

P.O. Box 128

San Clemente, CA 92672

Canada Wire and Cable Limited

Attn: Z. S. Paniri

Power \& Control Products Division

22 Commercial Road

Toronto, Ontario

CANADA M4G $1 \mathrm{Z4}$

Sal P. Carfagno

1616 Riverview Rd.

Gladwine, PA 19035-1211 
T. Champion

Georgia Power Company

62 Lake Mirror Road

Forest Park, GA 30050

CEA/CEN-FAR (3)

Attn: M. Le Meur

J. Calmet

G. Gauthier

Departement de Surete Nucleaire

Service d'Analyse des Matériels

B.P. 6

et Structures

92260 Fontenay-aux-Roses

FRANCE

Jim Civay

Washington Pub. Pow. Supply Sys.

P.O. Box 968

$\mathrm{M} / \mathrm{S}$ 981C

Richland, WA 99352

Commissariat a l'Energie Atomique CIS

Biointernational LAPRI (3)

Attn: G. Gaussens

$$
\text { J. Chenion }
$$

F. Carlin

BP No 32

91192 Gif-Sur-Yvette CEDEX

FRANCE

Commissariat a l'Energie Atomique

Attn: J. Campan

CEN Cadarche DRE/STRE

BP No 1

13115 Saint Paul Lez Durance

FRANCE

Kurt Cozens

Nuclear Management and Resources

Council

1776 Eye St. NW, Suite 300

Washington, DC 20006-2496

George Daniels

Rochester Gas and Electric

89 East Ave.

Rochester, NY 14649-0001

Allen Davidson

Patel Engineers

408 Cedar Bluff Road

Suite 353

Knoxville, TN 37923
Barry Dooley

EPRI

3412 Hillview Avenue

Palo Alto, CA 94304

Electricite de France (2)

Attn: G. Kauffman

C. Rey

(S.E.P.T.E.N.)

12, 14 Ave. Dubrieroz

69628 Villeurbanne

Paris, FRANCE

Electricite de France

Attn: F. Duchateau

Direction des Etudes et Recherches

1, Avenue du General de Gaulle

92141 CLAMART CEDEX

FRANCE

Electricite de France (2)

Attn: M. Pays

M. Dorison

Direction des Etudes et Recherches

Les Renardieres

Boite Postale No 1

77250 MORET SUR LORING

FRANCE

John R. Ferraro

Northeast Utilities Service Co.

P.O. Box 270

Hartford, CT 06141-0270

FRAMATOME (2)

Attn: G. Chauvin

E. Raimondo

Tour Fiat - Cedex 16

92084 Paris La Defense

FRANCE

Edward E. Galloway

Detroit Edison

2000 Second Avenue

Detroit, MI 48226

J. B. Gardner

29 Miller Road

Bethany, CT 06525

Jeff Gebhardt

Energy Operations

GSB 3-West

Route 3 Box 137G

Russelville, AR 72801 
J. Gleason

Wyle Laboratories

P.O. Box 077777

Huntsville, AL 35807-7777

Larry Gradin

ECOTECH

6702 Bergenline Avenue

West New York, NJ 07093

Ken Hancock

EBASCO Plant Services, Inc.

2 World Trade Center

90th Floor

New York, NY 10048

Izhar Haque

Ontario Hydro

700 University (A8H4)

Toronto, Ontario

CANADA M5G1X6

Bruce L. Harshe

Consumers Power Company

1945 Parnall Road

P-14-408

Jackson, MI 49201

Jerry Henley

Digital Engineering Inc.

658 Discovery Drive

Huntsville, AL 35806

John Hoffman

Raychem Corporation

300 Constitution Drive

Menlo Park, CA 94025

John J. Holmes

Bechtel Western Power Company

12440 E. Imperial Highway

Norwalk, CA 90650

Phil Holzman

STAR

195 High Street

Winchester, MA 01890

ITT Cannon Electric Canada

Attn: B. D. Vallillee

Four Cannon Court

Whitby, Ontario L1N 5 V8

CANADA
Nels Johansson

INPO

Suite 1500

1100 Circle Parkway

Atlanta, GA 30339-3064

Suresh Kapur

Ontario Hydro

700 University

Toronto, Ontario

CANADA M5G1X6

Brent Karley

Nebraska Public Power District

141415 th Street

P.O. Box 499

Columbus, NE 68601

S. Kasturi

MOS

25 Piedmont Drive

Melville, NY 11747

T. A. Kommers

The Okonite Co.

1601 Robin Whipple

Belmont, CA 94002

Yasuo Kusama

Japan Atomic Energy Research Inst.

1233 Watanuki-machi

Takasaki, Gunma-ken

JAPAN 37102

Vince Lamb

Westinghouse

P.O. Box 355

Pittsburgh, PA 15230

Jack Lasky

The Okonite Company

P. O. Box 340

Ramsey, NJ 07446

M. Lebo'n

Consolidated Edison Co. of New York

4 Irving Place

New York, NY 10003

Ting Ling

Cablec Industrial Cable Co.

East Eighth St.

Marion, IN 46952 
Stuart Litchfield

Cleveland Electric Illuminating Co.

P.O. Box 97-E-290

Perry, OH 44081

G. Littlehales

The Rockbestos Company

P.O. Box 1102

East Granby, CT 06026-1102

Alex Marion

Nuclear Management and Resources

Council

1776 Eye St. NW, Suite 300

Washington, DC 20006-3706

Sam Marquez

Public Service Co. of Colorado

2420 W. 26th Avenue

Denver, CO 80211

B. G. McCollum

EBASCO Plant Services, Inc. $400 \mathrm{~N}$. Olive

L.B. 80

Dallas, TX 75201-4007

R. McCoy

Yankee Atomic Electric Company 1671 Worcester Road

Framingham, MA 01701

Richard D. Meininger

ECAD Services

P.O. Box 229

Middletown, PA 17057

Fred Mogolesko

Nuclear Engineering Department

Boston Edison Company

25 Braintree Hill Office Park

Braintree, MA 02184

T. Narang

Texas Utilities Electric Company

P.O. Box 1002

Glen Rose, TX 76043

David K. Olson

Northern States Power

P.O. Box 600

Monticello, MN 55441
Ontario Hydro (2)

Attn: R. Wong

B. Kukreti

700 University Avenue

Toronto, Ontario M5G 1X6

CANADA

Ontario Hydro (2)

Attn: Jean-Marie Braun Greg Stone

800 Kipling Avenue KR151

Toronto, Ontario M8Z 5S4

CANADA

Keith A. Petty

Stone \& Webster

P.O. Box 2325

Boston, MA 02107

Paul Phillips

Kansas Gas \& Electric

201 N. Market

Wichita, KS 67202

Paul J. Phillips

University of Tennessee

434 Dougherty Eng.

Knoxville, TN 37996-2200

Ben E. Preusser

Arizona Public Service Co.

Arizona Nuclear Power Project

P.O. Box 52034; Station 6078

Phoenix, AZ 85072-2034

Larry Raisanen

Detroit Edison

6400 N. Dixie Highway

Fermi 2, M/C 205EF2TAC

Newport, MI 48166

Albert B. Reynolds

University of Virginia

Reactor Facility

Charlottesville, VA 22901

Ted Rose

Electro-Test, Inc.

P.O. Box 159

San Ramon, CA 94583 
T. P. Schaefer

Conax Buffalo Corp.

2300 Walden Avenue

Buffalo, NY 14225

M. Shaw

Institute of Materials Science

University of Connecticut

Box U-136

97 N. Eagleville Rd.

Storrs, CT 06268

G. Sliter

Electric Power Research Institute

3412 Hillview Ave.

Palo Alto, CA 94304

Marcia Smith

Pacific Gas \& Electric

P.O. Box 56

Avila Beach, CA 93424

J. Solano

Illinois Power

V-928D

Route 54 East

Clinton, IL 61727

Richard St. Onge

Southern California Edison

P.O. Box 128

San Clemente, CA 92672

Clint Steele

Washington Pub. Pow. Supply Sys.

P.O. Box 968

$\mathrm{M} / \mathrm{X}$ 981C

Richland, WA 99352

Jan Stein

EPRI

3412 Hillview Avenue

Palo Alto, CA 94304

Don Stonkus

Ontario Hydro

800 Kipling Avenue

Toronto, Ontario

CANADA M8Z 5S4

Harvey Sutton

Virginia Power

P.O. Box 26666

Richmond, VA 23261
Mike Sweat

Georgia Power Company

333 Piedmont Avenue

Atlanta, GA 30302

Steve Swingler

Central Electricity Research Labs.

Kelvin Avenue

Leatherhead, Surrey

UNITED KINGDOM KT 22 7SE

M. Tabbey

Fluorocarbon Corp.

1199 Chillicothe Rd.

Aurora, OH 44202

Aki Tanaka

Ontario Hydro

700 University Avenue, A7-F1

Toronto, Ontario

CANADA M5G 1X6

Doug Van Tassell

Florida Power \& Light

P.O. Box 14000

700 Universe Beach

Juno Beach, FL 33408

G. Toman

Ogden Env. \& Energy Services Co.

1777 Sentry Parkway West

Abington Hall Suite 300

Blue Bell, PA 19422

Alfred Torri

Risk and Safety Engineering

1421 Hymettus Ave.

Leucadia, CA 92024

Joseph Weiss

EPRI

3412 Hillview Avenue

Palo Alto, CA 94304

Robert N. Woldstad

GE Nuclear Energy

175 Curtner Avenue

San Jose, CA 95125

Gil Zigler

Science and Engineering Associates

P.O. Box 3722

Albuquerque, NM 87190 
H. Garg (5)

USNRC/NRR/OSP

M/S OWFN $8 \mathrm{H} 7$

A. Marinos
USNRC/NRR/OSP
M/S OWFN 8H7

M.Vagins

USNRC/RES

M/S NL-005

\section{S. Aggerwal \\ USNRC/RES \\ M/S NL-005}

S. D. Alexander

USNRC/NRR

M/S OWFN 9D4

R. Moist

USNRC/NRR

M/S OWFN 9D4

U. Potapovs

USNRC/NRR

M/S OWFN 9D4

R. Wilson

USNRC/NRR

M/S OWFN 9D4

H. Walker

USNRC/NRR/OSP

$\mathrm{M} / \mathrm{S}$ 8D1

C. Anderson

USNRC Region I

R. Paolino

USNRC Region I

N. Merriweather

USNRC Region II

C. Paulk

USNRC Region IV

T. Stetka

USNRC Region IV

G. Hubbard

USNRC/NRR

M/S 8D1 OWFN
P. Shemanski

USNRC/NRR

M/S 11F23 OWFN

Sandia National Laboratories:

MS0368 R. L. Clough, 1811

MS0367 K. T. Gillen, 1812

MS0615 D. L. Sevier, 2752

MS0423 M. J. Jacobus, 4114 (5)

MS0736 N. R. Ortiz, 6400

MS0744 W. A. von Riesemann, 6403

MS0744 D. A. Powers, 6404

MS0737 M. P. Bohn, 6449

MS0737 E. E. Baynes, 6449

MS0737 D. M. Ramirez, 6449

MS0737 C. F. Nelson, 6449

MS0737 S. P. Nowlen, 6449

MS0737 R. A. Vigil, 6449 (25)

MS0741 A. J. Moonka, 6471

MS0728 L. D. Bustard, 6624

MS0899 Technical Library, 7141 (5)

MS0619 Technical Publications, 7151

MS9018 Central Technical Files, 8523-2

MS0100 Document Processing for

DOE/OSTI, 7613-2 (10) 

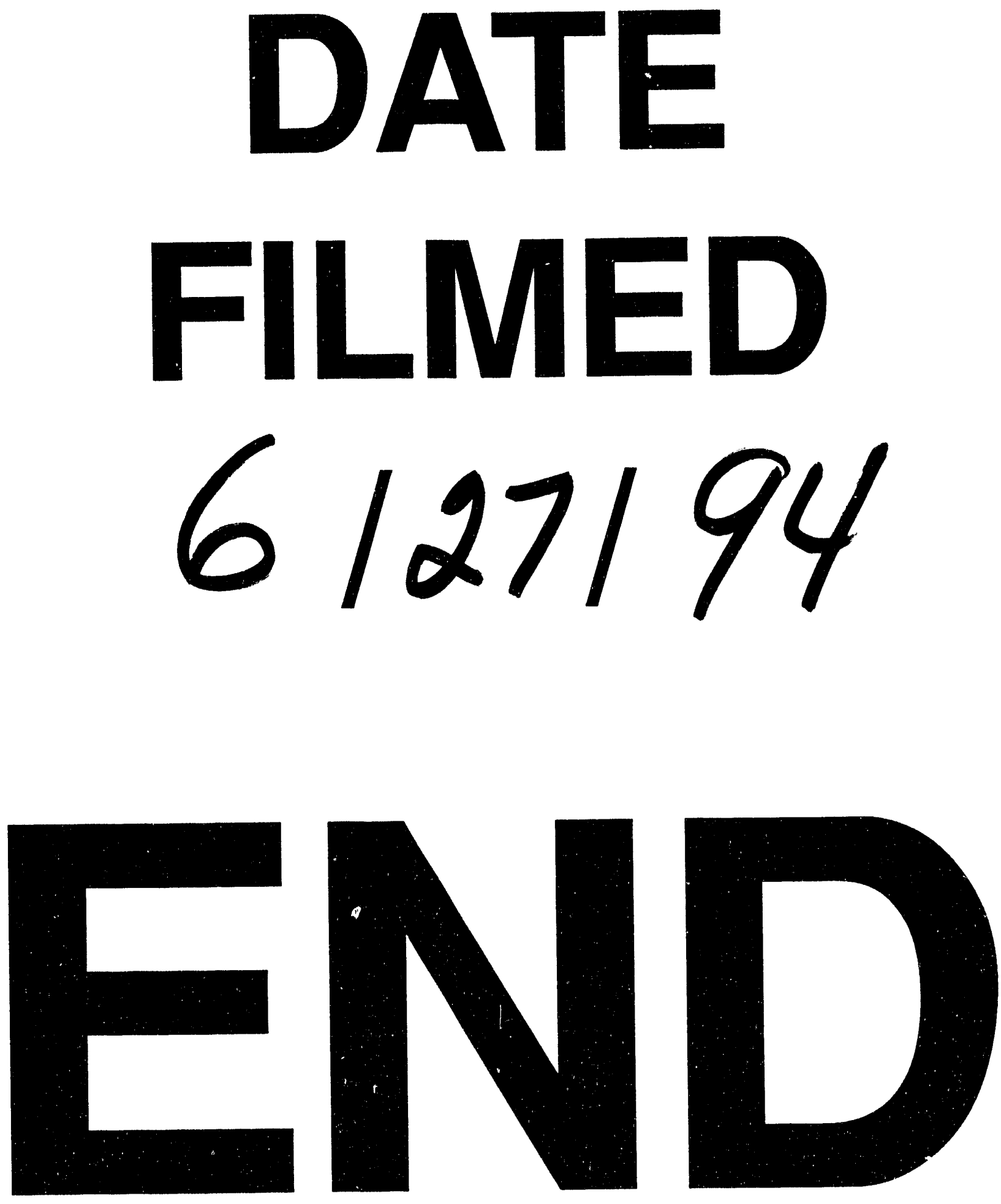


$$
\underline{-}
$$
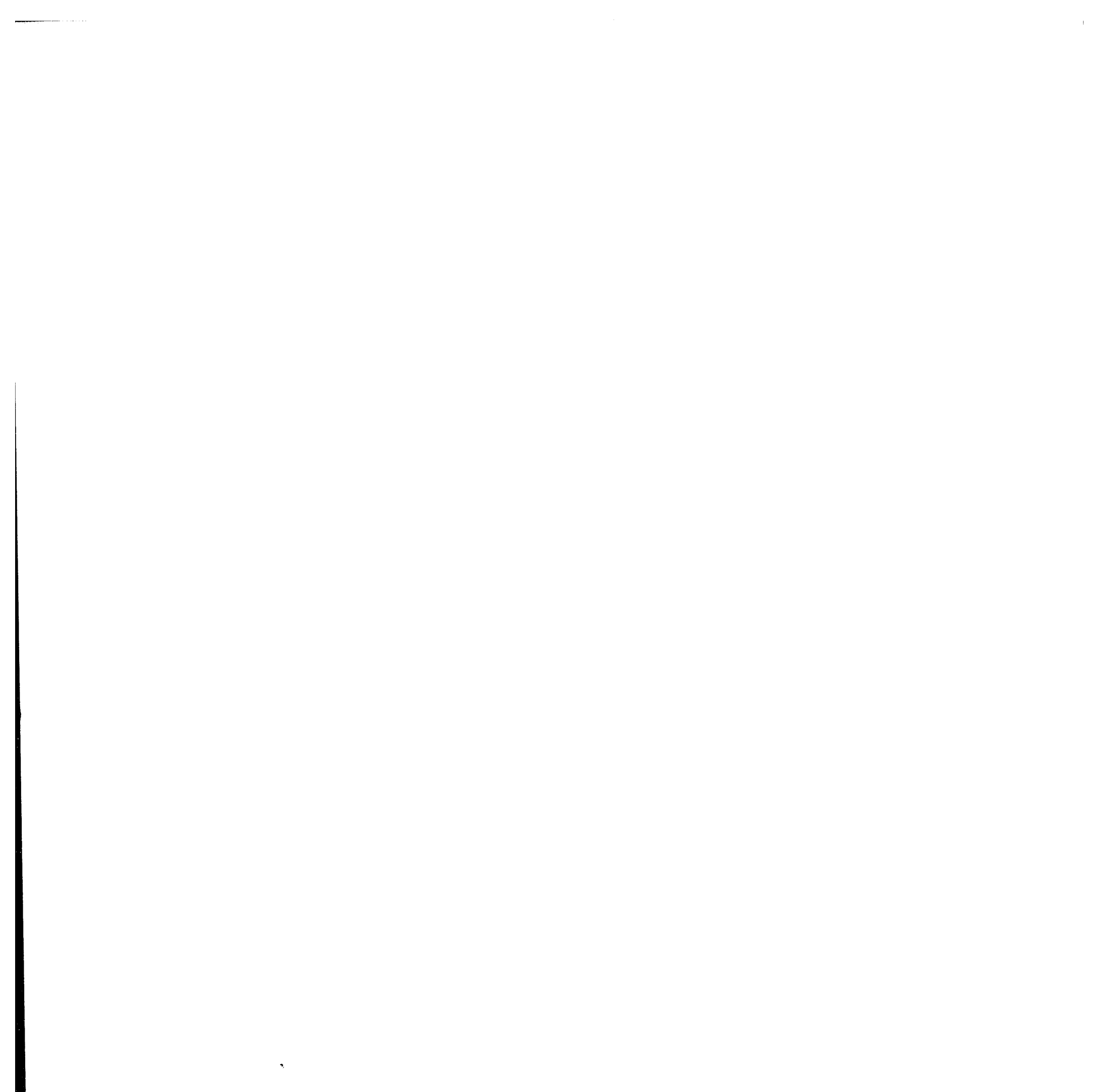

)

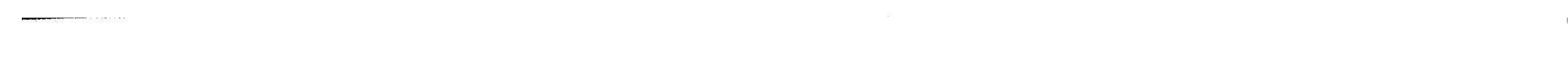

